Portland State University

PDXScholar

Winter 1-8-2015

\title{
Liberalization, Contention, and Threat: Institutional Determinates of Societal Preferences and the Arab Spring in Tunisia and Morocco
}

Matthew Thomas Lacouture

Portland State University

Follow this and additional works at: https://pdxscholar.library.pdx.edu/open_access_etds

Part of the Comparative Politics Commons

Let us know how access to this document benefits you.

\section{Recommended Citation}

Lacouture, Matthew Thomas, "Liberalization, Contention, and Threat: Institutional Determinates of Societal Preferences and the Arab Spring in Tunisia and Morocco" (2015). Dissertations and Theses. Paper 2130.

https://doi.org/10.15760/etd.2128

This Thesis is brought to you for free and open access. It has been accepted for inclusion in Dissertations and Theses by an authorized administrator of PDXScholar. Please contact us if we can make this document more accessible: pdxscholar@pdx.edu. 
Liberalization, Contention, and Threat:

Institutional Determinates of Societal Preferences

and the Arab Spring in Tunisia and Morocco

by

Matthew Thomas Lacouture

A thesis submitted in partial fulfillment of the requirements for the degree of

\author{
Masters of Science \\ in \\ Political Science
}

Thesis Committee:

Lindsay Benstead, Chair

Bruce Gilley

Richard Clucas

Portland State University

2014 
(C) 2014 Matthew Thomas Lacouture 


\section{Abstract}

Why do revolutions happen? What role do structures, institutions, and actors play in precipitating (or preventing) them? Finally, What might compel social mobilization against a regime in the face of potentially insurmountable odds? These questions are all fundamentally about state-society (strategic) interactions, and elite and societal preference formation over time. The self-immolation of Muhammad Bouazizi in Sidi Bouzid on December 17, 2010, served as a focal point upon which over twenty years of corrupt, coercive authoritarian rule were focused into a single, unified challenge to the Ben Ali regime. The regime's brutality was publicized via social media activism and satellite television, precipitating mass mobilization across Tunisia and, eventually, throughout the region and beyond. In light of the rapid and unforeseen nature of these events, scholars writing about the causes of the Arab Spring have focused their critiques on scholarship that they felt overemphasized the role of institutions and elite-level actors over 'under the radar' changes within society. This paper essentially agrees with this point of view, but is not content to simply 'throw out' institutionalism. As Timur Kuran (1991) argued in the wake of the unforeseen collapse of communism in Eastern Europe, one cannot understand revolution without understanding the 'true' preferences of social actors. In this way, the inevitability of revolutionary surprises seems a given so long as analysts continue to look from the top-down. Yet, this paper contends that institutions $d o$ still matter. They matter because different institutional arrangements incentivize and constrain regime strategies, which, in turn, inform the strategic calculations and 
preference orderings within society. These two societal variables are determined - in part - by the degree of regime flexibility, and they affect whether, how, and where social actors choose to vent their dissent.

This paper proposes a model for the development of contentious social mobilization under authoritarianism. In order to do so, two models - one game-theoretic, and the other rooted in the contentious politics subfield of political sociology - are synthesized toward elucidating how altered societal preferences affect strategic interactions between the regime and society over time and during acute contentious episodes. The synthesized model is then illustrated through narrative case studies of two North African states that experienced divergent outcomes in the wake of the Arab Spring: Tunisia and Morocco. The limited spaces and institutions for the expression of dissent in Tunisia gradually changed societal preferences over time. In 2010, Tunisians' preferences shifted from various socioeconomic demands and other issue-specific grievances toward a galvanized demand for the fall of the regime. In Morocco, on the other hand, social actors, by and large, continued to prefer limited reforms to a complete upheaval of the political system. This paper contends that this divergence in preferences and therefore outcomes was in part determined by the variation in the two regimes' respective strategic mixes of concessions and/or coercion. To the extent that such strategies and institutions were more flexible - i.e. were more permissive of (limited) political contention and contestation - social movements were less likely to become emboldened against the regime. 


\section{$\underline{\text { Acknowledgements }}$}

Working on this paper has been as illuminating as it has been arduous, and it surely would not have been possible without the unswerving support of my family - my parents Dick Lacouture and Jackie Wright, and my brother JP Lacouture. Further, my advisor and thesis chair, Professor Lindsay Benstead has provided me with invaluable guidance and encouragement both inside and outside of the classroom. I also owe a debt of gratitude to Professors Bruce Gilley and David Kinsella for their generous support, advice, and challenging instruction. Professor Richard Clucas was very kind to offer his time as the third member on my committee. Additionally, I would like to thank Professor Joseph Lampert for helping me to develop and refine a normative foundation for my empirical work, for giving me so many opportunities, and for indulging my philosophical questions and musings along the way. Thank you also to Christian Echt in the Systems Science department, who provided considerable guidance in developing the game theoretic portions of this thesis. Finally, I would also like to thank Professors Christopher Shortell, Masami Nishishiba, Bob Fountain, and Ronald Tammen for their respective and instrumental roles in helping me to grow as a researcher and as a burgeoning scholar during my time at Portland State University. 


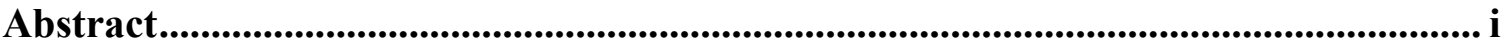

Acknowledgements .................................................................................................................. iii

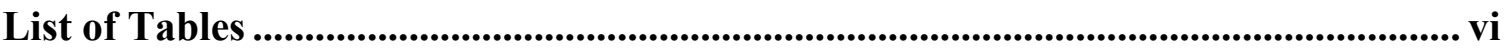

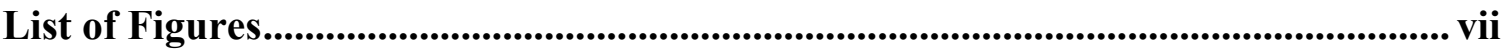

PART ONE: Introduction and Literature Review ....................................................... 1

CHAPTER 1: Introduction ......................................................................................... 1

1.1. Revolution in the Arab World: Inevitable surprise or oversight? ................... 1

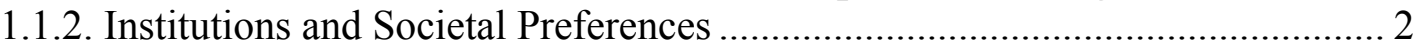

1.2. Overview and Organization of the Paper .............................................................. 6

1.2.1. Competing theories of democratization and authoritarian persistence ............ 6

1.2.2. Toward a Synthesized Model (Chapters 3 and 4):......................................... 7

1.2.3. Research Model and Methods (Chapters 5-8) ............................................. 9

CHAPTER 2: Competing Theories of Democratization and Authoritarian

Persistence in a Revolutionary Context .............................................................. 12

2.1. Introduction: Correlates of Democratization............................................... 12

2.2. Structural Requisites and Mechanisms ........................................................ 14

2.3. Modernization Theory and the Arab Spring ................................................... 19

2.3.1. Modernization in the MENA .................................................................... 20

2.3.2. Political-Economic Explanations for the Arab Spring................................... 23

2.4. Authoritarian Adaptation: Capacities and strategies of regime persistence 25

2.4.1. Political and Economic Liberalization as an Authoritarian Strategy............. 26

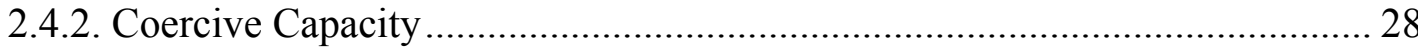

2.5. Conclusion: Revolutionary surprises and the need for a new approach ........ 33

PART TWO: Modeling Liberalization, Revolution, and Threat in the MENA ....... 38

Chapter 3: Emboldened Social Mobilization - a game theoretic approach................. 38

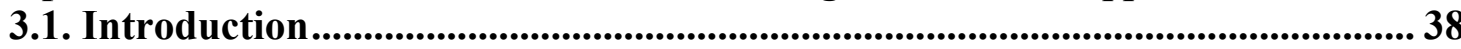

3.2. The 'Liberalization Game' .................................................................................... 39

3.3. The 'Liberalization Game' in the MENA ......................................................... 44

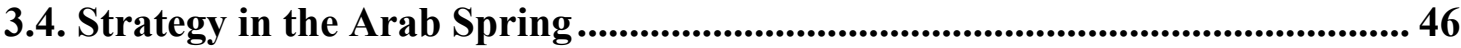

3.5. Emboldened mobilization under (tough) authoritarianism ........................... 47

3.5.1. Preceding the 'Liberalization Game' ...................................................... 51

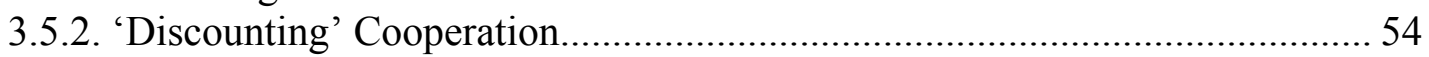

3.5.3. Conclusions: Narrating the 'Emboldened Society Game' ............................ 55

CHAPTER 4: Threat and Contention - 'Emboldening' Society ................................. 56

4.1. Introduction: Filling in the blanks ..........................................................57

4.1.1. Contentious Politics: shifting toward the MENA ........................................ 58

4.2. Political Opportunity and Contentious Politics ............................................. 60

4.3. Threat and Opportunity under Authoritarianism ....................................... 63

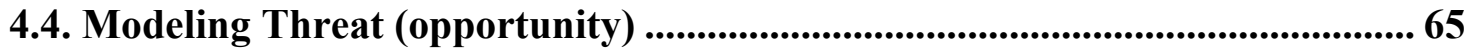

4.5. Threat and Societal Preferences .................................................................... 69 
4.5.1. The Effect of Regime-Type on Strategic Preferences ................................. 71

4.6. Contentious Politics in the MENA - toward a unified model......................... 75

PART THREE: Narrating Contentious Changes in the MENA .............................. 77

CHAPTER 5: Case Study Typology and Hypotheses .............................................. 78

5.1. Regime types in the MENA..................................................................... 78

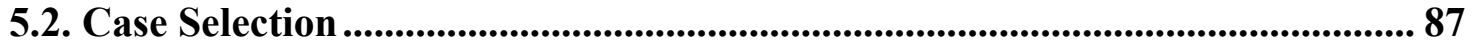

5.3. Restatement of Propositions and Hypotheses....................................................... 89

CHAPTER 6: Tunisia - Mounting Tensions and Shifting Preferences...................... 91

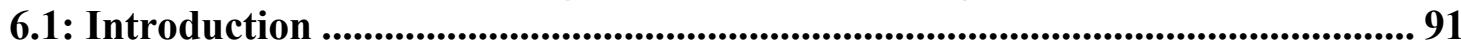

6.2. Contentious Episodes in Tunisia ..................................................................... 92

6.2.1. Contentious Politics and Regime Transition I: 1987-97 ............................. 92

6.2.2. Changes in Contention: The 2008 Gafsa Mining Basin Riots ........................ 96

6.2.3. Contentious Politics and Regime Transition II: 2010-11 ............................ 100

6.2.4. 'Dynamics of Contention' during the Jasmine Revolution.......................... 104

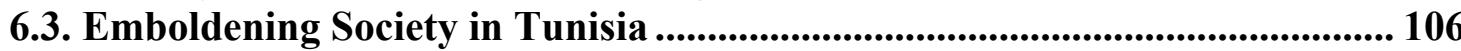

6.3.1. Institutionalized Mechanisms for Dissent in Tunisia................................ 109

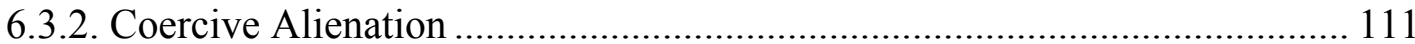

6.3.3. The Mixed Bag of Modernization in Tunisia ............................................ 113

6.3.4. The role of Islam................................................................................. 116

6.3.5. Liberation Technologies as Repertoires of Contention .............................. 118

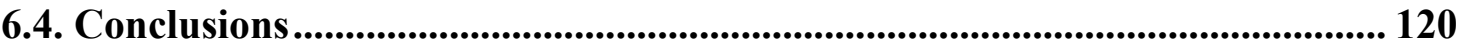

CHAPTER 7: Morocco - Lynchpin Flexibility and Contention ............................... 122

7.1. Introduction - Monarchical flexibility ............................................................. 122

7.2. Contentious Episodes in Morocco: Protesting in restrained 'spaces' ........... 124

7.2.1. Contentious Politics and Regime Transition III: 1999-2002 ..................... 124

7.2.2. Patterns of Contention in Morocco: 2002 - 2008 ......................................... 128

7.2.3. Contentious Politics and Regime Continuity: \#Feb 20 (2011)..................... 133

7.3. Institutional Determinates of Regime Flexibility in Morocco....................... 138

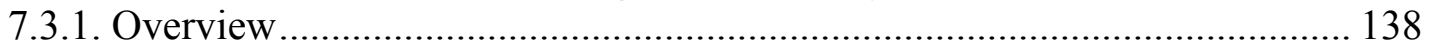

7.3.2. 'Lynchpin' Contention and Contestation................................................. 139

7.3.3. Opposition Politics and Depoliticization in Morocco................................ 141

7.3.4. Moderation and Exclusion of Islamic Contention in Comparative Perspective

7.3.5. Coercive Flexibility

7.4. Conclusion: Institutions and contentious framing in Morocco....................... 149

CHAPTER 8: Model Summary, Limitations, and Conclusions ............................. 149

8.1. Modeling Institutional Determinants of Contentious Framing ..................... 150

8.2. Omissions and Limitations ................................................................................ 154

8.3. Flexibility and the Arab Spring ................................................................ 155

8.4. Conclusions and Further Research Opportunities ....................................... 157

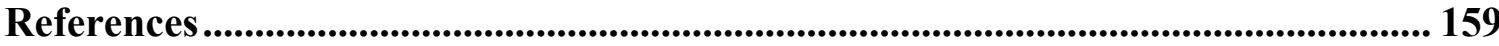




\section{List of Tables}

Table 2.1. Arab Spring Comparative Data................................... 24

Table 8.1. Patterns of Contention in Tunisia and Morocco...................... 151 


\section{List of Figures}

Figure 1.1. Model................................................ 9

Figure 3.1. 'Liberalization Game' I................................. 41

Figure 3.2. 'Liberalization Game' II................................ 49

Figure 3.3. 'Liberalization Game' III.............................. 53

Figure 4.1. Tilly and Goldstone's Model.............................. 68

Figure 5.1. Degrees of Contention: From low contention to high............ 88

Figure 6.1. The Arab Spring in Tunisia................................ 104

Figure 7.1. The Arab Spring in Morocco.............................. 138

Figure 8.1. Concessions are favored................................ 153

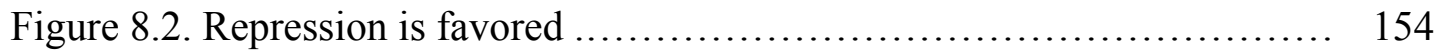




\section{PART ONE: Introduction and Literature Review}

\section{CHAPTER 1: Introduction}

\subsection{Revolution in the Arab World: Inevitable surprise or oversight?}

The self-immolation of Muhammad Bouazizi in Sidi Bouzid on December 17, 2010, served as a focal point upon which over twenty years of corrupt, coercive authoritarian rule were focused into a single, unified challenge to the Ben Ali regime (Angrist 2013, 548). Regime brutality and social media activism caused protests to spread across Tunisia and, eventually, throughout the region and beyond (Lynch 2012; Hess 2013). Yet, as Michele Penner Angrist (2013) posited, “[t]hese [immediate] elements were important to the unfolding of the 2011 Tunisian Revolution, but they do not account for the entire story" (548). The narrative of Tunisian society as governed by a 'pact of obedience' improbably set alight by a single contentious act was indeed far from the case. Yet, no one, including Angrist herself, had predicted the precipitous ejection of Ben Ali from Tunisia in 2010. Nor did anyone predict that Ben Ali's departure would catalyze a revolution throughout the Middle East and North Africa (MENA) resulting in an unprecedented outburst of social mobilization and statesponsored brutality. Nor, in fact, did anyone predict that the aftereffects of the so-called "Arab Spring" would still be felt today: in the form of the nascent but precarious democracy in Tunisia; or the heartbreaking reassertion of military rule in Egypt; or, finally, in Syria's catastrophically tragic, brutal, and far-reaching spiral into state fracture at the hands of Bashar al-Assad. These states were believed to exist in a "political grey 
zone" (Carothers 2002) - aside and apart from the "Third Wave" of democracy

(Huntington 1991) - wherein authoritarian stability was ensured through the maintenance of "robust" coercive institutions (Bellin 2004).

Yet revolution happened nonetheless. Consequently, scholars of the region and of revolutions are left to wonder if all analyses of the Arab Spring are destined to be decried as merely adding to the "regularly produce[d] multitudes of explanations for revolutions that no one had predicted"? (Kuran 1995, 1533). As Timur Kuran proposed in his seminal The Inevitability of Future Revolutionary Surprises (1995), “...massive changes in private opinion may leave public opinion undisturbed, only to be followed by a tiny change that transforms public opinion radically through a bandwagon process" (1535). If expressed preferences can be "falsified" by social actors, then even analysts with intimate access to a political system - i.e. 'insiders' - may find themselves in the dark. Moreover, if most pre-Arab Spring analyses of MENA authoritarianism were institutional or political-economic in nature, how can scholars be expected to gain the type of 'behind the veil' insights into societal preferences that Kuran believed were necessary to truly understand "revolutionary surprises"? In sum, was the "surprise" of the Arab Spring really inevitable?

\subsubsection{Institutions and Societal Preferences}

Why do institutions matter? And how do institutional factors relate to structural explanations of social revolution, democratization, and authoritarian persistence? One potential answer is that, lacking the 'thick', interpretivist description that Kuran suggested, analysts might still be able to determine which political arrangements are 
more or less conducive or susceptible to widespread "preference falsification" and societal alienation. Structural variables, such as the preferences of society vis-à-vis the regime are both informed by, and serve to inform regime-level institutions. This paper identifies a generalized variable, regime flexibility-generally manifested as the limitation or facilitation of institutional mechanisms for the expression of dissent and narrowly observed in state reactions to mobilization - as having the potential to shift (strategically-defined) societal preferences over time. Revolution is possible under conditions of coercive authoritarianism when society comes to prefer the risk of going up against a state's coercive apparatus to continuing to participate - implicitly or explicitly in its "controlled"-liberalization processes. The lack of institutionalized mechanisms for dissent necessarily pushes oppositional expressions of dissent outside of the political sphere (Angrist 1999a; Lust 2011). As societal actors form new networks, and find opportunities for networking and expression "under the radar", they develop new contentious framings that serve to embolden society toward action. While no government can claim to serve the interests of all of its citizens or to provide unconstrained institutional arenas for the expression of dissent, flexibility can nevertheless be conceived of as existing along a continuum. Inevitably, some members of society will become alienated from the regime and will remove themselves from the political sphere. The difference across regime-types, however, is that some regimes are more flexible than others and therefore offer sufficient opportunities for institutional change. This keeps enough individuals and groups partial to the status quo and/or the promise of future reform so as to ensure stability over time and in the face of contingent shocks. Just as democratic consolidation relies upon members of society accepting democratic norms as 
the 'rules of the game', so too are competitive authoritarian regimes reliant upon members of society acquiescing to the 'rules' of controlled-liberalization (Linz and Stepan 1996; Schedler 2004; Przeworski 1991). Hence, this paper offers regime flexibility as an independent variable that works to decrease the likelihood of contentious politics taking on a regime-change orientation as dictated by particular strategic orderings of societal preferences.

The goal of this paper is to suggest one way by which institutional and socialstructural approaches to democratization and contentious politics can be synthesized toward explaining how regime type informs the development and orientation of social movements. Institutional theories have tended to focus on how regime strategies and state coercive apparatuses have trended toward authoritarian persistence (Blaydes and Lo 2012; Blaydes 2011; Bellin 2004; 2012). With regards to instances of regime transition, institutionalists have placed regime elites - specifically regime hard-liners and soft-liners - and their dealings with civil society front and center in terms of explanatory power (O'Donnel and Schmitter 1986; Przeworski 1991). Structuralists, on the other hand, have either dedicated their analyses to variables related to socioeconomic development and class relations (Lipset 1959), or to changes in the either the state or within society that might or might not incentivize social mobilization (Inglehart and Welzel 2009; Diamond 2009). Theda Skocpol (1979) concisely summarized the social-structural framework:

"If our aim is to understand the breakdown and building-up of state organizations in revolutions, we must look not only at the activities of social groups. We must also focus upon the points of intersection between international conditions and pressures, on the one hand, and class-structured economies and political organized interests on the other hand. State executives and their followers will be found maneuvering to extract resources and build administrative and coercive 
organizations precisely at this intersection. Here, consequently, is the place to look for the political contradictions that help launch social revolutions" (32).

It is at just this intersection where regime-specific institutional factors play a part.

Further, the institutions and strategies developed by the incumbents in authoritarian states - in reaction to not only international and socio-economic concerns but also to normative legitimacy concerns - bears directly on how society relates to the state - i.e. whether and how dissent is articulated (Welzel 2009; Beetham 1999).

Hence, the role of regime and civil society elites, as well as the strategies of authoritarian persistence, both inform and are informed by state-society interactions. Contentious preferences are constructed through these interactions. The focus of this paper is primarily on the Middle East and North Africa (MENA) and the experience of the 'Arab Spring', where the institutional-structural synthesis is readily apparent and relevant to contemporary world events. However the hope is that the findings herein will be relevant to cases outside the region. This paper analyzes two key relationships that are found under authoritarianism: (a) between 'liberalizing' institutions and society; and, (b) between coercive institutions and society. With regards to the first relationship, as Cavatorta \& Haugbølle noted in detail, regardless of the paradigm, many interpretations of the Arab Spring were fundamentally focused on institutions and strategies at the elite and regime-level. They therefore failed to take into account how "in the longer term the values and modes of behavior of the ruling elites and small sectors of the urban population" were becoming increasingly "out of kilter with the ones that the majority of the population had" (190). Here, we strike a more nuanced position, arguing that 
institutions remain vital toward informing societal preferences - both over time and during acute contentious episodes.

Analysis of the second relationship draws upon research from Eva Bellin (2012; 2014), Jason Brownlee (2007) and Blaydes and Lo (2012). In general terms these scholars have put forth that the MENA region's democratic deficit is exceptional not due to primarily cultural or economic causes, but is rather the result of states' capacities to maintain and deploy their "robust" coercive apparatuses. As the story goes, the divergent outcomes of the Arab Spring hinged primarily on coercive capacity. However, the relationship between coercive institutions and society is not simply one of deterrence and stabilization within authoritarian states. Indeed, in Goldstone and Tilly's (2001) account, threat can also act as a destabilizing variable - provoking societal dissent, unrest, and mobilization. Threats can also mount overtime, making both everyday life and future prospects untenable.

\subsection{Overview and Organization of the Paper}

\subsubsection{Competing theories of democratization and authoritarian persistence}

The first chapter of this Thesis will serve as a both a literature review and an argument for the need to bring institutional, systemic, and sociological frameworks to bear on the question of social revolution in the MENA. Drawing primarily from the modernization theories of democratization, the elite-transitology school, and the authoritarian capacity literature, it is argued that the addition of a social-constructivist approach is necessary in order to fully understand the strategic relationship between authoritarian liberalization/coercion and societal preferences. 


\subsubsection{Toward a Synthesized Model (Chapters 3 and 4):}

In order to more fully flesh out these two relationships and their role in leading up to - and informing the direction of - the Arab Spring, this thesis will attempt to synthesize one novel model and another adapted model, each focusing on a particular relationship and employing particular institutional, sociological, and strategic frameworks. The first model, presented in chapter three employs a game theoretic analysis that draws upon the work of Przeworski (1991) and Blaydes and Lo (2012). By detailing the strategic relationship between regime Liberalizers and Social actors, it becomes clear that authoritarian regimes play an iterative, strategic 'Liberalization Game' over time with society. When social mobilization occurs, actors order their strategic preferences in relation to their historical knowledge of similar previous iterations. The game theoretic analysis concludes by suggesting that the reordering of societal preferences can have dramatic consequences for how events play out during periods of intense political contestation - similar to how Przeworski and Blaydes and Lo suggested alternate liberalizer preference orderings (i.e. 'tough' liberalizers and 'soft' liberalizers). Two preference orderings are presented: conservative and emboldened. In emboldened societies, actors prefer to risk regime repression and potential societal insurrection to continued acquiesce in the oft-repeated 'Liberalization game'.

Chapter four looks at the second relationship, adapting elements of the politicalsociology framework of contentious politics, specifically Goldstone and Tilly's (2001) "Threat (opportunity)" model. The question this adapted model seeks to answer is: how 
do societal preferences shift over time and/or during acute contentious episodes?

Goldstone and Tilly's basic hypothesis says that regime threat can actually be broken down into two composite variables - current threat and repressive threat. Repressive threat typically disincentivizes mobilization and serves as a deterrent in much the same way as Eva Bellin (2004) suggests. However, it can also embolden society by provoking extreme outrage in reaction to heightened and publicized instances of brutality. Current threat, on the other hand, represents the prolonged combination of coercion, concessions, and co-optation that a regime employs strategically over time, as well as the concessions and co-optation employed during acute contentious episodes. Regime institutions partially dictate the 'strategic mix' - or combination of repression and concessions - that a regime is predisposed to utilize. Over time, current threat in inflexible regimes - where the strategic mix 'favors' repression and rampant corruption over credible reform - can mount, thereby provoking social mobilization. This occurs when iterations of the Liberalization Game and the use of repression by the regime causes constructed societal framings to shift. In emboldened societies, contentious framings come to view the continuance of the regime as no longer preferable to the risks inherent in directly challenging the regime via mass mobilization. Framings can shift due to primarily internal factors (as in Tunisia) or they can become altered, per Skocpol, by a combination of internal factors and external events and pressures, such as the regional 'cascade' of the Arab Spring that started after Ben Ali's fall (Lynch 2012; Bellin 2012; Angrist 2013). Thus, the synthesis of the two models/relationships are summarized in the following two hypotheses: 
Hypothesis 1 (institutions, strategies, and threat): Regimes that permit high levels of contestation within parliament and exercise restraint with regards to a limited level of public contention were more flexible and were thereby able to survive the Arab Spring. Case 2, Morocco exemplifies such a regime.

Hypothesis 2 (institutions, strategies, and threat): Regimes that significantly limited parliamentary contestation and repressed popular political contention - i.e. that were inflexible - were more likely to become destabilized by the Arab Spring social movements. Case 1, Tunisia exemplifies such a regime.

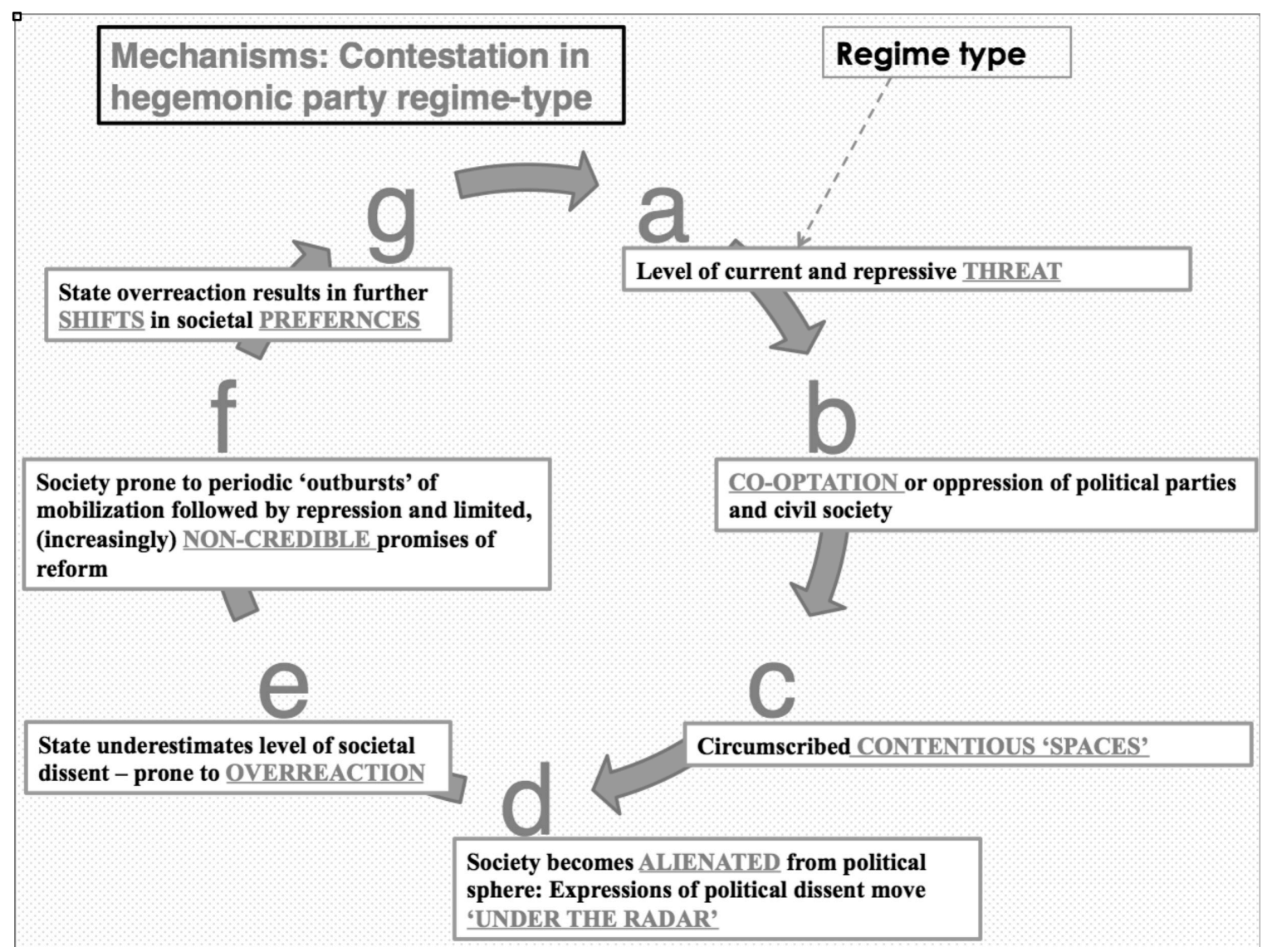

[Figure 1.1. The Model in Tunisia]

\subsubsection{Research Model and Methods (Chapters 5-8)}

In order to add some empirical weight to the formal theoretical chapters, narrative case studies will be relied upon. The selection of the two cases - Tunisia and Morocco will be elucidated in chapter five. A Most Similar Systems Design (MSSD) as outlined 
by Przeworski and Teune (1970) will be utilized. The independent variable of concern to the present study is regime flexibility, while the outcome of interest is societal preferences (i.e. an emboldened or conservative society). By revealing a link between these two variables, this study hopes to synthesize institutionalism, contentious politics, and strategic frameworks in order to better understand how mobilization can occur under coercive authoritarianism. To this end, the use of game theory in political science modeling has a long and fruitful history (see: Przworski 1991; 2001; Stokes and Boix 2003; Blaydes and Lo 2012). According to Robert H. Bates (2009):

“...game theory is... employed to model, i.e. to capture the logic that structures human interaction. Such explanations can and should be shaped by the understandings achieved through fieldwork and by the materials mobilized in thick descriptions. Grounded in the realities as experienced by other human beings, explanations move the researcher toward a sense of 'therefore.' The 'therefore' to which game theory gives rise is a recognition that the behavior one seeks to explain is what one must of necessity expect, given one's understanding of the political setting" (2).

Thus, in order to successfully utilize a game theoretic analysis in the development of a political model, a strong link must be drawn between the strategic interactions detailed by the game theory to the actual human experiences and interactions that rise out of rigorous empirical analyses. The game theoretic model represents a theoretical expectation, which must then bear out in the empirical analysis.

Informed by these concerns, the content of the case studies themselves will follow the contours of a historical-narrative case study. Per Blaydes and Lo (2012), narrative case studies are particularly well suited toward explicating and elaborating upon the type of iterative, extensive form games such as those presented in chapter three. According to Tim Büth (2002): 
"Using narratives to provide empirical support for one's model has a number of benefits, especially when we seek to examine explanations for historical processes with an important temporal dimension, but it also raises methodological questions that warrant closer attention. Specifically, how do we delineate a sequence of events so as to justify the imposition of a narrative beginning and end onto a continuous empirical record? How does the imposition of a narrative closure affect the generality of our conclusions? What is a narrative's "truth claim?" How useful are narratives for the assessment of alternative explanations?" (482).

As such, two additional concerns are placed upon the case study narratives in order to 'fit' the game theoretic model: justified, discreet temporality and elucidation of the "truth claims' that come out of the narrative. With regards to the former, the case study chapters will utilize the theoretically-justified temporal unit of the "contentious episode" - defined in detail in chapter four - to narrate the strategic interactions between state and society. Both case studies will delineate three historical contentious 'cases' - including the Arab Spring mobilizations - wherein elements of both the 'Liberalization game' model and the 'Threat (opportunity)' model will be teased out. These narratives will then be followed up with a generalized analysis of the institutional and societal factors that caused the shifts in contention (or lack thereof) described in the narrative portion. 


\section{CHAPTER 2: Competing Theories of Democratization and Authoritarian Persistence in a Revolutionary Context}

\subsection{Introduction: Correlates of Democratization}

In The End of the Transition Paradigm, Thomas Carothers (2002) rightly called into question a number of assumptions underpinning both the modernization and democratic transitions paradigms exemplified by e.g., Seymor Martin Lipset (1959), Dankwart A. Rustow (1970), O’Donnell \& Schmitter (1986), Samuel Huntington (1991), and Adam Przeworski (1991). Carothers' initial observation that "[b]y far the majority of third-wave countries have not achieved relatively well-functioning democracy or do not seem to be deepening or advancing whatever democratic progress they have made" at least serves to diminish the euphoria of much Third Wave scholarship (9). In his estimation many regimes were empirically not moving toward or away from democracy; nor, in his view, were they properly conceived of as types of democracy (6-9). In Carothers' terms, then, many of these states had instead entered "a political gray zone" (9). One of the new regime types subsumed within this grey zone he termed "dominantpower politics" wherein "...one political grouping... dominates the system in such a way that there appears to be little prospect for alternation of power in the foreseeable future", despite the existence of a "limited but still real political space, some political contestation by opposition groups, and at least most of the basic institutional forms of democracy" (11-12). Because of the apparent durability of dominant-power states, Carothers argued that it ought to be understood as an "alternate" direction, as opposed to a "way station" on the path to "liberal democracy" (14). The consequence of not doing so would be to “impose a simplistic and often incorrect conceptual order on an empirical tableau of considerable complexity" (15). 
Carothers' conception relates usefully to the study of the Middle East and North Africa. In this region, he observes that, "The liberalization trend that arose in the Middle East in the mid-1980s and has unfolded in fits and starts ever since has moved some countries out of the authoritarian camp into the dominant-power category. These include Morocco, Jordan, Algeria, Egypt, Iran, and Yemen” (13). Thus, according to Vickie Langohr, "[t]hat [liberalization efforts] have not led to meaningful democratization does not make the Arab world a democratic 'outlier': rather, it is part of a larger trend in which most recent moves away from authoritarianism have faltered" $(2009,193)$. This allows the region to be understood not in exceptionalist terms, but rather within the framework of a broader global phenomenon. Yet, given the empirical evidence suggesting that "there is broad support for democracy in the Arab world" (Jamal and Tessler 2012), the authoritarian character of the region has remained largely consistent over the last halfcentury; which suggests that Carothers' 'alternate destination' thesis might hold in the MENA.

Up until the Arab Spring (and perhaps still), the robust authoritarianism paradigm represented the dominant and best means of describing regime trajectories in the MENA. As late as 2007, Michele Penner Angrist posited that, "we are not likely to see substantial regime change in Tunisia in the next ten to fifteen years" (1999b: 190). While this hypothesis has been proven wrong by the events of the last few years, it was more than justified at the time given that, despite a move towards (nominal) pluralism upon assuming power, Ben Ali was still the dominant political actor in Tunisia twenty years after assuming power. However, Angrist also offered a prescient caveat to her assessment of the regime-strengthening aspects of electoral competition in Tunisia: 
"By allowing more voices to be heard in politically weak institutions in debates that are neither open nor reported to the public, the regime can test the political waters for new policy initiatives and more accurately gauge the state of public opinion. [...] As long as the economy performs reasonably well, regime stability is assured. But in the event of a downturn, the lack of peaceful mechanisms for public, popular articulation of dissent means that over the medium to long term instability could loom on Tunisia's horizon" (Angrist, 1999b: 143)

Thus, Angrist's concerns reflect the type of analytical synthesis of institutional and contentious politics paradigms that this paper argues is necessary for understanding patterns of society-regime interactions in authoritarian regimes. In short that "the lack of peaceful mechanisms for... dissent" emboldened political contention in Tunisia, diverging from Morocco where such mechanisms were more firmly and reliably in place (ibid). The rest of this section will be devoted to a critical overview of institutional and structural theories of democratization and authoritarian persistence. These frameworks offer important insights into the democratic deficit in the MENA. Carothers will serve as a useful bridge between democratization, on the one hand, and authoritarian persistence as a reaction or reassessment of democratization theory - on the other hand. Ultimately, however, both schools remain deficient in their ability to account for large-scale contentious political episodes - such as those seen during the 2010-11 Arab Spring.

Society lies between structures and institutions, and it is the interaction of both structures and institutions upon society that informs the preferences and capabilities of society visà-vis regime persistence.

\subsection{Structural Requisites and Mechanisms}

Modernization theory - taken broadly - posits that as levels of socioeconomic prosperity increase, the level of democracy will also increase. As one of the progenitors 
of the modernization thesis, Seymour Martin Lipset (1959) succinctly stated that, "the more well-to-do a nation, the greater the chances that it will sustain democracy" (75). The modernization thesis has since proven quite robust - though not uncontroversial (Boix and Stokes 2003). Welzel (2009) contends, however, that modernization theory "has been repeatedly challenged, but time and again it has been re-established against these challenges" (80). One line of contention falls within the debate between endogenous and exogenous democratization (Przeworski and Limongi 1997; Boix and Stokes 2003). Przeworski argued that - contra Lipset and his successors - development can only act exogenously to help ensure transition and consolidation, such that above a $\$ 6,000$ per capita income threshold, “democracies last forever" $(2009,16)$. In sum, development is exogenous - i.e. it helps democracies flourish - but does not affect democracy endogenously - i.e. their empirical evidence failed to bear out that development causes democracy. Boix and Stokes (2003), however, rebutted Przeworksi et al. 's refutation of endogenous democratization by setting the time period of statistical analysis back prior to 1950 . According to Geddes,

"...though the average effect for the whole period is slim relative to the effect of development on maintaining democracy... Boix and Stokes... show that when the dataset is divided by time periods, economic development is an extremely important predictor of transition prior to 1950 , but has only a small (though statistically significant) effect in the post-1950 period" (3).

These findings prompted an important question that relates crucially to the question of MENA democratization, “... why in effect could a country 'buy' democracy more cheaply - for a lower level of per capita income - in the late-nineteenth-century England or Norway than in late-twentieth-century Chile or Benin?” (Boix and Stokes 2003, 545) Effectively, after World War II, development became significantly better at helping states 
keep democracy and substantially worse at facilitating its development it in the first place.

If democracy used to be a reliable endogenous factor, new variables were impeding or retarding its effect in the Post-World War II world.

Correspondingly, according to Barbara Geddes (2009), "little beyond greater certainty about [Lipset's] original claim has been added to the pile of knowledge we can be responsibly sure we know" (2). This is because economic development is "correlated with many other trends" and one or more of those may be the causal mechanism that accounts for the apparent relationship between development and democracy - including "increasing education, equality, urbanization, experience of working in factories, and the weakening of traditional loyalties to tribe and village" (3). S.M. Lipset's analysis pointed to increased education and the lessening of socioeconomic divisions within society (1959). With regards to the former, his findings suggested,

"the most important single factor differentiating those giving democratic responses from others has been education. The higher one's education, the more likely one is to believe in democratic values and support democratic practices" (79, original emphasis).

Referring to the latter, Lipset said that, "increased wealth and education... serve democracy by increasing the extent to which the lower strata are exposed to cross pressures which will reduce the intensity of their commitment to given ideologies and make them less receptive to supporting extremist ones" (83). Thus, modernized individuals have a greater 'stake in the game' and are therefore more likely to selfmoderate and participate broadly rather than rebelling against the system when they are dissatisfied. A corollary to this is that elites and more well-to-do classes, upon 
understanding that the lower strata are inclined to work within the system and to selfmoderate, will be less threatened by the idea of the alternation of power.

Still, these variously proposed independent variables, while significantly correlated with democratization empirically, fail to explicate exactly what it is that development does to engender democracy (Diamond 2009). Essentially, the actual microfoundations of democratic change at the societal and individual level remains unexplained. One potential answer is that, according to the World Values Survey (WVS) work of Inglehart and Welzel (2009), the shift in values that modernization has yielded have tended, more often than not, towards those "espousing democratic values" (99). Indeed the "higher the levels of education, income, mass media exposure, and occupational status, the more democratic the peoples' attitudes, values, and behavior" (ibid). The underlying reason for this phenomenon is that as economic development raises individuals out of below-subsistence and subsistence levels, they correspondingly move up the Maslow "hierarchy of needs" - i.e. away from "survival values"” and towards "'self-expression values", which emphasize "human autonomy and choice"' (100). Stated in broad terms, Inglehart's and Welzel's research has shown that "people who grew up in periods of economic prosperity and security tended to have 'postmaterialist' values' emphasizing (for example) freedom and the environment", whereas those who grew up in poor socio-economic conditions "tended to have 'materialist values', (emphasizing socioeconomic and physical security)" (100). Even more importantly, “... as people come to embrace self-expression values... they come to demand democracy - and not just any democracy but the institutions to protect individual freedom and choice that encompass liberal democracy" (101). 
Similarly, Diamond's (2009) 'spirit' of democracy framework wears its normative value-orientation on its sleeve. Whereas Lipset's entire framework is rooted in and lends itself towards a procedural/institutional and therefore minimalist conception of democracy, Diamond is more concerned with the quality of democracy - i.e. with the ideal of 'liberal' democracy - which stems from a foundation of normative justifications for democracy akin to that of Jeremy Beetham (1999). It follows then, that Diamond is not satisfied with a modernization thesis that only concerns itself with why classes/groups/elites might acquiesce to a certain procedural arrangement - i.e. minimalist democracy. Certainly democratic competition is an important mechanism by which opposing groups and elites can alternate office peacefully, govern moderately, and lie in opposition patiently. Nevertheless, there needs to be a salient normative tether, which engenders and sustains the notion within society that democracy is the only game in town. Society should view its government as congruent with widespread societal values and needs - i.e. as the rightful and legitimate governing power. Further, as individuals gain personal, intellectual, and economic autonomy, democracy becomes the only viable option in terms of the ought/is dichotomy between normative values and the array of regimes capable of realizing and protecting those values.

So conceived, modernization acts to "enhance the resources available to ordinary people, and this increase the masses' capabilities to launch and sustain collective actions for common demands, mounting effective pressures on state authorities to respond" (Welzel 2009, 81). Hence, "[t]he major effect of modernization, then, is that it shifts the power balance between elites and the masses to the masses side" (ibid). Consequently, "[d]emocratization processes of recent decades have been most far-reaching and most 
successful where the masses were mobilized into democracy movements in such numbers and so ubiquitously that state authorities could not suppress them easily" (ibid). However, possessing a particular set of values is one thing and expressing them publicly and contentiously is an entirely more dangerous and fraught prospect under authoritarianism (Kuran 1995). Consequently, as Carothers (2002) has argued, authoritarian regimes did not take the Third Wave lightly, and instead moved quickly to adapt to the mechanisms of democratization and liberalization; and indeed to twist them to their own purposes - i.e. regime persistence.

\subsection{Modernization Theory and the Arab Spring}

What does modernization theory tell us about democratization in the MENA, generally, and the mechanisms leading up the Arab Spring, particularly? Firstly, Herb (2005) and Ross (2001) have shown that a high degree of oil wealth bodes ill for democratization. According to Michael Herb, rentier states - states that are reliant upon resource rents as a significant proportion of overall GDP - lack the tether of taxation necessary to connect a government thus instituting a relationship of mutual obligations (at the very least). Ross's (2001) findings support the hypothesis that higher personal and corporate taxes are strongly associated with more democratic government. Further, Ross found that oil wealth is linked to higher levels of military spending, thus fortifying authoritarian rentier states against mass insurrection. While these results are compelling, they are also only a small part of the overall story - indeed, there are many authoritarian states in the MENA region that are not rentier state, in that they are not resource dependent (Dunning 2008). These states are therefore forced to rely upon other state 
capacities - primarily, institutions of cooptation and coercion - to ensure authoritarian persistence (more on that below).

\subsubsection{Modernization in the MENA}

Sabri Ciftci (2010) tested three competing hypotheses for explaining support for democracy (or lack thereof) in Muslim countries - modernization theory, social trust, and religiosity. Ciftci proposed two potential reasons why modernization may not lead to democratic support: (a) different individuals, social classes, and societies may have different relationships with their governments - i.e. a greater level of government reliance/independence; and (b) the,

"...second reason for the problematic nature of the teleological interpretation of modernization theory concerns cultural implications. Although, modernization is expected to foster mass democratic values and beliefs as a result of industrialization, urbanization, and increased wealth and education, it is not clear how these values and beliefs are brought about or whether they are causes or consequences of democratization" (1446).

Ciftci, in order to sharpen the paper's focus differentiated between economic and cultural interpretations of modernization theory stating that "it can be expected that individuals with positive perceptions of gender equality and those who are more tolerant will be more supportive of democracy compared to those lacking these opinions" (1446). The results of his regression analysis "[lent] strong support to cultural and partial support to economic implications of modernization theory [...] education and income $[$ had $]$ positive and significant effects on both specific and diffuse support, confirming these hypotheses" (1454).

Correspondingly, Ciftci's findings lent support to Inglehart and Welzel's argument that modernization informs mass values. First, according to Ciftci, “... higher 
levels of education increase favorable attitudes toward democracy in a general way, whereas economic status leads people to evaluate democracy based on its specific outcome" (1456). Accordingly, per Lipset and others, education was shown to promote democratic values generally, while performance legitimacy was shown to be an important variable in determining the democratic (or non-democratic) satisfaction of those better off economically (Hess 2013). Second, Ciftci explains that, "[w]omen are less likely to provide specific (and diffuse) support for democracy in many parts of the Islamic world (i.e., Albania, Bosnia, Egypt, Indonesia, Jordan, Nigeria, and Turkey)" (1458). The correlation between women, democracy, and the Islamic world has been upheld by Inglehart and Welzel (2003); but narrowed by Donno and Russet (2004) as being more of an Arab phenomenon than an Islamic one. Broadly, then, Ciftci's conclusions provide ammunition to the value-oriented or "cultural" 'school' of modernization theory in the MENA context; but they also confirm the basic "economic" hypotheses concerning development and democracy, albeit to a notably lesser extent.

MENA, scholars have also found that democratic values are themselves quite widespread throughout the region while regimes are remaining rigidly authoritarian (Tessler, et al. 2012). This is why an entirely new paradigm came about to explain them - the "upgraded", "durable" or "robust" authoritarianism paradigm (Schedler 2006; Posusney \& Angrist 2005; Bellin 2004). However, casting durable authoritarianism as an alternate direction - per Carothers - ignores the normative vector of global democratic norms. Citizens in general are becoming more supportive of democracy, not less (Tessler, et al. 2012; Welzel 2009; Diamond 2009). While elites might be able to co-opt democratic institutions, slogans, and procedures, they will always fall short of 
establishing the breadth and quality of institutionalized mechanisms of dissent that democracy has on offer. Because dominant-power regimes lack - to varying degrees quantitatively and qualitatively acceptable institutionalized mechanisms for the venting of political opposition, they will tend to vacillate between legitimacy crises and coercive dilemmas (Diamond 2009; Przeworski 1991). Essentially, regimes that ignore popular preferences, alienating citizens from the political sphere, will tend to be vulnerable to mass mobilizations (Kuran 1995). The question then becomes, what makes mass mobilizations more likely to occur?

Such incongruities between popular values and regime institutions necessarily place pressures on authoritarian regimes (Diamond 2009). As a result, for "autocracies lacking the kind of legitimacy provided by democratic procedures, the maintenance of political power is heavily dependent on economic performance criteria" (Hess 2013, 246). However, if this really were true, according to Hess, then long-term economic depression or stagnation ought to noticeably affect regime stability. To the contrary, citing Geddes (1999; see also 2009), Hess argues that '“[w]hile low growth is 'never good news,' only sudden and severe economic crises in the short term seem to be capable of destabilizing otherwise-resilient personalist and single-party autocracies" (ibid). Geddes (2005) offers that this is because authoritarian regimes presented with economic crisis quickly devolve into inter-elite and elite-military fractionalization, unable to cope with the rapid unrest generated by such a sudden shock to the status quo. While such explanations might apply to Taiwan and the Philippines, however, they do not adequately parallel the Arab Spring. 


\subsubsection{Political-Economic Explanations for the Arab Spring}

Economic crises did not factor significantly into the outbreak of protests throughout the Arab world in 2010-11 (Hess 2010). According to Hess, "the cases in question experienced tepid growth, not outright collapse, in the lead up to the turbulent year of 2011. Tunisia's GDP per capita increased 3.5 percent in 2008, 2.0 percent in 2009, and 2.6 percent in 2010, while Egypt's grew by 5.3 percent in 2008, 2.9 percent in 2009, and 3.3 percent in 2010" (256). Albrecht (2012), argues bluntly that "it's not the economy, stupid":

"[The Arab Spring countries] show a significant degree of variance in the state of development, clearly detected in the difference in human development and economic strength between the 'more developed' countries Bahrain and Libya, on the one hand, and the 'less developed' countries Egypt, Syria, and Yemen [...] Tunisia falls somewhere in the medium range of development in that it has limited per-capita income, but one of the most advanced economies in the region" (251).

Indeed, Table 2.1 bears out that there are very few prima facie similarities between the Arab Spring countries along either economic (GDP, Unemployment), development (literacy, education), or across democratic (FH, Polity iv) indexes. 


\begin{tabular}{|c|c|c|c|c|c|c|c|c|c|c|}
\hline \multicolumn{11}{|c|}{ Table 2.1: ARAB SPRING COMPARATIVE DATA (from 2010 unless otherwise no } \\
\hline $\begin{array}{l}\text { Countr } \\
\text { y }\end{array}$ & $\begin{array}{l}\text { GDP/cap } \\
\text { (PPP)* }\end{array}$ & $\begin{array}{l}\text { Pop } \\
\text { (mil)* }\end{array}$ & $\begin{array}{l}\text { Unempl } \\
\text { oy \%* }\end{array}$ & $\begin{array}{l}\text { Ren } \\
\text { tier }\end{array}$ & $\begin{array}{l}\text { Lit } \\
\% * *\end{array}$ & $\begin{array}{l}\text { Enrolment } \\
\text { ratio**** }\end{array}$ & $\begin{array}{l}\text { PR } \\
\text { (FH) }\end{array}$ & $\begin{array}{l}\text { CL } \\
(\mathbf{F H})\end{array}$ & $\begin{array}{l}\text { Polit } \\
\text { y iv }\end{array}$ & $\begin{array}{l}\mathrm{A} \\
\mathrm{S}\end{array}$ \\
\hline \multicolumn{11}{|c|}{ "Hegemonic Party Regimes with Competitive Elections"** } \\
\hline Egypt & 6343.946 & 78.7 & 9.185 & 0 & 73.9 & 33.47 & 6 & 5 & -3 & 1 \\
\hline Yemen & 2598.591 & 24.39 & $\mathrm{n} / \mathrm{a}$ & 1 & 65.3 & 10.87 & 6 & 5 & -2 & 1 \\
\hline Algeria & 7112.053 & 35.42 & 9.961 & 1 & 72.6 & 28.76 & 6 & 5 & 2 & 0 \\
\hline \multicolumn{11}{|c|}{ "Monarchies with High Levels of Contestation" } \\
\hline $\begin{array}{l}\text { Morocc } \\
\text { o }\end{array}$ & 4794.021 & 31.85 & 9.063 & 0 & 76.1 & 14.32 & 5 & 4 & -6 & 0 \\
\hline Jordan & 5767.221 & 6.113 & 12.5 & 0 & 95.9 & 40.43 & 6 & 5 & -3 & 0 \\
\hline Kuwait & 38803.21 & 2.072 & 3.582 & 1 & 93.9 & $\mathrm{n} / \mathrm{a}$ & 4 & 4 & -7 & 0 \\
\hline $\begin{array}{l}\text { Bahrai } \\
n\end{array}$ & 27129.381 & 1.107 & $\mathrm{n} / \mathrm{a}$ & 1 & 94.6 & 36.87 & 6 & 5 & -8 & 1 \\
\hline \multicolumn{11}{|c|}{ "Single Party Regimes with Limited Contestation" } \\
\hline Tunisia & 9459.895 & $\begin{array}{r}10.54 \\
4\end{array}$ & 13 & 0 & 79.1 & 36.06 & 7 & 5 & -4 & 1 \\
\hline Syria & 5040.577 & $\begin{array}{r}21.39 \\
3 \\
\end{array}$ & 8.613 & 0 & 84.1 & 25.72 & 7 & 6 & -7 & 1 \\
\hline \multicolumn{11}{|c|}{ "Monarchies with Limited Electoral Competition" } \\
\hline $\begin{array}{l}\text { Saudi } \\
\text { Arabia }\end{array}$ & 22818.037 & $\begin{array}{r}27.56 \\
3\end{array}$ & 10 & 1 & 87.2 & 37.34 & 7 & 6 & -10 & 0 \\
\hline UAE & $45,759.38$ & 5.218 & $\mathrm{n} / \mathrm{a}$ & 1 & 90 & $\mathrm{n} / \mathrm{a}$ & 6 & 5 & -8 & 0 \\
\hline \multicolumn{11}{|c|}{$\begin{array}{l}\text { *Data from IMF (http://www.imf.org/external/data.htm); 'Rentier' designation taking from Herb } \\
\text { (2005); } \\
\text { ** Data from CIA factbook } 2014 \text { (https://www.cia.gov/library/publications/the-world- } \\
\text { factbook/fields/2103.html) } \\
\text { *** Data from UNESCO (http://data.uis.unesco.org/index.aspx?queryid=130\&lang=en\#); } \\
\text { FH data from Freedom House ; Polity iv } \\
{ }^{4} \text { Arab Spring variable: } 1 \text { for regime change or insurrection; } 0 \text { for no regime change or insurrection } \\
\text { All data accessed on July } 7^{\text {th }} 2014\end{array}$} \\
\hline
\end{tabular}

Yet, while the economies in general might not have shown indicators of looming unrest, it is possible that the notable demographic presence, in many Arab countries, of a "large, educated youth cohort" that "became increasingly frustrated with its poor job prospects" may have played a role (257). This line of inquiry conforms to empirical findings from Campante and Chor (2012):

"Countries that saw large increases in the size of this 'not-so-young' cohort amid a labor market with a high unemployment rate are in turn more liable to 
experience a change in political leadership. This in fact augments the role of the underlying expansion of schooling, as the significance of the interaction of this previous term with the unemployment rate remains significant. Overall, we view this as consistent with the idea that the opportunity cost in labor markets helps to explain the patterns in the political turnover data, as this slightly older cohort should be most active" (186).

However, Albrecht (2012), looking that the Arab Spring form a contentious politics point of view put forth that, "[e]conomic hardship might have had an impact on an individual's decision to join anti-government protests, but such economic indicators do not suffice to explain sustained mass uprisings" (250). Furthermore, such empirical results do not do much to elucidate the mechanisms by which some regimes were successful at demobilizing protesters (e.g. Morocco), while others were not (e.g. Tunisia). For one, different regimes found themselves equipped with quite different strategic predispositions, capacities, and tools at their disposal in 2010-11.

\subsection{Authoritarian Adaptation: Capacities and strategies of regime persistence}

According to Andreas Schelder, the MENA region, as of 2002, represented 17.2\% of the world's electoral authoritarian regimes and $32 \%$ of its closed authoritarian regimes - for a combined total surpassing all other regions of the world (47). Explanations for the MENA's authoritarian exceptionalism range from cultural/religious (Huntington 1995; Inglehart and Welzel 2003) to political-economic (Ross 2003), but by and large "commentators have followed the conventional wisdom embraced by researchers of authoritarianism in academia, which centers on the capacity of autocratic regimes to maintain elite cohesion while also stamping out popular challenges" (Hess 2013, 260). Authoritarian capacity can be conceptualized along three dimensions: political, economic, and coercive. This conception best illustrates the ways by which authoritarian regimes 
have restructured in such a way as to counter the democratizing dynamics discussed above. Yet, it should be understood that this type of analysis is incomplete in that it only looks at one half of the state-society relationship. Thus, the statement that "authoritarian breakdown is less associated with the tactics, grievances, or organization of popular protests and more with the top-down deficiencies of regimes themselves" denies empirical reality (ibid). The crux of this paper is that authoritarian institutions, structural factors, and contentious mass mobilizations need to be understood as forming a political ecosystem comprised of complex interactions and feedbacks over time. While these elements are capable of existing in equilibrium for long periods of time - i.e. in the form of persistent authoritarianism - they are also potentially vulnerable to legitimacy crises and contingent shocks.

\subsubsection{Political and Economic Liberalization as an Authoritarian Strategy}

In their analysis of democratization in South America, O'Donnell \& Schmitter (1986), strongly emphasized elite-level agency over structure, putting forth that "'structural features'... [are not] major factors in either the onset or the outcome of the transition process" (8). Further cementing their institutionalist bona fides, they went on to say that,

"...there is no transition whose beginning is not the consequence - direct or indirect - of important divisions within the authoritarian regime itself, principally along the fluctuating cleavage between hard-liners and soft-liners" (19).

Their hypotheses subsequently came under significant criticism following the so-called people-power movements. As Larry Diamond (2009) notes, "as more transitions happened and more scholarship accumulated" transitions were increasingly observed to 
be inextricably linked to popular mobilizations - and thus not primarily elite-driven (52). Nevertheless, the strategic interactions of regime elites remained a key unit and level of analysis in the study of democratization, and, with Przeworski (1991) and others, for studying authoritarian persistence. As the Third Wave progressed through the 1990s and into the early 2000s Carothers' assessment that regimes were entering into a political 'grey zone' became more and more undeniable. Regimes were adopting policies of economic (e.g. privatization) and political liberalization (e.g. elections) without releasing the reigns of power (Gandhi and Lust-Okar 2009).

Przeworski (1991) provides a succinct explanation as to how this might be the case: "[p]rojects of liberalization launched by forces from within the authoritarian power establishment are invariably intended as controlled openings of political space" (57). The purpose of such controlled openings is, in Przeworski's estimation, primarily to achieve a "broadened dictatorship" such that regime liberalizers are able to leverage an increased base of support against hardliners within the regime (ibid). Boix and Svolik (2013) depart from this line of reasoning, however, arguing that " $[\mathrm{t}]$ his argument is unfortunately less specific about why such co-optation could not occur without institutions" (301). Their reassessment argues that co-optation requires political institutions in order to "alleviate commitment and monitoring problems, whether in co-opting opposition or in power-sharing between the dictator and existing allies" (ibid). While other assessments of distributive politics such as Blaydes (2011) and Brownlee (2007) would agree with Boix's general logic, they would probably not be so quick to throw out Przeworski's hypothesis as a powerful incentive for liberalization, particularly in the MENA. Blaydes and Lo (2012), for instance, show that - through a combination of game theoretic and 
narrative analysis - Egyptian president Anwar Sadat, upon coming to power following Nasser's death in 1970, employed a strategy very much in line with what Przeworski proposed in Democracy and the Market. Hence, in Egypt the freedom to engage in authoritarian liberalization strategies hinged on the regime's coercive capacity. Egypt, Tunisia, Morocco, and other MENA states that lacked any oil wealth to leverage were obliged to maintain tight control over economic and political liberalization. Indeed, while "they implemented some liberalizing reforms, these regimes by and large had steadfastly sustained their discretionary grip over the economy, which largely contributed to a 'rent-seeking urban bourgeoisie and landed elite with no interest in democracy or political participation"” (Hess 2013, 261). Doing so required the liberal use of repression and oppression.

\subsubsection{Coercive Capacity}

Eva Bellin (2004) offers that the Middle East and North Africa is not exceptional because of its poor socio-economic structures, cultural/religious orientation, or its sultanistic institutional configurations. These are all elements that can be found elsewhere. On the contrary, "the solution... to [MENA] exceptionalism lies less in absent prerequisites for democratization and more in present conditions that foster robust authoritarianism, specifically a robust coercive apparatus in these states" (143, emphasis added). Prospects for democratic transitions in these countries have been effectively "extinguished" by the repressive dominance of internal security forces and, in some cases, the military. Four factors are enumerated and elaborated upon in support of this general hypothesis: (1) "the fiscal health of the coercive apparatus" due to various rent sources; (2) "the maintenance of international support networks" as supported by Cold War 
powers before 1990, and afterwards by foreign counterterrorism and oil interests; (3) the "low level of institutionalization of the coercive apparatus" low in Jordan and Morocco but relateively higher in Egypt and Tunisia; and (4) the "low level of popular mobilization that could typically be assembled to confront the coercive apparatus in the name of political reform" (Bellin 2012, 129). Bellin's reassessment of her 2004 findings in light of the Arab Spring, concluded that "[t]he trajectory of the Arab Spring confirms earlier analyses that the comportment of the coercive apparatus is pivotal to determining the durability of authoritarian regimes in the Arab world (and beyond) (142).

Lisa Blaydes \& James Lo (2013) further emphasize the importance of the 'muscular' coercive apparatus for authoritarian survival through their game theoretic analysis of 'managed liberalization'. Accordingly, liberalization efforts - such as allowing political pluralism in order to broaden the liberalizer's support base - will only take place in regimes where the coercive apparatus is sufficient to deter the organization of civil society. In environments where civil society "knows that the liberalizer will not repress... [they] organize with impunity" (122). Therefore, preemptively, the regime, [r]ecognizing that their threat of repression is non-credible [does] not allow civil society to organize" and a status quo dictatorship is maintained (122). This is illustrated by the authors' case study of Saudi Arabia wherein "the dividing line between civil society and the state is less clearly defined... than in other countries...", such that, “... while many other countries in the Middle East undertook controlled, top-down liberalization programs during this period, the Saudi liberalizers - unable to repress widespread civil organization - were not able to use civil society as allies in the struggle for control of the House of Saud" (126). This is in contrast to Egypt, where high levels of repression 
allowed for very tightly controlled political openings under both Sadat and Mubarak (Blaydes 2011; Cook 2012; Lynch 2012).

Each of the states under analysis has at one time or another shown its 'robust' ability (capacity and willingness) to repress civil society organization. In fact, as a result, in Tunisia and Morocco civil societies were co-opted, dissipated, or de-politicized into relative irrelevance by the time of the Arab Revolt (Angrist 1999a; Boukhars 2010; Blaydes 2011). By employing repression in this way, these regimes ensured that the only credible threat to their hold on power would have to come primarily from the ground-up; rather than from civil and political society intermediaries or from elites (Volpi 2013). Given that this is exactly what happened in 2011, it would seem that the deployment of states' coercive apparatuses over time was both highly successful at stifling mobilization opportunities, while also setting the stage for revolutionary surprises in the future (McAdam \& Tilley 2001; Kuran 1995).

In this vein, both Bellin's and Blaydes' accounts run into problems when faced with the eventual fall of the regimes in Tunisia and Egypt, especially given the fact that Ben Ali had no misgivings about using force at the first provocation in December 2010, nor did Mubarak in January 2011. While Mohammed VI also employed repressive tactics at first, it was a combination of contingent events and regime concessions that ultimately took the wind out of the revolution's sails (Lynch 2012). Writing in 2012, Bellin was able to reconcile her earlier account with the events across the Arab Spring states. Firstly, the institutionalization - or the "degree to which the military is institutionalized (in the Weberian sense) as opposed to being organized along patrimonial 
lines" - of the military played the most decisive role in the ultimate success of the revolutions (132). In these terms, Tunisia's military was one of the most independent in the region. Indeed, "Tunisia was well known for having a professional army which was small and removed from politics. It was not distinguished from the general population along ethnic or sectarian lines. It was not the beneficiary of economic cronyism with the regime. For these reasons the Tunisian military was less invested in the survival of Ben Ali and his cohort" (133). Therefore, given the costs of oppressing the "relatively peaceful" protestors - i.e. "undermining its internal coherence" - the military, when ordered to fire on the crowds instead "was able to imagine sending the regime elite packing" (134). Egypt's revolution basically mirrored this progression of events, given that the Egyptian military was similarly able to 'imagine' the fall of the regime in the face of high levels of mobilization. Where mobilization and military patrimonialism were both high - such as in Syria and to a slightly lesser degree in Libya - protests were met with heavy repression that quickly broke out into civil wars (Bellin 2012, 130-135; Lynch 2012). In another case of high mobilization, Bahrain, external coercion was brought to bear by the Saudi government in order to repress the largely Shia protesters (Lynch 2012).

The "failure of protest to snowball" in Morocco and Jordan, on the other hand, was attributed to "the successful division and cooptation of opposition elites topped off by the protective logic of monarchy", leading to initially low levels of mobilization that were less costly to subdue (Lynch 20120, 130). None of the states involved necessarily lacked for coercive capacity - or the actual physical resources for large-scale repression and surveillance. Rather, the level of mobilization was important in that it challenged coercive will to fire on civilian protesters (132). Where the coercive apparatus did fire on 
protesters, mobilizations quickly escalated to the point where the military became the decisive actor. While this creates a relatively straightforward narrative that correlates the level of institutionalization of the army with the (initially) successful revolutions in Tunisia and Egypt, it does not adequately account for why mobilization was raised to levels high enough to test the military's resolve. If it is, as Bellin offers, that 'successful division and cooptation of elites' in Morocco and Jordan is what accounted for the lowlevel mobilizations in those countries relative to Tunisia and Egypt - despite similar economic and political grievances - then why was patrimonialism so much more successful in the former two regimes than in the latter? Further, it is left partially unexplained as to why concessions were successful in Morocco and Jordan but rejected out of hand in Tunisia and Egypt (Lynch 2012). Certainly part of the explanation has to do with mass outrage at episodes of brutal regime repression in Tunisia and Egypt, but that only leads one to wonder why those regimes believed they could employ such brutal tactics with impunity in the first place. Moreover, it does not explain why - in the face of severe coercive repercussions - protesters in Tunisia and Egypt decided to take to the streets and demand the fall of the regime.

One possible explanation, according to Goldstone and Tilly (2001), stems from refuting the idea that "[t]he usual story of political opportunity goes basically in one direction - from opportunity to action" (180). Essentially, in the usual contentious politics conceptualization, "[a]s opportunity expands, actions mount; as opportunities contract, action recedes" (ibid). Within such a framework, "threat" and opportunity are viewed as diametrically opposed, as a negative force and a positive force, respectively (181). For Goldstone and Tilly, this is a "mistake", and threat ought to be more 
accurately conceived of as "an independent factor whose dynamics greatly influence how popular groups and the state act in a variety of conflict situations" (ibid). Understood in these terms, a formulation that hinges authoritarian persistence on "the state's capacity to maintain a monopoly on the means of coercion" and therefore its ability to "...face down popular disaffection and survive significant illegitimacy, 'value incoherence,' and even a pervasive sense of relative deprivation among its subjects", becomes a much more fraught argument to make (Bellin 2004, 143). The reason for this is that repression can, in certain circumstances, be as much of a reason (opportunity) to protest as, under other circumstances, it might be an impediment. Put another way, society may only be willing to live under a certain amount of current threat - i.e. the day-to-day insecurity, domination (and benefits) of living under the regime - relative to the concessionary gains its receives from the state and relative to the looming threat of repression.

\subsection{Conclusion: Revolutionary surprises and the need for a new approach}

Institutionalist frameworks within both the democratization and persistent authoritarianism schools of thought are often at a loss when it comes to predicting the trajectory of regimes. Revolutions tend to open up new paradigms, such as the shift from the Huntingtonian 'third wave' framework to that of 'robust' or persistent authoritarianism. Similarly, structuralists have shifted paradigms from Lipset's to Welzel and Inglehart's as methodological limitations and empirical observation have dictated. The variables and actors involved in both conceptual shifts remained broadly the same, but the specific mechanisms hypothesized as driving social relations adapted and shifted to meet new challenges and rectify old miscalculations. This was why Thomas Carothers rejected the to or from democratization teleology in favor of 
describing what alternative regime destinations might look like within a political 'grey zone'. As Cavatorta \& Haugbølle note in detail, regardless of the paradigm, many interpretations of the Arab Spring were fundamentally focused on institutions and strategies at the elite and regime-level. They therefore failed to take into account how "in the longer term the values and modes of behavior of the ruling elites and small sectors of the urban population" were becoming increasingly "out of kilter with the ones that the majority of the population had" (190). Much of this ought to be expected. As Timur Kuran wrote in 1995, "[a]s a practical matter... the dichotomy between social theories that produce complete knowledge and ones that generate only limited knowledge is more apparent than real. The critical difference is that some theories disguise their limitations while others make them explicit" (1534-5). Hence, in Kuran's view, the study of regime transitions and social revolutions has often been much better at description than prospection, even though it often poses as predictive. Revolutions in France, Eastern Europe, Iran, and now in the Arab world have all tended to fall under the rubric of 'revolutionary surprises'. Why is this?

Kuran argued that one potential reason why social scientists have had such a bad track record when it comes to prediction is that social actors possess the ability to falsify their preferences. Consequently, accurate measurement of the political temperament of such a society may be difficult, at least directly. By only looking at the ways in which institutional actors are able to coerce and co-opt their citizens into obedience or complicity, it is possible to overlook the subliminal ways in which regime dissatisfaction can be expressed, networked, and mobilized - or simply left dormant. This was Kuran's 
explanation for how revolutions seemed to spark out of nowhere: the discontent was there all along, but the regime's actions forced society to bury their objections deep and to find ways to express them 'under the radar' (See also Lust 2011). Thus, Kuran offered that a combination of microfoundational analysis and 'thick' interpretivist description might be the best way to recognize preference falsification and, in doing so, to recognize a looming revolution where one might otherwise see ironclad stability. Looking at the persistent authoritarian literature, one can (potentially) point to one such paradigmatic misapprehension. The question is, then, did these theories adequately recognize their limitations?

This paper contends that, for the most part, they did. The fact that most persistent authoritarianism research has maintained the to or from continuum framework vis-à-vis democracy - as opposed to adopting Carothers' 'grey zone'-as-alternative destination reflects the understanding that, while persistent, such regimes are still vulnerable. Scholars such as Angrist (1999a; 1999b) pointed to the confluence of stabilizing forces in Ben Ali's Tunisia - the economy and elite complicity primary among them - but also predicted that if any one thread was pulled too far out of place, the entire regime might come apart at the seams. While teleological arguments can be dubious and deceiving, democracy does seem to exert a sort of gravitational force over time. Regimes must either give in, or expend considerable effort in order to resist its pull. Regardless of which they choose, they must be ever mindful of its effects. This is exemplified by the fact that so many political regimes - democratic or authoritarian - couch at least some of their legitimacy claims in democratic terms, while also establishing (nominally) 
democratic institutions. The question then becomes, how do democratic rhetoric and democratic institutions affect the perceptions and actions of social actors?

This is where looking at preference falsification can be particularly instructive. Regime stability is not simply a matter of maintaining and strategically deploying the state's concessionary and coercive apparatuses. It also has to do with the degree to which the regime is able to manage and compartmentalize dissent. In other words, the dictator has the dual challenge of maintaining order while also keeping enough of the population either sufficiently cowed or otherwise invested in the persistence of the regime. Co-optation and coercion can only work insofar as they are able to narrowly and secretly target the sectors of society that might begin to subvert the regime. By forcing citizens to resort to preference falsification - to live, as it were, 'under the radar' - the regime risks losing track of the opposition. As a result, it cannot control the evolution of societal preferences. When a contingent event - a social or structural shock - or some other 'spark' occurs, the regime will then likely disproportionately calibrate its response. If the regime lacks information about both the size and type of dissent, then it will be ill equipped to 'weather the storm'. Thus, it ought to be apparent that institutional and elite-strategy interpretations, while not the whole story, bear significantly on how members of society choose to express dissent. This realization lends itself to a constructivist argument - synthesizing institutional and sociological frameworks as a way to describe shifts in societal preferences and revolution under authoritarianism.

The rest of this thesis will therefore be devoted to answering the twin questions that arise from the above assessment: 
Question 1: What factors might account for society becoming so 'emboldened' that it is willing to go up against a seemingly insurmountable and undoubtedly brutal coercive apparatus?

Question 2: What factors might account for the diversity of regime strategies when it comes to dealing with popular mobilization?

One initial conclusion immediately comes to mind: it is obvious that these two questions are related. The next two theoretical chapters will attempt to discern exactly why this is the case; while the following three case study chapters will attempt to put the theoretical findings in narrative context. 


\section{PART TWO: Modeling Liberalization, Revolution, and Threat in the MENA}

\section{Chapter 3: Emboldened Social Mobilization - a game theoretic approach}

\subsection{Introduction}

What might compel social mobilization against the state in the face of potentially insurmountable odds? In 2011, citizens across the Arab world flooded into the streets in countries where the specter of history promised only violent consequences. In Tunisiathe veritable first domino of the Arab Revolt - protesters had been brutally repressed as recently as 2008 during the Gafsa Mining Basin riots. So too in Egypt, where activists involved in mobilizations related to the second Palestinian intifada, the 2003 American invasion of Iraq, and the 2004 Kefaya! ("enough!") movement were met with mass arrests, torture, and beatings at the hands of the state police (Lynch 2012). At the 'bottom up' level of analysis, explanations of social revolution and mass mobilization have been concerned with 'under the radar' preferences and networks (Kuran 1995) as well as shifts in the political opportunity structure (McAdam and Tarrow 2001). On the other hand, democratic transitions studies primarily focused on strategic interactions between elites: "there is no transition whose beginning is not the consequence - direct or indirect - of important divisions within the authoritarian regime itself, principally along the fluctuating cleavage between hard-liners and soft-liners" (O’Donnell and Schmitter 1986, 19).

O’Donnell and Schmitter approached the subject using "strategic analysis... [shying] away from adopting a formalistic, ahistorical approach inherent in the abstract 
theory of games" (Przeworski 1991, 97). Accordingly, Przeworski's seminal Democracy and the Market (1991) employed just such a formalized methodology. The key takeaway from his game theoretic approach (discussed in detail below) was that regimes will not engage in liberalization when they do not believe that their repressive capacity is sufficient to cow civil society into cooperation - i.e. a "broadened" dictatorship wherein the liberalizers enjoy a increased base of support. Lisa Blaydes and James Lo (2012) come to a similar conclusion in their game theoretic analysis of liberalization in the Middle East and North Africa (MENA). However, both sets of conclusions were rooted in similar assumptions about the preferences of civil society in the face of potential liberalization. What follows is an analysis of the strategic implications of specific changes to that preference ordering, which offers a formalized hypothesis in response to the opening question: why might society mobilize in the face of assured violent repression?

\subsection{The 'Liberalization Game'}

Liberalization in authoritarian regimes is perpetrated exclusively for its value in perpetuating at least some element of the ruling elite's hold on power - it is always strategic, or managed liberalization. According to Przeworski, "[p]rojects of liberalization launched by forces from within the authoritarian power establishment are invariably intended as controlled openings of political space" (57). The purpose of such openings is to broaden "the social base of the regime: to allow some autonomous organization of the civil society and to incorporate the new groups into the authoritarian institutions" (ibid). In the MENA, the motivations for liberalization are legion: co-opting non-regime elites into the regime, appeasing international actors concerned with 
democratization or human rights, and providing an institutional 'vent' for society and elites to 'release steam' (Blaydes 2011; Brownlee, 2001). Yet, liberalization “is inherently unstable”, liberalizers may achieve a Broadened Dictatorship [BDIC in figure 3.1], or, in response to providing some political leeway, civil society might Organize rather than Enter into the newly liberalized-but-controlled political system. Put another way, civil society organization - e.g. the formation of independent organizations, parties, and unions - may lead to the "melting of the iceberg of civil society that overflows the dams of the authoritarian regime" (Przeworski 1991, 58). The regime is then left with two distasteful options: repression [Repress] or political transition [Reform]. Repression, though, is risky. Will the regime succeed in putting down the protests? If so, a narrowed, more repressive dictatorship [NDIC] results; if not, insurrection and civil war [INSURRECTION] loom on the horizon. Consequently, if the liberalizers are not sufficiently confident in their chances at defeating mass mobilization, they will refrain from liberalizing in the first place, preferring instead the status quo [SDIC]. 


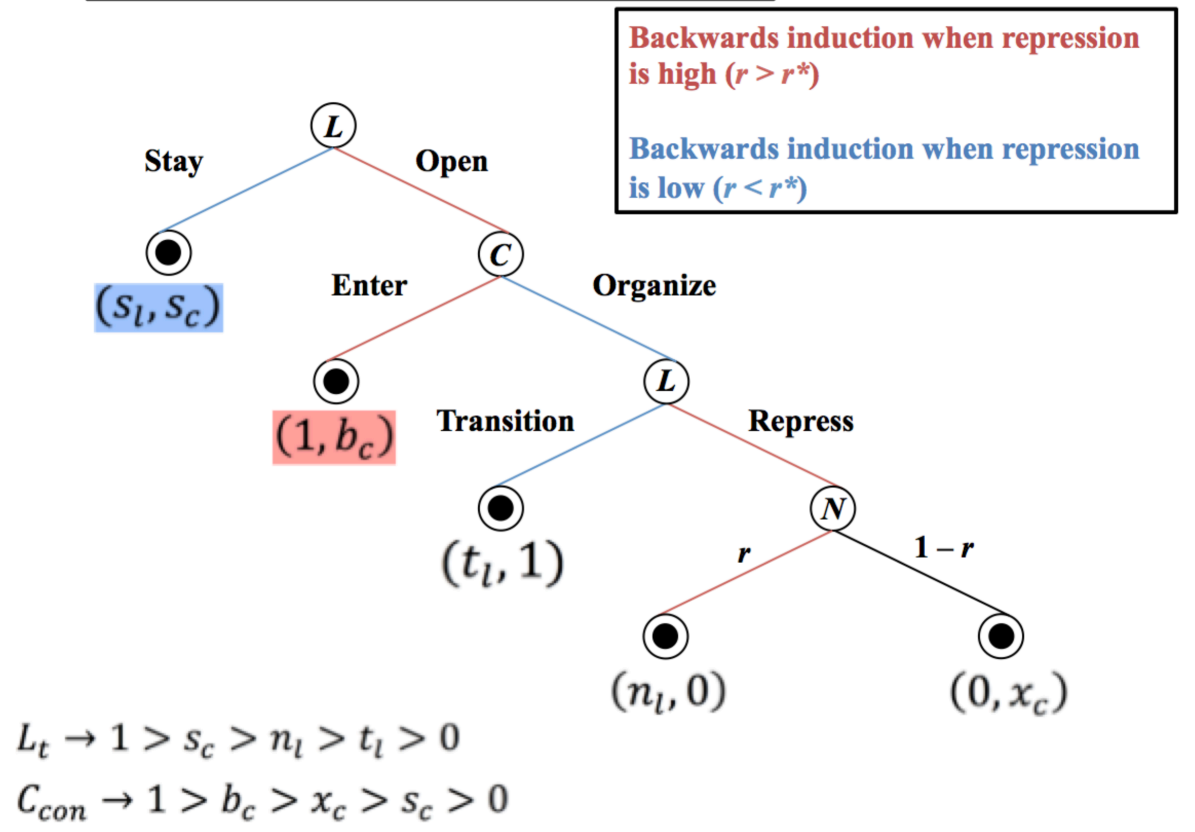

[Figure 3.1: 'Liberalization Game' I - from Blaydes \& Lo 2012, 117]

The Liberalization Game theorized by Adam Przeworski in Democracy and the Market (1991) formalizes the role of repressive capacity in dictating the strategic choices of regime liberalizers and civil society. If the liberalizers are "soft", then they prefer BDIC $>$ SDIC $>$ TRANSITION $>$ NDIC $>$ INSURRECTION - i.e. they prefer reform to repression (Blaydes \& Lo 2012, 117). However if they are of the "tough" variety, then they prefer a narrowed dictatorship to transition and therefore the ordering is thus: BDIC $>$ SDIC $>$ NDIC $>$ TRANSITION $>$ INSURRECTION. Yet - assuming that both parties have perfect information regarding each other's (and their own) strategic choices and preferences - there are only two possible equilibrium outcomes. The regime's eventual success in subduing a mobilization by civil society, $r$-determined by 'nature' and expressed as a probability - cannot be known by either side. However, "they both have 
some belief about the value of $r$ " (Blaydes \& Lo 2012, 117).

Using backwards induction on the game in Figure 3.1, it turns out that the strategic choices made by both the regime and civil society hinge on whether or not $r$ is estimated to be large enough to act as a deterrent vis-à-vis civil society. If the regime believes $r$ to be sufficiently high - i.e. the success of repression is probabilistically likely - then (tough) liberalizers within the regime will favor political opening; knowing that they can control and constrain it. Correspondingly, they will refrain from liberalization otherwise. Knowing this, civil society will 'take what it can get' and agrees to cooperate with tough liberalizers when $r$ is high. Soft liberalizers, while preferring transition to a narrowed dictatorship - which civil society knows - nevertheless prefer the status quo to both of those options. The result is, then, no political opening at all and the status quo prevails [SDIC]: “[i]f liberalizers decide to take no action, in Przeworski’s language to 'stay with Hardliners,' then the outcome of the game is status quo dictatorship" (ibid).

Przeworski offers two potential scenarios, based on the constraints imposed within the Liberalization Game, wherein regime transition might occur. The first is to "[s]uppose the regime liberalizers are in fact proto-democratizers" (62). For this scenario to actually come to fruition, however, it would require the proto-democratizers to simultaneously telegraph their authoritarian credentials to the hardliners within the regime, while also somehow conveying to civil society their genuine democratic bona fides. The degree of political jujitsu and subterfuge entailed in this particular narrative suggests that its practicality is limited to say the least. The second scenario progresses as follows: 
"[tough] Liberalizers open, expecting the society to enter. But the society has a lower estimate of successful repression and believes that Liberalizers have the same estimate. Hence, society organizes. Once Liberalizers observe that the society is continuing to organize, they downgrade their estimate of successful repression to the point where they prefer TRANSITION to the outcome expected under repression.

Consequently, because $r$ is both a probability and an implied belief about a probability, “...civil society organizes, and Liberalizers update their beliefs about the effectiveness of repression as they watch the streets" (64).

Two more plausible scenarios are then offered by Przeworski, both either bending or breaking the epistemic assumptions underlying game theoretic methodologies - that "preferences are fixed and that actors are rational, even if ill informed" (ibid). Przeworski describes the first scenario as "sociological". Essentially, Liberalizers and society come to see each other as "willing to listen and make concessions", causing elites to view transition as, "less of a chasm" and repression is subsequently re-framed as "simply uncivilized". As a result, "Liberalizers change their preferences endogenously as a result of bargaining with the opposition" (65). The non-rational scenario represents a catchall for the myriad ways in which intentions, strategies, and preference assumptions can be badly conveyed or misinterpreted. Further, there is the inherent paradox that "[g]ame theory is generally concerned with problems of strategic rationality - problems in which the rational decisionmaker must take into account the fact that the outcomes of various possible actions available. Are influenced by the choices made by other rational decisionmakers" (Little 1991, 52). Consequently, if one or the other party acts irrationally - i.e. arbitrarily or based on idiosyncratic utility calculations - strategic predictions become nigh impossible to make. Therefore, “...liberalization... is not a 
feasible project unless everyone has full and accurate knowledge about everybody else's preferences and the probability of successful repression" (Przeworski 1991, 65). However, as we shall see, while irrationality cannot be captured by these models, some degree of uncertainty can be accounted for while still yielding interpretable and applicable explanations.

\subsection{The 'Liberalization Game' in the MENA}

Blaydes and Lo (2012) carry Przeworski's conclusions forward into their own extended Liberalization Game, which accounts for two levels of uncertainty regarding the 'type' of civil society - i.e. as being moderate or radical (Islamist) - and the type of Liberalizer. Their game theoretic model does not much change the implications of low repressive capacity for the prospects of regime liberalization. When repressive capacity (likelihood) is low, liberalizers will still simply opt for the status quo - they will not stick their neck out against the hardliners. Blaydes and Lo employ a case study of Saudi Arabia in order to illustrate this proposition. Essentially, in the Kingdom, "the dividing line between civil society and the state is less clearly defined... than in other countries..." such that, “...while many other countries in the Middle East undertook controlled, topdown liberalization programs during this period, the Saudi liberalizers - unable to repress widespread civil organization - were not able to use civil society as allies in the struggle for control of the House of Saud" (126). Contrastingly, where liberalizers were of the tough variety and had a high repressive capacity, such as in Egypt, controlled liberalization became a strategic feature of the regime (130; Blaydes 2011; Albrect 2013). 
Blaydes and Lo's game theoretic model departs importantly from Przeworski's in at least two cases. Essentially, the added uncertainty regarding the 'type' of liberalizer and civil society throws a wrench into the proceedings. The difference between civil societies has to do with the implications of the TRANSITION end node. If, after liberalizers have opted for increased political openness civil society signals that it is more radical than it is moderate: "i.e., radicals value theocracy more than moderates value democracy", then "the result is either insurrection or a narrowed dictatorship" (122). Conversely, if civil society is able to telegraph that it is more moderate - "i.e., moderates value democracy more than radicals value theocracy" - "the result is either insurrection or a narrowed dictatorship [with tough liberalizers]" and democracy when faced with soft liberalizers (122). Ultimately, the game's equilibria are significantly impacted by the dual uncertainties vis-à-vis Liberalizer type and Civil Society type. In the political and electoral events that led up to the civil war in Algeria (1991-2002), for instance, “...incomplete information played an important role in the calculations (and miscalcuations) of key actors", because society "believed that the regime was unlikely to violently repress the populace" due to past experience (129). Hence, uncertainly about the 'type' of Liberalizer collided with the regime's uncertainty about society: "[t]he FIS [the Islamic Salvation Front political party] was fairly vague about its platform in the runup to the [1990] election" which led to concern about whether or not the FIS would "alter the constitution, instituting an Islamic state" (ibid). The consequences were ultimately tragic: "The army quickly established a High State Council to rule Algeria and, by March of 1992, the FIS was banned and its leadership repressed. The years to follow would 
bring almost a complete devolution of power as Algeria fell into a period of violence" (ibid).

\subsection{Strategy in the Arab Spring}

Signé and Smida (2014), a working paper for the Center on Democracy, Development, and the Rule of Law (CDDRL) at Stanford University, brought game theoretic analysis to bear on the Arab Spring. Signé and Smida's analysis focused on the strategic interactions between Ben Ali and the Tunisian Military subsequent to the 2011 mass protests. They employed a sequential game in the vein of Przeworski and Blaydes and Lo that addressed the inherent information asymmetry between the regime and the army; arriving at a formalized explanation for why the military "refused Ben Ali's order to open fire on its own population" (10). In doing so they further elucidate the strategic pressures that popular mobilization imposes on authoritarian regimes. Specifically, they show that the regime, when faced with mass mobilization, has two initial options reform or repress, and that the chance of repression, $r$, is much more complex than a simple 'rolling of the dice'.

Accordingly, information asymmetry turns out to be quite significant in accounting for how events actually played out in Tunisia:

"Due to incomplete information, Ben Ali's decision to order the shooting is not perfectly based on the army's expected utility because he doesn't know at which points the army will refuse to the order to open fire. In other words, Ben Ali has vague information about the limit at which the army will accept to shoot. For simplification, we assume here that Ben Ali's decision to order a repression is based on an expectation that the army will follow his order. The army, however, follows its preferred expected utility given that we assume that it has complete information about Ben Ali's expected utility" (19). 
Thus, because the army, crucially, was sufficiently institutionalized such that it was able to imagine a future beyond Ben Ali, it could afford to behave as a separate strategic actor during the 2011 revolution (Bellin 2012). Therefore, while Ben Ali's actions were based on the information available to him - e.g. the military's willingness to intervene on the behalf of the regime as recently as 2008 - the military's decisions were based on their own cost benefit calculations. Specifically, the army weighed its expected utility of firing on a popular motivation of unprecedented size and scope, against the that of taking their chances with the opposition (Signé and Smida 2014, 19-20). Because "the Generals [had] more information than Ben Ali's regime... [they had] control over the final equilibria", and therefore had the luxury of making a more informed and pragmatic decision (19). Importantly, the richness of this analysis is that the game all takes place within what Przeworski and Blaydes and Lo simplify as ' $r$ and $(1-r)$ ' - i.e. the repression 'lottery'. By attaching a deeper level of analysis to the regime's strategic and probabilistically informed decision to repress, they help to illuminate the narrative richness of the final 'move by nature' - i.e. there exist myriad variables that might affect how different actors from different perspectives view the chances of revolution. We now take this into account by looking at Civil Society's relationship with repression.

\subsection{Emboldened mobilization under (tough) authoritarianism}

The most important takeaways from these three formalized analyses is that (a) repressive capacity is the most important variable governing the players' strategic decisions; (b) with prefect information, TRANSITION is only attainable as the result of obfuscated or altered preferences, strategic miscalculations, or the introduction of factors outside the rational parameters of the game (Przeworski 1991, 57-61), and (c) 
information asymmetries and/or uncertainties can muddy the waters, making transition or repression possible in otherwise unlikely scenarios. Further, all three models essentially treat $r$ as a "move by nature", and it is only at "the very end of the game [that] ...the result of the repression "lottery"' is known (Blaydes and Lo 2012, 117) ${ }^{1}$. This alters the strategic choices of both parties based on their respective expected utility calculations for 'participating' in the repression lottery. Within the game both parties are referencing the same value of $r$, but they are weighing the expected utility of the lottery against their own preference orderings. Blaydes and Lo calculate the regime's expected utility as follows:

$$
\begin{gathered}
U_{l}(\text { repression })=(r) n_{l} \\
\left.U_{l} \text { (transition }\right)=t_{l} \\
(r) n_{l}=t_{l} \\
r=\frac{t_{l}}{n_{l}} \equiv r^{*}
\end{gathered}
$$

[Directly from: Blaydes and Lo 2012, 118]

The state's assessment of its repressive chances is likely to be the most accurate. This isn't a particularly giant leap: it behooves the state to telegraph its relative repressive strength as well as to collect information on the strength of civil society. However, the examples of mass mobilization in the face of assured repression are legion throughout

\footnotetext{
${ }^{1}$ However, as noted above, Signé and Smida (2014) delve further into the complexity of such an assertion by having a Ben Ali-specific $r$-value, and giving the Generals their own, similar but distinct, probability-for-repression variable, $q$.
} 
history. If we continue to assume perfect information and rationality, what could possible account for such a turn of events. I hypothesize that the answer has to do with the probabilistic role of $r$ and it's relationship with the non-probabilistic utilities elsewhere in the game. If civil society is dealing with a tough liberalizer, the last real agential strategic choice in the game occurs at civil society's first choice node - i.e. Enter or Organize [see: Figure 3.2]. At this point, civil society knows that if the regime believes that $r>r^{*}$ it will Repress and so the choice to Organize hinges on the relative utility of Enter $\left(b_{c}\right)$ versus the expected utility of 'rolling the dice' between INSURR $\left(x_{c}\right)$ or BDIC $(0)$.

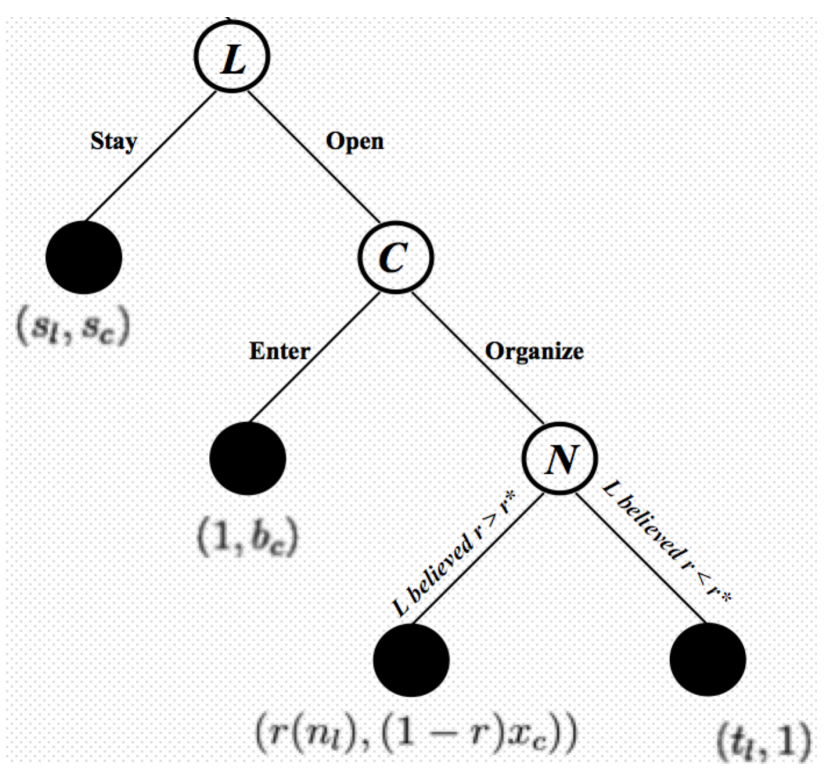

[Figure 3.2, Liberalization Game II - Przewoski's 1991 model simplified]

We can compare expected utilities within Przeworski's model and decide if there is a conceivable scenario in which a rational civil society might choose to organize in the face of expected repression. Of concern is the relationship between the Liberalizer's 
belief about $r$, and the expected utilities of $b_{c}$ and NDIC (0) plus $x_{c}$, for civil society. Based on these utilities, then, is there a value of $r$ - and therefore an equilibrium within the game theoretic model - where liberalizers believe $r>r^{*}$ and civil society still chooses to organize? This can be determined by setting civil society's two utilities equal to each other as follows in order to determine when and if civil society will be indifferent between the two outcomes:

$$
\begin{gathered}
U_{c s}(\text { enter })=b_{c} \\
U_{c s}(\text { repression })=(1-r) x_{c} \\
b_{c}=(1-r) x_{c}
\end{gathered}
$$

and then solving for $r$ :

$$
\frac{x_{c}-b_{c}}{x_{c}}=r \equiv r^{* *}, \text { iff } x_{c}>b_{c}
$$

Given that $r$ is a probability between zero and one, this relationship can only be true when $x_{c}>b_{c}$. Let us call this scenario proposition 1 .

Proposition 1 (emboldened civil society): there is some value of $r$, lets call it $r^{* *}$ (as opposed to $r^{*}$ above), where civil society is indifferent between repression and a Broadened Dictatorship, if and only if civil society's preference ordering is actually TRANSITION (1) $>$ INSURRECTION $>$ BDIC $>$ SDIC $>$ NDIC (0). In this preference ordering $x_{c}>b_{c}$ and the expression $\left(x_{c}-b_{c}\right) / x_{c}=r$ can be true.

Thus, it is conceivable - both theoretically and narratively - for there to be values for $x_{c}$ and $b_{c}$ where civil society will prefer to 'roll the dice' of repression rather than endure a Broadened Dictatorship. In this case society will choose to organize even when the (tough) regime believes that repression will be successful. Lets call this new type of civil society, emboldened. Because this can only occur when the liberalizer is tough and believes $r>r^{*}$, the new equilibrium lies at Liberalizer: (Open, Repress) and Civil 
Society: (Organize) - with the new outcome being either a Broadened Dictatorship or Insurrection.

\subsubsection{Preceding the 'Liberalization Game'}

At this point the above game might seem to be open to two narrative criticisms when applied to the events of the Arab Revolt. First, there was no strategic opening move on the part of the regime that started the game; events were precipitated by mass mobilization and protests. Second, the game, as it were, was not being played between regime elites on one side and civil society elites per se on the other. Instead Ben Ali was only able to communicate with the masses by either repressing or offering concessions, and communications from civil society to Ben Ali would have taken the form of further mobilization or demobilization. However, neither of these objections changes much strategically or mathematically. If, instead of beginning at the Liberalizer node at the top of Przeworski's game tree, we start the game at a modified Repress or Reform node changed to Repress or Offer Concessions - that leads into a modified Enter or Organize node - Accept (concessions) or Reject (concessions) - we can see that the strategic choices still hinge on the same variables as Przeworski's original game. In which case the strategic outcomes can then be expected by both players to flow naturally out of the Accept node. The narrative here is that the game tree begins at the regime's choice between repressing initial protests or offering concessions. Essentially, both players can expect that, if society is convinced to peacefully demobilize, civil society will be plunged back into the Liberalization game. This means that the same basic strategic logic will still apply: if civil society prefers a Broadened Dictatorship to insurrection and $r>r^{*}$ for the regime, then society will prefer to accept concessions and the regime will prefer to 
offer them: the equilibrium will be Liberalizers play (Offer Concessions, Open, Repress) and Civil Society plays (Accept, Enter). If, conversely, civil society is emboldened, the above strategic calculations hold that, for values of $r<r^{* *}$ civil society will choose to Organize, even if it knows that the regime will Repress. This causes the regime to be indifferent between playing (Repress) and (Offer Concessions) when it knows society is going to play (Reject) [see figure 3.3]. This scenario appears in the Tunisian case study and is summarized in Proposition 2.

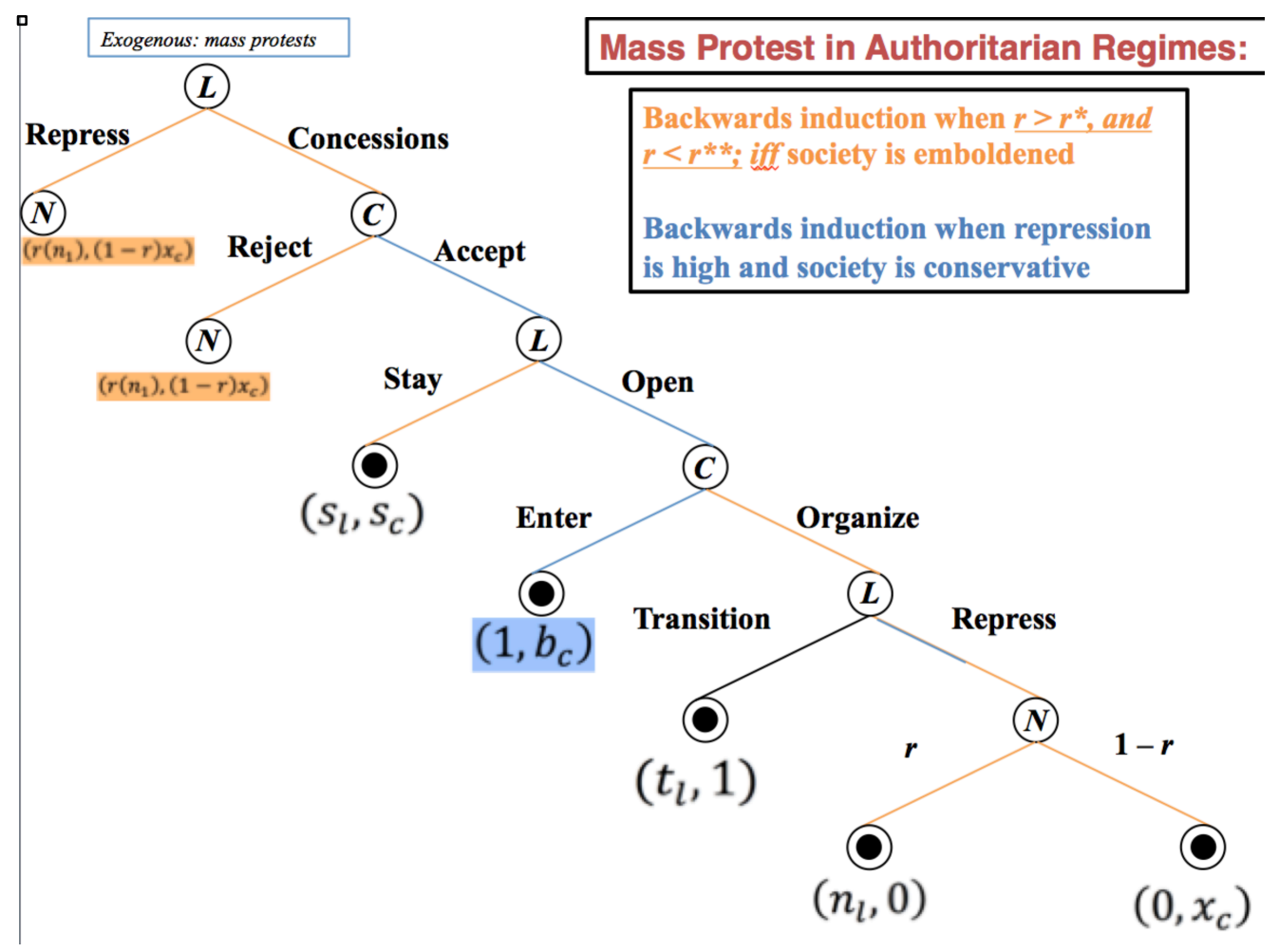

[Figure 3.3, Liberalization Game III - amended extensive form game]

Proposition 2 (expanded game with emboldened society): If the regime is tough - i.e. it prefers NDIC to Transition - and civil society is emboldened - i.e. it prefers the expected value of Insurrection and NDIC (probabilistically determined) to BDIC - then there is an equilibrium in which mass mobilization 
will prompt regime repression and civil society will reject any concessions short of "the fall of the regime".

Narratively, this makes intuitive and empirical sense. Society knows that if it accepts concessions from the regime in return for demobilizing, it will have to make the same strategic decisions down the line as during historical liberalizing phases. If society has reason to believe that the expected value of risking repression will not substantively differ from a broadened dictatorship, it stands to reason that it will prefer to risk repression if certain circumstances prevail. According to the cursory variable analysis above, such circumstances would entail either a decrease in $r$-increasing the expected utility of $x_{c}$ - or a decrease towards zero of the expected utility from $b_{c}$. Put in less formal terms, if society's chances of toppling the regime through insurrection increase, or the expected conditions under continued regime cooperation appear especially distasteful, then civil society can be considered emboldened and therefore increasingly willing to mobilize against the regime. On the other hand, if society is not emboldened, the preference ordering remains the same and the game plays out similarly to the original game in Democracy and the Market. In this case, the equilibrium is at Regime: (Offer Concessions, Open, Repress); Society (Accept, Enter). The Moroccan case exemplifies this proposition, which is expressed in Proposition 3.

Proposition 3 (with conservative civil society): If civil society does not prefer Insurrection to BDIC, then it is conservative. Conservative civil society will by nature of its preference ordering be subject to the original conclusions drawn by Przeworski (1991). Specifically, that the regime's coercive power will incentivize society to choose Accept (concessions) and subsequently Enter into a Broadened Dictatorship. 


\subsection{2. 'Discounting' Cooperation}

Further conclusions can be drawn by converting the ordinal preferences of both players into cardinal values in order to see how $b_{c}, x_{c}$, and $s_{c}$ relate to one another. This could be done by keeping the worst outcomes at zero and assigning a value one through four to the other outcomes in order of preference. With actual numerical values we can then compute the value of $r^{*}$ at $1 / 2$ and $r^{* *}$ at $1 / 3$. Now, based on the calculations in the previous section, we can observe that $r$ can never be simultaneously greater than $r^{*}$ and less than $r^{* *}$, even if $x_{c}>b_{c}$. Nevertheless, if we apply a discount to the payoff from $b_{c}, \delta$, we can solve the inequality $r^{*}=\left(x_{c}-\delta b_{c}\right)$, to see under what condition a (discounted) $b_{c}$ might allow for $r^{* *}=<r=<r^{*}$. Solving the equation gives $\delta=<3 / 4$; such that for any values of $\delta$, where $0=<\delta=<3 / 4$, then, $r^{* *}=<1 / 2$. In essence, what this means is that, if the expected utility from BDIC decreases sufficiently in the eyes of civil society, while ceteris paribus conditions hold, then society will be willing to risk repression rather than enter into a broadened dictatorship.

What this scenario represents is a situation in which a broadened dictatorship is not seen as sufficiently different from the status quo. As the utility of BDIC diminishes towards that of SDIC, the repressive capacity necessary to adequately deter society increases. What exactly does the discount parameter mean in this context? Essentially, given the nature of the expanded extensive form game introduced in figure 3.3, society's choice to Accept or Reject concessions stems in part from its knowledge of how the Liberalization game has played out in the past. Consequently, society knows what a broadened dictatorship actually looks like, because it has seen political openings in the past. To the degree that civil society distrusts and therefore devalues the promise of a 
genuine political opening, even if it knows that the regime will never chose to transition (i.e. that the Liberalizer is tough), it will come to see the obdurate opposition as preferable. To put this another way, if the regime has set a precedent of offering political inclusion only to ultimately preserve the status quo - and the status quo should be considered quite distasteful given that protests against the regime were what set the 'game' in motion - then the likelihood of the civil society Rejecting concessions will increase.

\subsubsection{Conclusions: Narrating the 'Emboldened Society Game'}

Combined with Przeworski's conclusions in Democracy and The Market, the above expanded extensive form game shows the theoretical significance of shifting preferences. The key difference between the 1991 game analysis and the game in figure 3.3 is that instead of new equilibria based on "Liberalizers' preferences shifting endogenously as the result of bargaining with the opposition", it is the endogenous shifting of society's preferences that creates new equilibria. The emboldened civil society 'type' is also similar conceptually to Blaydes and Lo's alternative civil society types (i.e. radical and moderate). However, in their game they altered civil society's preferences to reflect a divergence in transitional aspirations - specifically, between theocracy and democracy. They also plugged uncertainty about the type of Liberalizer into the game. The extended game summarized in Propositions 1 and 2 of this paper, on the other hand, keeps Liberalizer type static, while changing the mid-game preference ordering of society. Instead of one game where there is uncertainty about types, I instead separately analyze slightly altered versions of the Przeworski game in order to draw conclusions about the effect of a particular type of regime on a particular type of civil 
society. This is an important distinction, both theoretically and mathematically - since I am not computing equilibria based on any inherent uncertainties. Perfect information still (however unlike reality) abounds.

Nevertheless, the above game theoretic analysis as it stands is quite illuminating in that it shows that perfectly rational actors with full information about the types of agents involved will still make strategic decisions leading to the kinds of revolutions that were observed in the Arab Revolt. Yet, because I am not baking the different society types into a single game, it is now important to turn to what might cause civil society to change from conservative to emboldened in the first place. In this way - as Ialnazov and Nenovsky (2011) and others have done - circumstances outside of the game will be shown to prompt a 'jump' from one game (i.e. the conservative game) to another game in which the payoffs - along with preference orderings - differ (i.e. the emboldened game). Thus, the initial question posed at the start of this paper - why might society mobilize in the face of surefire repression? - can be reformulated as:

Why might society prefer to risk violent repression to continued cooperation with the regime?

This will be the main point of inquiry throughout the following theoretical and case study chapters. 


\section{CHAPTER 4: Threat and Contention - 'Emboldening' Society}

\subsection{Introduction: Filling in the blanks}

The game theoretic model proposed in chapter 3 details how shifts in societal preferences can result in strategic outcomes that are otherwise not possible within Przeworski's (1991) model. The key difference between the two preference orderings posited in chapter 3 - conservative and emboldened - had to do with society reaching a point where it preferred risking either a narrowed dictatorship or insurrection over acquiescing to (historically informed) promises of regime-driven liberalization. In the case of an emboldened civil society, this preference ordering significantly affected the strategic outcomes of mass mobilization. On the other hand, if civil society's preferences remained conservative - i.e. in line with Przeworski's 1991 ordering - then society was more likely to demobilize in return for political concessions. Yet, this model only tells part of the story. There also needs to be a mechanism that explains how preferences might actually shift over time. This chapter - and the case study that follows - argues that the effect of regime flexibility - in both its historical and reactionary expressions - on the political opportunity structure serves to either reinforce societal conservatism or to embolden society against the regime.

The interaction of institutional strategies on structural factors, specifically strategies of political control on the political opportunity structure (POS) contribute to the shift (or reinforcement) of societal preferences vis-à-vis the continuance of the regime (Tilly 2007; Tarrow 1998; Goldstone and Tilly 2001; Beinin, et al. 2011). Strategies deployed by authoritarian states in order to prolong the life of the regime differ crucially 
in their relative degree of political flexibility (Roko 2012; Malesky and Schuler 2011). By their very nature, authoritarian governments are typically inflexible and prone to alienating and driving oppositional preferences underground (Przeworski and Ghandi 2006; Kuran, 1995). Nevertheless, this paper argues that all such governments are not created equal, and some authoritarian states will exhibit more or less rigidity and will be more or less successful at constraining political opportunity. To the extent that a regime offers few institutionalized mechanisms for dissent and can promise little in the way of substantive political reform, its strategies will serve to alienate - or even embolden society. Consequently, the shape and severity of contentious politics in a patrimonial authoritarian system is meaningfully affected by the regime's strategies - especially with regards to whether and how strategies of co-optation and coercion are deployed.

\subsubsection{Contentious Politics: shifting toward the MENA}

According to Charles Tilly contentious politics can be understood to include "all occasions a) on which some set of people make collective, public, visible claims on other people, claims which if realized would affect the objects' interests, and b) in which at least one party to the claims, including third parties, is a government" $(2007,56)$. Contentious politics, therefore, encompasses a wide range of political processes and events, including: "revolutions, rebellions, wars, ethnic conflicts, social movements, genocide, electoral campaigns, most strikes and lockouts, shaming ceremonies, collective seizures of commodities, and many other forms of interaction" (ibid). The game theoretic model in chapter 3, then, defines one such instance of contentious politics: mass protests make a claim on the government and the government responds, which leads to further strategic (and contentious) choices. Two quick definitional points are helpful at 
this point. A government is defined by Tilly as "an [autonomous] organization controlling the principal concentrated means of coercion within some substantial territory" (ibid). While claims are defined as "statements of preference with respect to the behavior of specific other people" (ibid). Thus, the stakes of contentious politics in the form of mass protests are quite substantial, given that society is making "collective, public, [and] visible" claims on a government that controls the principal means of coercion - i.e. the police and military forces. Yet, the state and society - through their interaction and through various endogenous and exogenous processes - both possess the ability to evolve in terms of preferences and capacities relative to each other. Certain changes can prompt society to mobilize while others might do the opposite (Meyer and Minkoff 2004).

Contentious politics as a subfield has at one time or another adopted a number of ontological and epistemological approaches, from methodological individualism described by Tilly (2007) as "the dominant mode within the study of contentious politics" - to "relational analysis": "the least familiar but most promising ontology" (56-7). In relational analysis "changing connections among potential actors modulate social identities, shared definitions of what is possible and desirable, collective costs and benefits of joint action, and mutual commitments; they thereby shape content itself" (57). According to Joel Beinin (2011), this shift in ontological perspective placed a "new emphasis" on interpersonal networks. Actors' perspectives and framings - considered dynamically - along with "spaces" of contention, informed the new relational scope of analysis deployed in the study of contentious politics (6). Briefly summarized, societal networks inform and are informed by state policies and actions, which then affect how opportunities and threats are framed by society. According to Barany and El-Mahdi 
(2012), "Framing creates the necessary resonance to transform individual subjectivity into shared inter-subjectivity, and thereby to transform dispersed, disgruntled individuals into an organized protest movement, with shared objectives and even a shared identity. Civil society is thus redefined" (23). Framing then contributes to whether and which "repertoires of contention" - i.e. modes and methods of expressing contentious claims are deployed in "contentious performances" (ibid). Essentially, the relational analysis of contentious politics adopts a much more constructivist - or event post-modern - approach to the question of how political dissent and claims upon the state evolve and are expressed (Tilly 2007, Roko 2012). The conceptual framework for understanding how contention is framed, repertoires are adopted, and, ultimately, how mobilization against the state occurs, is the Political Opportunity Structure.

\subsection{Political Opportunity and Contentious Politics}

"The political opportunity structure (POS) as "[s]ynthesized in numerous versions", generally refers to "the world outside of the social movement" (Meyer and Minkoff 2004, 1459). Sidney Tarrow defines the POS as "consistent - but not necessarily formal or permanent - dimensions of the political environment that provide incentives for people to undertake collective action by affecting their expectations for success or failure" ([1994] quoted in Meyer and Minkoff 2004, 1459). Two key points are important to consider with respect to conceptualizing the POS. First, “...changes in political opportunity correlate with changes in the volume and tactics of social mobilization" (1463). Consequently, the shape of contentious politics hinges upon changes in the POS over time. Secondly, the POS, especially in the relational perspective, is highly contextual: "[w]hat provokes mobilization for one movement or constituency 
may depress mobilization of another, and be completely irrelevant to a third" (1461).

Political opportunity can be understood in terms of both opportunities and constraints (Roko 2012; Meyer and Minkoff 2004). With regards to the former, certain shifts in the POS can 'encourage' people to engage in contention - such as "increased political access", elite support, "political realignments", and visibly diminished state power (Roko 2012, 27-28). Conversely, other factors can actively discourage social mobilization most notably, state repression (ibid).

According to Korany and El-Mahdi (2012), "The POS model is useful for understanding the evolution of a dispute, as well as its political process, by bringing together the various elements that combine to create the political opportunity for collective dissent" (23). Specifically:

"Thus POS acts like an open door that protesters realize they can pass through or a door they realize they are strong enough to push open. In this, POS plays a double role: It is a process factor that accounts for the chances of a protest's success. Just as importantly, it addresses the nagging problem of agency versus structure and acts like a bridge between the two to emphasize the impact of the protesters' role in influencing the political results of the struggle. The POS model emphasizes the organic interactions between agency and structure" (ibid).

Consequently, the POS functions very much like a "balance sheet of the costs and benefits, constraints and opportunities", which are at stake in considering mobilization (24). However, each of the elements within the balance sheet are highly contingent upon societal framing. Thus, there is an element of "quiet encroachment" where structural and institutional effects mount over time, just as there is also an element of immediacy - i.e. temporally narrow actions and reactions. Additionally, framing affects the object of dissent - are contentious claims addressed to parliament, the regime, the despot, etc.? 
Further, it sets both the tempo and severity of contentious claims - does the mobilization want policy change, or regime change? Framing also helps to determine which repertoires of contention are available and/or preferred as well as whether "benefits, constraints, and opportunities... are acted upon collectively rather than as dispersed groups" (24).

Hess (2013) emphasizes the importance of this last outcome, arguing that it is “not only if regimes are 'high' or 'low' capacity, but also how particular states' structures can impede or facilitate the appearance of national-level protest movements as autocratic regimes interact with popular claimants" (268). His case study analysis of Egypt, Tunisia, and China concludes with the following summary:

"While fragmented outbursts of social unrest transformed into protests coordinated and sustained on the national level in Egypt and Tunisia, protests in China have remained scattered and oriented around local and limited issues and targeted against subnational officials. The divergence on this outcome, that is, on the prevailing mode of protest (national contention in the Arab Spring cases and parochial contention in China), helps explain why the PRC has continued to endure and not faced nationwide protest movements despite the frequency of protest actions overall within its borders" (ibid).

Accordingly, the modes or repertoires of protest are shown to differ - in this case between either nationally or parochially oriented - as the result of institutions, strategies, and state-structures interacting with the POS. According to Tilly, "To ask why a shift from one sort of repertoire to another occurs opens up an inquiry into general relations between contention and social change" $(2007,63)$. Social changes - such as urbanization, the rise of capitalism or communism, and the "diffusion of models for claim-making" can significantly alter the POS and, therefore, the repertoires of contention (ibid). Further, “...we can also examine how the spread of demonstrations affects police practice, 
whether repeated strikes promote changes in wage levels, when concerted demands for democratization actually lead to expanded suffrage" (ibid). Thus, put simply, "[c]ontention and social change clearly influence each other" (ibid).

So, what role does the POS play in setting and shifting societal preferences? Hopefully, the above summary of contentious politics has shown that the POS bears significantly on not just societal preferences but also on how preferences manifest into contentious claims against the state over time. The authoritarian persistence literature touched upon in chapter 2 argued that state capacity and state preferences/strategies were only one part of the revolutionary puzzle of the Arab Revolt. Chapter 3 presented a model that posited how state capacity both informed and was informed by societal preferences and strategies. The POS framework, then, shows how societal preferences are constructed within relational processes that involve institutional and structural factors, which are then subject to societal framing. While there are myriad ways in which structures and institutions might affect the POS and thus shape contentious politics and popular mobilization, the focus here will be on how regime strategies (informed by institutional constraints and incentives) - with regard to the deployment of concessions and coercion - as determined by regime-type, affect how society interprets political opportunities and constraints. The framework, posited by Goldstone and Tilly (2001) of political 'opportunity/threat' provides an instructive semi-formalized model for how regime preferences bear directly upon societal preferences.

\subsection{Threat and Opportunity under Authoritarianism}

According to Goldstone and Tilly (2001), "The usual story of political 
opportunity goes basically in one direction - from opportunity to action" (180).

Essentially, in the usual contentious politics conceptualization, "As opportunity expands, actions mount; as opportunities contract, action recedes" (ibid). Within such a framework, "threat" and opportunity are viewed as diametrically opposed, as a negative force and a positive force, respectively (181). For Goldstone and Tilly, this is a "mistake", and threat ought to be more accurately conceived of as "an independent factor whose dynamics greatly influence how popular groups and the state act in a variety of conflict situations" (ibid). Understood in these terms, a formulation that hinges authoritarian persistence on "the state's capacity to maintain a monopoly on the means of coercion" and therefore its ability to "...face down popular disaffection and survive significant illegitimacy, 'value incoherence,' and even a pervasive sense of relative deprivation among its subjects", becomes a much more fraught argument to make (Bellin $2004,143)$. The reason for this is that repression can, in certain circumstances, be as much of a reason (opportunity) to protest as, under other circumstances, it might be an impediment. Put another way, society may only be willing to live under a certain amount of current threat - i.e. the day-to-day costs and benefits of living under the regime relative to the concessionary gains it receives from the state and relative to the looming threat of repression.

Unpacking the concept of 'threat', "the state can increase prospective or current harm" by increasing "taxes, increasing violence [...], taking away rights or property" or it can decrease "current or prospective" harm by making political or material concessions or by preferring concessions over repression when confronted with protests. Further, the types and severity of concessions and repression are also integral to how society will 
react to and perceive threats. Hence, while the state "has substantial control over both kinds of threat", societal framing is essential to the processes by which threats are interpreted and then acted upon (185). Brutal repression can either cow civil society (e.g. China and the 1989 Tiananmen Square protests) or it can enrage society, spurring rapid mobilization (e.g. Tunisia in January of 2011) (Hess, 2013). The difference between these two cases has to do with both the severity of the states' repression as well as the nature and perspectives of society. Moreover, concession can also be a double-edged sword:

"...modest concessions can lead to increased demands for further change, either because of the de Tocqueville effect - minor changes made by the regime are an advertisement of its illegitimacy, but do not fully correct that illegitimacy, and thus lead to greater demands for elimination or transformation of the regime - or because the concessions attract other supports who now feel that they too can extract more from the regime" (Goldstone and Tilly 2001, 188-9).

This analysis largely conforms to the basic assumptions underlying Przeworski's

Liberalization Game: concessions might lead to civil society Organization or they might serve the regime's ends by broadening the liberalizers' base of support. The crucial difference, however, is that Przeworski's model does not strategically take into consideration the galvanizing effects of coercive threat - i.e. how society might become emboldened by state repression and limited opportunities for the venting of dissent. It considers threat as an obstacle, not as an opportunity.

\subsection{Modeling Threat (opportunity)}

Goldstone and Tilly begin their analysis by laying out a "simple formula" for determining expected gains $(\mathrm{G})$ from popular protests against a given regime as equal to "the gains that would result from success (V), (which may be new advantages obtained or 
current or perspective harms avoided) times the probability of success, or 'opportunity' $(\mathrm{O})$, minus the cost incurred from protest $(\mathrm{C})$, which includes time and resources expended, and the [expected] repression incurred..." (184). Written out the formula becomes,

$$
G=(V x O)-C
$$

where "we expect protest actions to occur if the expected results are a net gain" (ibid). Opportunity in this context represents an index of several variables related to the relative strength of the state and that of society, respectively. Further, Tilly and Goldstone along with others (notably: Pzresworski \& Ghandi 2006) - recognized that " $[\mathrm{t}]$ he value of achieving success depends on whether things might be gained by action, but this includes both new advantages (A) and avoiding harms that are currently experienced or anticipated; such harms under the existing regime are one kind of 'threat' which we may label 'current threat', $\left(\mathrm{T}_{\mathrm{c}}\right)(184-185)$. Another type of threat they label as "repressive threat", $\left(\mathrm{T}_{\mathrm{r}}\right)$, which amounts to the deployment of a state's coercive apparatus in order to quell mobilized dissent. The state is able to adopt various strategies that allow it to control how much and which type of threat (or combination of threats) they will tend to utilize. This includes "increas[ing] prospective or current harm by increasing taxes, increasing violence against the population or specific groups, taking away rights or property, or other such actions... the state can also decrease current or prospective harm by making concessions, that is changing its policies to improve conditions for poplar and/or elite groups" (185). Additionally, the state can also "choose to respond to protest 
action with varying levels of repression" (185).

By relying upon a particular mix of concessions and repression, a given regime can "manipulate both the value of success, and the costs imposed by various threats" (ibid). This essentially alters the expected gains formula and hence Goldstone and Tilly offer an expanded formula that takes the above variables into consideration:

$$
\begin{gathered}
G=[O x(A+T c)]-\operatorname{Tr} \\
\text { "where } O=k 1 \text { (state weakness) }+k 2 \text { (popular support) } \\
+k 3 \text { (strength of nonstate allies and opponents)" (ibid) }
\end{gathered}
$$

The above formula is quite useful in making sense of how political opportunity and regime threats/concessions figure into the calculus of popular mobilizations. Goldstone and Tilly then illustrate how this formula might apply in practice by providing the following graph:

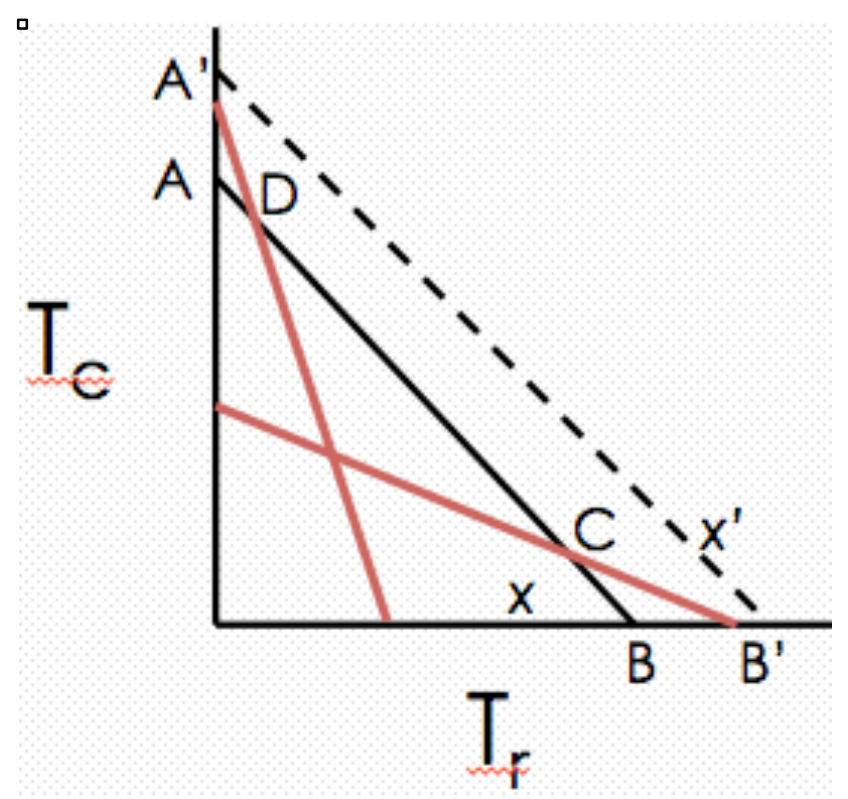

[Figure 4.1: Tilly and Goldstone $(2001,187)]$ 
In this figure, the y-axis, $T_{c}$ represents concessions or rather what concessions are functionally equivalent to, a reduction in $\mathrm{T}_{\mathrm{c}}$. The $x$-axis represents state repression, $\mathrm{T}_{\mathrm{r}}$, as defined above. Accordingly, line $A B$ represents the "sufficient combined actions" necessary in order to deter or quell popular protest against the regime. Any mixture of concessions/repression that falls to the left of $A B$ will therefore be insufficient toward this end, and conducive to spurring continued protest actions. What becomes particularly interesting about this framework is that it shows how important information discrepancies between what the regime believes $A B$ to be and what it actually might be-once the resolve and strength of the opposition is actually made known through protest actions. This means that, according to Tilly and Goldstone, the regime is likely to underestimate $A B$ and choose some mixture of concessions and repression, $x$, that not only fails to deter further protest actions but actually stokes the flames of protest (188-90). What this means in terms of figure 4.1 is that the area of insufficient action under line $A B$ is actually expanded, as delineated by a new line $A^{\prime} B^{\prime}$, representing a net increase in the concessionary and repressive actions necessary to 'put the fire out' (ibid).

Two important conclusions can be drawn from the above analysis and description of events. The first is that information gaps and imbalances can have drastic consequences for a state when it comes to initially reacting to widespread mobilization activities. The regime knows what its strategy line $(l)$ is - that is, it knows the limits on what concessions it is willing to make and how much repression it is willing to deploy. What it does not know is where line $A B$ is, and what strategy $x$ might cause $A B$ to shift to the right of its constant costs line. Thus, regime strategies that inform the state about where $A B$ might be - such as elections, police intelligence, polling, and a high level of $T_{c}$ 
(Malesky and Schuler 2011) - are of vital importance during contentious political mobilizations. Secondly, where $A B$ is 'positioned' by societal actors, is significantly influenced by what Goldstone and Tilly refer to as "the intermingling of framing and opportunity" $(2001,185)$. What this means is that the position of $A B$ is largely a function of societal perceptions of the indexed variable $O$ as well as about the values of $T c$ and $A$. Hence, framing - or how perceptions about the socio-political environment are constructed and perceived - and opportunities - particular institutional and environmental constraints - feed back into each other when fixing the position of $A B$. Finally, when the regime employs repression and 'misses the mark' of line $\mathrm{AB}$, and, as a consequence, the new line, $\mathrm{A}^{\prime} \mathrm{B}^{\prime}$ is formed will only occur when $r^{*}>r>r^{* *}$, as described in chapter 3 .

\subsection{Threat and Societal Preferences}

Regime type may in fact bear considerably on the information gathering abilities of the state (see: Malesky and Schuler 2011), however, as noted in chapter 3, the success of repression cannot be completely known ahead of time. The impact of information gaps, then, is that they increase the risk of under- or overreaction. While the research question of whether and how regime-types might differ in their propensity for under/over-reaction appears quite interesting, it will not be focused upon in this paper. However, the second conclusion - concerning where line $A B$ is initially positioned (as well as where it $A^{\prime} B^{\prime}$ might be (re)positioned) - directly relates to the game theoretic analysis in chapter 3 . The value of $T_{c}$ at any particular point in time is set both by the strategies and institutions of the regime and by the perceptions of same by society. This effectively equates to the value society places on the continuance of the regime, and it is weighted relative to $T_{r}$. Depending on the other elements of the POS - i.e. the variables 
$O$ and $A$ - society is then able to compute the estimated gains of protest $(G)$ as well as to determine the point $(A B)$ at which their contentious claims will have been met (or deterred). The relationship between $T_{c}$ and $T_{r}$ is, in effect, what serves to embolden society. The current threat of the regime informs whether or not protests will occur initially, while the regime's strategic mix of coercion and concessions (changes in $T_{c}$ and $\mathrm{T}_{\mathrm{r}}$ ) are what determine the tempo and continuance of social mobilization once it has begun.

Thus, the initial (and expected) values of $T_{c} / T_{r}$ - i.e. the general strategy of reform, concessions, and repression employed by the regime are both immediately informed by current conditions and reactions, and historically informed vis-à-vis past episodes of liberalization and repression. Based on Goldstone and Tilly's formula above, then, if $T_{c}$ is significantly larger than $T_{r}$ (or $O$ and/or $A$ are sufficiently larger, or all three are) we can consider society emboldened. Further, once protests begin, the regime can opt to steer society towards the status quo (by offering material concessions), to broaden the dictatorship (by offering finite political concessions), or risk the uncertainty of repression. Society's willingness to accept the former two options and/or its susceptibility to being cowed by the third option is related to the initial placement of line $A B$ - which, in turn, is set by the initial value of $G$. Thus, the cycle of protest can be said to be set into motion by the POS as influenced by the presence of different aspects of threat. Yet, the POSthreat calculation is, in actuality, a historically informed, and dynamically constructed process. Therefore, the strategic calculations of Society - first to mobilize and then to either accelerate mobilization or to demobilize - are always in reference to both historical and immediate threat assessments. 


\subsubsection{The Effect of Regime-Type on Strategic Preferences}

What about the different 'strategic mixes' of the regimes? Two very general strategies can be extrapolated from Goldstone and Tilly's analysis: (a) concessions are 'preferred' to repression; or (b) repression is 'preferred' to concessions (189). One such explanation conforms to Blaydes and Lo's (2012) and Przeworski's (1991) analyses discussed above: that when repressive capacity is low, political liberalization will not be observed. While not explicitly stated in these analyses, the lack of political concessions does not preclude the existence of other types of concessions. In Saudi Arabia, for instance, the regime responded to protests by offering material concessions in the form of rent distribution (Lynch 2012). Blaydes (2011) cites another argument for preferring concessions: “...political opposition is coopted through its participation in policyinfluential legislatures by way of electoral competition. [...] when the opposition is strong, dictators make more extensive policy compromises to keep the opposition from rebelling" (15). Thus, authoritarian regimes with functioning parliaments are more likely to prefer concessions - either political or via rent distribution (also see: Przeworski and Gandhi 2006). However, Blaydes objects to this thesis in the case of highly patrimonial regimes: “...parliaments and the elections that bring them to power, in cases like Egypt, exist to serve some other purpose than cooptation via a shared policy space" $(2011,16)$. Her conclusions rest upon the fact that patrimonial legislatures tend to have very little policy-making power. Consequently, if any policy concessions are implemented, it is usually at the behest of the dictator.

However, looking back at Przeworski's (1991) account, there is still something to be said about the initial impulse to 'Open' the regime. Inherent in the initial decision is a 
cost-benefit analysis informed by external (Brownlee 2011; Yilmaz 2010) and internal (Blaydes 2011, Posusney and Angrist 2005) considerations. One such consideration has to do with the sources of legitimacy within the authoritarian system (Lucas 2004, Albrecht and Wegner 2008). If the regime's legitimacy rests on its control over state institutions - primarily the legislature - there will be less room for pluralism and thus substantive political reform (Albrecht and Wegner 2008). Accordingly, writing in 1999 Angrist described political parties in Tunisia, as "weak and insignificant" organizations that "do not loom as credible alternatives to the [Neo-Destour]... They are stricken with intra-leadership rivalries and conflicts... [lack] clear policy programs nor..." the ability to campaign effectively (Angrist, 1999a: 753). Further, "the ND uses its power monopoly to keep these parties weak" (753). Contrastingly, in Morocco, "ruling elites [can] open channels of communication with existing opposition forces in order to offer reforms that [meet] some of the demands of... protestors, as mediated by... established political actors" (Volpi, 2012: 984). Accordingly, with regards to political/economic crises and mass popular dissent:

"Explanations of institutionalized authoritarianism retain more of their relevance... [because] the possibility of a gradual reform of the regime is perceived to exist, domestically and internationally. In those contexts, because alternative means of practicing and institutionalizing new forms of political governance are already being considered and routinized to some degree, processes of regime change are articulated in more structured and predictable patterns - that is, reform of institutions" (983, emphasis added).

Therefore, Controlled but real multipartyism, the hands-off approach of (constitutional) monarchal rule, and a strategy of cooptation that has allowed for broader inclusion especially of moderate Islamist parties/candidates - each contribute to a regime strategic preference for concessions in Morocco relative to hegemonic systems such as Egypt - at 
least during the decade or so leading up to the Arab Spring (Vairel 2011). It follows then, that, "the possibility of a sudden and dramatic failure of a regime is best understood in terms of a lack of opportunity for an institutionalized (or partially institutionalized) process of political change" (Volpi 2012, 983).

Additionally, such regimes more forcibly push citizens out of the political sphere, where they are made to adapt and find new modes of articulating and aggregating dissent. Citizens are then more likely to cross the established oppositional norms of the regime and therefore to be subject to the state coercive apparatus (Kuran 1995; Angrist 2013; Vairel 2011; Beinin and Vairel 2011). Such alienation can serve to shift oppositional preferences toward insurrection and regime change (Angrist 2013). Within the subset of MENA authoritarian regimes that have multi-party elections, lack significant resource rents, and have a history of coercive state oppression (Jordan, Morocco, Egypt, Tunisia) the primary differentiating factor - leading to regime-threatening popular mobilization was the societal perception (or lack thereof) that the regime was flexible. The pluralistic institutions of constitutional monarchies (Morocco) created a political environment wherein the "possibility of a gradual reform of the regime is perceived to exist, domestically and internationally... and alternative means of practicing and institutionalizing new forms of political governance are already being considered and routinized to some degree, processes of regime change are articulated in more structured and predictable patterns - that is, reform of institutions" (Volpi, 2012, 983; emphasis added). 
Accordingly, cooptation in such regimes is less alienating than in patrimonial personalistic regimes where there are few channels for state-sanctioned political dissent outside of the leader's party. This, then, results in a higher reliance upon the state coercive apparatus and, consequently, the increased chance that society becomes emboldened. If elections in authoritarian regimes serve in part as 'pressure valves' allowing for the state-sanctioned articulation of (some) dissent, then elections in patrimonial regimes - where the leader's party wins by dominating margins (around 80$90 \%)$ - are much less effective in this regard than in more pluralistic regimes; and therefore force more of the opposition to seek out alternative modes for dissent. Angrist (2013) posits that "[i]n order for a popular movement to oust an incumbent regime, an interaction between two phenomena must unfold" (549). The first is that "masses of citizens from socioeconomic classes and political divisions must sustain physical protests across most of a state's territory for a significant period of time" (ibid). The second phenomenon "that must unfold for a revolution to success is that, in the face of broad and sustained mass civic protest, the architecture of the authoritarian regime must fail to counter, respond, and repress" (550). This paper purports to explain how these two phenomena intersected (or failed to) by synthesizing elements of transitional institutionalism with a constructivist approach centered on societal preferences and framings vis-à-vis perceived regime threat. Accordingly, we hypothesize one final proposition to synthesize the institutional-strategic model presented in chapter 3 with the institutional-contentious politics model presented above:

Proposition 4 (threat and society): Regime strategies of co-optation and coercion affect the interrelated variables of current threat $(\mathrm{Tc})$ and repressive threat $(\mathrm{Tr})-$ both over time and during episodes of contention. Flexible authoritarian regimes 
are those in which co-optation/concessions are deemed "cheaper" than coercion; while rigid or inflexible regimes are those in which the opposite is true. Flexible regimes will be conducive to the social construction of conservative contentious framings; while inflexible regimes will be conducive to the development of emboldened contentious framings.

\subsection{Contentious Politics in the MENA - toward a unified model}

The application of social movement theory (SMT) and the contentious politics paradigm to Middle East and North African studies has gained considerable steam following the Arab Uprisings. Such analyses give lie to the notion that the MENA has somehow been immune to the trends of social mobilization that have been so integral to democratization in the Global North. Sidney Tarrow and Charles Tilly (2009) outright reject the claim that social movements are a "'northern' phenomenon" (12). While "movements emerged out of the atmosphere favorable for campaigning, associating, and public presentation of liberalizing Western states and themselves advanced their democratization [...] once invented... the movement form itself became modular and diffused around the world" (ibid). Joel Beinin and Frederic Vairel (2011) argue that "the Middle East and North Africa is a complex and fascinating laboratory not only to confirm the applicability of SMT but also to enrich our theoretical knowledge of social movements and other forms of political contestation" (2). Their edited volume applies the SMT and contentious frameworks to the study of "collective action under authoritarianism", human rights campaigns, "Islamic Social Movements", and "labor struggles" among other themes. They conclude by framing political contention in the MENA in terms of "[c] ontextually conditioned rationality", a lens through which the development of informal networks can be understood as arising out of a specific socio- 
structural milieu, comprised of a "combination of poverty, states with limited capacity to provide essential services, and authoritarianism" (ibid).

Holger Albrect (2013) applied the contentious politics framework to the specific context of Egyptian political opposition under Hosni Mubarak. Albrect's focus is on the "schizophrenic personality" of the Egyptian opposition: on the on hand, it is in direct contention with the regime while political pluralism simultaneously serves to bolster the authoritarian system (xxiii). The same could easily be said for Tunisia, but applied to a much more closed system (Angrist 2013). In Bahrany and El-Mahdi's edited volume (2012) they argue for contentious politics as "a useful approach for decoding the Arab Spring" (24). Both Albrect and Bahrany and El-Mahdi argue that elite-focused analyses in the vein of democratic transitology drastically overemphasize the role of such actors and forces. Johan Roko (2012), through interviews conducted with activists in Tunisia and Morocco in the wake of the Arab Spring, concluded that a "a social constructivist approach to identify how structural, long-term socio-economic and political changes could help spur collective action" is needed in order to account for the events of 2010-11 (115). Taken as a whole, these works on political contention in the MENA address a number of misconceptions regarding political and social change in the region. The most important of which has to do with refuting the notion, along with deemphasizing elitefocused accounts, that "current mobilization was abrupt and completely unexpected... [implying] a previous state of dormancy" (ibid). To this end, these studies serve to elucidate the "multiplicity of elements that underlie such milestone events" as the Arab Spring (Bahrany and El-Mahdi 2012, 24). While elites and institutions surely played a 
roll, the Arab Spring cannot be 'decoded' without confronting the long-term impact of underlying relational, contentious networks within society (Kuran 1995, Lust 2011).

Because of the relatively nascent state of contentious politics scholarship in the Middle East and North Africa, there are myriad avenues of further research to be done. The common trend throughout the above-cited literature has been to steer away from the institutional and elite-level assumptions of democratization theory and the persistent authoritarian literature detailed in chapter two. By adopting a constructivist ontology as many of these studies have, they are perhaps too eager to throw out the methodological tools that comparative democratization and authoritarian studies have employed over the years. As Beinin and Vairel (2011) have emphasized, the contentious processes of societal actors in the MENA can "be understood in rational terms" (24). This implies that they can also be understood in rational-strategic terms, in line with analyses of elitelevel actors. Consequently, there ought to be room for bringing strategic-rational models of elite preferences and actions to bear upon those of societal actors when both are intertwined in contentious politics. The following case studies of Tunisia and Morocco aim to illustrate how the contentious politics paradigm can be applied to a game theoretic model of elite and societal strategies and preferences. The flexibility of the regime -i.e. regime's preference for concessions over coercion - informs Society's perception of the current threat relative to the threat of repression. This perception, then, informs Society's preferences vis-à-vis risking continued cooperation and risking reprisals for contentious opposition. *** 


\section{PART THREE: Narrating Contentious Changes in the MENA}

\section{CHAPTER 5: Case Study Typology and Hypotheses}

\subsection{Regime types in the MENA}

Regimes throughout the Middle East and North Africa most typically exhibit characteristics of neo-patrimonalism, "in which the leader treats the state as his private fiefdom and gives only rhetorical attention to formal political institutions" (Brownlee 2002, 37). Albrecht \& Schlumberger (2004) point out that "(neo) patrimonialism, in which political power rests primarily on co-optation..." is the "specific type of nondemocratic rule still dominating in the Arab world" (372). Elections under patrimonialism are dominated by patronage concerns: "in authoritarian elections, the distribution of state resources trumps by far any role of elections as arenas for contests over the executive or critical policies. Parliament is, rather, a basis from which one can call upon ministers and bureaucrats to allocate jobs to constituents" (Lust-Okar 2006, 459). As a result, political institutions in such regimes are primarily devoted to maintaining sophisticated networks of clientelism. Piattoni (2001) provides a theoretical and conceptual framework for considering the functionings of clientelism. Instead of viewing clientelism in terms of power dynamics, Piattoni looks at the patron-client relationship from an economic perspective. More specifically, Piattoni uses a supply and demand framework wherein both patron and client need something to from each other. This can be called an economistic view. Her assumption is thus "clientelism and patronage are strategies for the acquisition, maintenance, and aggrandizement of political 
power, on the part of the patrons, and strategies for the protection and promotion of their interests, on the part of the clients, and their deployment is driven by given sets of incentives and disincentives" (2). It follows then, that the specific nature and functionings of patrimonial systems can manifest in a diversity of state-institution-society relationship-types. In both Egypt and Tunisia, for instance, “[c]lientelistic networks were often twinned with more overt political control of associations", whereas in Morocco and Jordan, "they thrived as informal bonds between the regime and organizations that were seemingly autonomous" (Roko 2011, 18). Clearly, then, a more finely-tuned typology is needed in this analysis in order better establish the diverging contours at stake.

In a related - but slightly different typology - Larry Diamond (2002) characterized most MENA regimes - including Tunisia and Morocco - as "Hegemonic Electoral Authoritarian" regimes. Such regimes are found "where elections are largely an authoritarian façade, the ruling or dominant party wins almost all the seats... repeatedly over 95 percent in Singapore, about 80 percent in Egypt in 2000 and Mauritania in 2001, 89 percent in Tanzania in 2000, and repeatedly over 80 percent in Tunisia during the 1990s" (ibid, 29-32). Accordingly, "[In Hegemonic regimes] elections and other 'democratic' institutions are largely façades, yet they may provide some space for political opposition, independent media, and social organizations that do not seriously criticize or challenge the regime" (2002: 26). Yet this characterization - and those similar to it (Schedler, 2004) seem to also be missing some crucial nuance, given that Morocco and Jordan are both also included within the hegemonic authoritarianism regime type, yet seem to function quite differently from Egypt and Tunisia - both in 
terms of institutions and electoral pluralism (see: chapters $6 \& 7$ ).

Consequently, another concept, paternalism, is necessary in order to further distinguish among MENA regime types. According to Jason Brownlee - with reference to Robert Snyder's (1992) conceptualization - the "neopaternalistic" or "personalistic regime" is one wherein "a legal-rational order is subordinated to the whims of a central leading figure who rules arbitrarily" (2002: 47). This characteristic turns out to quite clearly distinguish between states such as Tunisia, Algeria and Egypt (as paternalistic regimes), on the one hand, and Morocco and Jordan, on the other. While both sets of regimes were largely supported by networks of patron-client relationships, the Tunisian regime was primarily reliant on funneling all such networks through the dominant party apparatus within parliament. Contrarily, in Morocco, clientele networks are distributed through a pluralistic array of political parties and informal relationships, all of which are reliant upon parliament as the primarily distributive vector, and therefore the king - as the ultimate arbiter - for the state access he can provide (Lust-Okar, 2006; Lucas 2004; Anderson 1987).

Hence, it appears that the degree of contestation might adequately serve as a criterion for typing the regimes under consideration. Accordingly, Lisa Blaydes (2011) categorizes MENA regimes in four groupings that run roughly parallel to the above analysis: "Hegemonic party regimes with competitive elections" (e.g. Egypt 2010, Algeria, Yemen 2010); "Monarchies with high levels of electoral contestation" (Jordan, Oman, Kuwait, Morocco); "Single-party regimes with limited contestation" (Tunisia 
2010, Iraq 2002, Syria 2010); and "Monarchies with limited electoral contestation" (e.g. Saudi Arabia, UAE, Bahrain) (210-31). This appears to be a useful typology that emphasizes the role of electoral competition (Angrist, 1999a; 1999b; 2007). The distinction between hegemonic and single-party states lies primarily on the qualitative differences in electoral contestation - with single-party states providing "only limited opportunities for competitive engagement" (Blaydes 2011, 224). Therefore, both Syria and Iraq fall under this classification because competition is primarily used to allocate state goods to particular ethnic or religious cleavages linked to the regime $(2011,210-31)$. Tunisia, by contrast, employs a similar - though reduced - strategy to Egypt's of increasingly inviting political groups and elites to compete over patronage goods irrespective of any "natural bonds". Further, both states have used political exclusion, especially with respect to religious parties, as a means by which to punish and ostracize opposition that gains too much support or adopts too extreme a platform (Albrecht \& Wegner 2006; Angrist 1999b; Anderson 1997).

In this context, the first Tunisian constitution, which was ratified in 1959, "created a tremendously strong president and executive branch and a weak, peripheral parliament" (Angrist 1999a: 751-2). The electoral process was merely nominal in that "[m]ajoritarian electoral rules ensured that parliamentary seats were monopolized by the ND [Neo Destour Party of Bourguiba]", which created an "(im)balance of power between the parliament and the executive branch" that "remained unchanged" until the Jasmine Revolution in 2010-11 (752). Similarly, in Egypt, the primary consequence of interregime competition in lieu of competition within parliament was that the state was 
incentivized to seek out and minimize "potential dissent from political forces... independent from direct state control" (Albrect \& Wegner, 2006: 129-130). This manifested in a constant balancing act wherein civil society actors were brought into or banished from the political arena, balanced against each other, and even co-opted as tools of the regime. Civil society actors in Tunisia - such as trade unions - who desired inclusion and thus access to rents were forced into the clientelistic system emanating from parliament (Angrist 2013).

Jordan and Morocco, on the other hand, "delimit their domains while maintaining ambiguity and pluralism among their subjects" (Lucas 2004, 107). This divides the MENA monarchies, generally, and Jordan and Morocco, specifically, from the personalistic, single-party dominant states in the region. According to Lucas, "one can clearly categorize Middle Eastern monarchies as a subtype of authoritarianism based on their political pluralism, limited political mobilization, predictable limits on the power of rules, and regime mentalities" (ibid). It is important to note, however, that Jordan and Morocco are also distinct from other monarchical regimes, particularly the Gulf monarchies: Kuwait, Qatar, UAE, and Saudi Arabia (Lucas 2004; Herb 1999; Kostiner 2002). Michael Herb (in Lucas 2004) identifies two subtypes of regional monarchal regimes: "dynastic monarchies" and "linchpin" monarchies. In the former state, "members of the ruling families monopolize the highest state offices, including the premiership and the portfolios of Interior, Foreign Affairs, and Defense, the ministries known in the Gulf as the wizarat al-siyada, or ministries of sovereignty" (Herb 1999, 8). In the latter regime type, the monarch "stands above and way from routine politics to a 
greater degree than the dynastic monarch," while also encouraging "social pluralism and mobiliz[ing] it along vertical lines to participate in the governing of the state, underneath the leadership of the monarchy" (Lucas 2004, 108). Accordingly, per Lucas, "Jordan and Morocco serve as prime examples of the linchpin variant of monarchical authoritarianism" (ibid).

Thus, the key difference between dynastic states and linchpin states has to do, generally speaking, with the degree to which the regime is able/ compelled to embrace political pluralism. The strategy of dynastic monarchies - a type that also (noncoincidently) overlaps with the classic "reinter state" (see: Ross 2001) - dictates that patronage networks are maintained primarily through the family apparatus (Blaydes and Lo 2012). In these regimes, "the families have developed robust mechanisms for the distribution of power among their members, particularly during successions, and exercise a thus far unshakable hegemony over their states" (Herb 1999, 8). Jordan and Morocco, conversely, rely upon a strategy of "divide and rule" (Lucas 2004, 115). Within this type of monarchy, "[m]ultiple and pluralistic groups... find it difficult to organize and unify their interests against the monarchy. Groups generally direct competition against their lateral partners" (ibid). The monarch's role then becomes picking "his policy-making partners from the ruling coalition" (115). Consequently, political actors are forced to compete against their peers while simultaneously becoming reliant upon the monarch-asgrand-arbiter. Moreover, the monarch is able to derive a great deal of legitimacy from his position 'above the political fray' - assuming a more fatherly image vis-à-vis society (Albrecht and Wegner 2006, 129; Lucas 2004; Herb 1999). 
The unique position - both strategically and from a legitimacy standpoint - of the linchpin monarch also has major implications in comparison to what Albrecht and Wegner (2006) call "hegemonic parliamentary rule" in Egypt (and Tunisia) ${ }^{2}$ - as opposed to "competitive parliamentary rule" (128). In "Morocco the parliament constitutes the arena for political competition, whereas in Egypt [and Tunisia] this is not the case" (129). Crucially, this is indicative of where the centers of legitimacy lie in each state. For Egypt, "the president needs the parliament to create legitimacy whereas the political elites are individually co-opted via the ruling National Democratic Party (NDP) (ibid). This means that, similarly to Tunisia, the Egyptian president cannot tolerate much "dissent and contention within parliament", given that legitimacy depends on the "hegemony of the president's party in parliament" (ibid; Angrist 1999a). This is demonstrably different for the Moroccan king, where the monarchy is ostensibly impartial to - but yet superordinate over - parliamentary contestation and competition (ibid). With regards to the hypotheses of this paper, this means that in Morocco, "there is a sphere for articulation and political contest, namely parliament and elections", that was essentially absent in Tunisia (ibid).

A key difference between Egypt and Tunisia - and indeed both Morocco and Jordan - lies in the degree to which elections figure into the overall clientelist scheme. Between 2000 and 2010 voter turnout in Tunisia (for both presidential and parliamentary elections), and Morocco and Jordan (for parliamentary elections) ranged between 37\%

2 Albrecht and Wegner (2006) focus their analysis on Morocco and Egypt, but as will be shown in chapter 6 - their analysis of Egypt very easily maps onto the Tunisian case. 
and 91\%. Contrastingly, in Egypt the turnout for both presidential and parliamentary elections did not surpass 25\%. As Jason Brownlee (2011) points out, in “the Arab world's most populous state, a country that exemplifies electoral authoritarianism, more than $90 \%$ of the population is not bribed, coerced, or even artificially reported into lodging votes for the ruling party and its standard bearers" (821). This raises some important questions about the importance of elections in clientelist regimes:

"To what extent are calculations about regime survival, clientelism, and state dominance at work in an exercise that involves so few of a country's citizens? What explains the extraordinary amount of electoral absenteeism in Egypt? Last, if elections are not a salient arena of contentious politics, through which alternative institutions and processes does the regime co-opt its critics, disperse rents, and act like a state?" (ibid)

By way of response, Lisa Blaydes provides some possible explanations including, "widespread cynicism about the efficacy of political participation, lack of confidence in the fairness of the procedures, and the weakness of party platforms" (116). Nevertheless, she adds, "considering the low policy stakes involved with these elections, the fact that one-quarter of registered voters do turn out is a nontrivial phenomenon" (ibid). This is supported by her finding that "whereas some voters cast their ballots on an ideological basis, the majority of Egyptian voters expect to receive a direct material benefit for their vote" (ibid, 164). This is further exemplified by recognizing the frequent, "vigorous" competition between NPD candidates and between opposition and NDP candidates both in terms of rhetoric and expense - that has taken place since 1990 (22). Consequently, while voter turnout is quite low, a sizable absolute number of Egyptians do participate in elections primarily as means by which to reap rewards from the 
patrimonial system. In this way, the significance of the Egyptian electoral system as a focal point for clientelism cannot be discounted.

In attempting to work out why some patrimonial MENA regimes fell to popular mobilizations while others were able to 'weather the storm' the above analysis points to an important dichotomy. The distinction between the countries under consideration remains with the hegemonic/competitive spectrum within parliaments in authoritarian systems, as derived from Albrecht and Wegner (2004) and Blaydes (2011). Both linchpin monarchies and patrimonial, personalistic regimes rely on patronage networks in some way as a (key) source of legitimacy and co-optation. However, the degree to which contestation exists, both institutionally and qualitatively, along with the responsiveness of the regime to popular and elite demands, represents a fundamental divide between these two regime types. Both regime types employ the electoral and intra-parliamentary strategies that best protect and consolidate their respective sources of legitimacy and political control (Jamal \& Lust-Okar 2002). The difference is that, for the linchpin monarchies, the strategies that reinforce legitimacy are also quite effective at moderating, controlling, and occasionally appeasing, opposition and dissent (ibid). Furthermore, dissent and dissatisfaction are often then directed at parliament and not explicitly directed toward the monarchy (Susser 2000; Leveau 2000; Lucas 2004). For the personalistic regimes, strategies of managed liberalization, democratization, and pluralism are more likely to create 'winners and losers' and to have dissent pointed directly at the regime i.e. the president (Albrecht 2013). Thus, a key distinction between the two regimestrategy-types has to do with their respective effects on the shape and nature of 
institutionalized mechanisms of dissent.

\subsection{Case Selection}

The above typology suggests a continuum dictated by increasing levels of contestation within parliament, which is, in turn, informed by the ability of leaders to utilize coercion and locate sources of legitimacy outside of parliamentary institutions (Volpi 2012). Roughly, utilizing Volpi (2012) and Blaydes (2011), a generalized continuum of North African regimes prior to the Arab Spring might be as follows (from low contention to high contention):

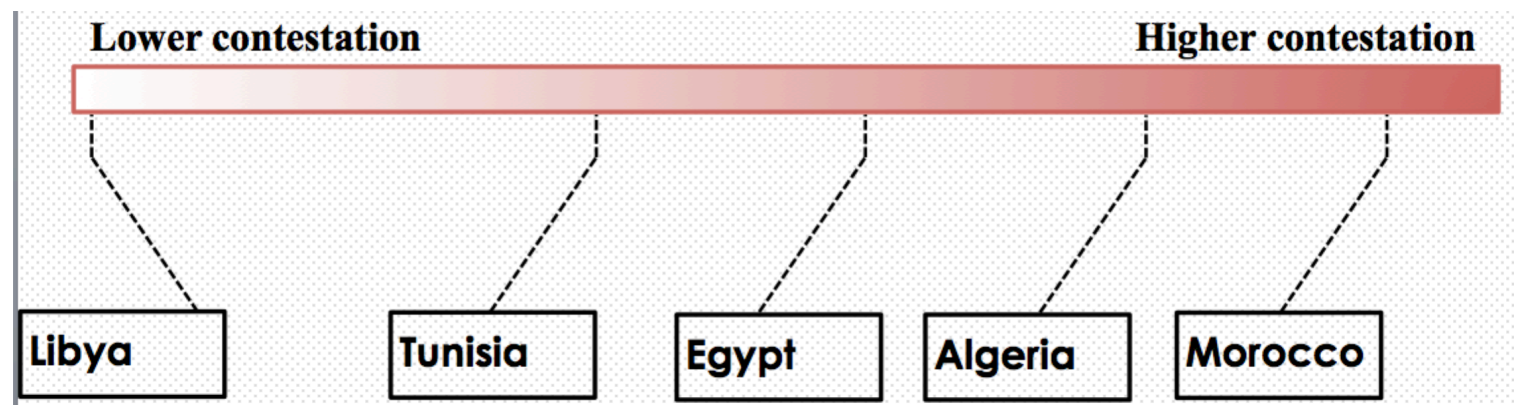

[Figure 5.1; Degrees of Contention: From low contention to high; Derived from Volpi (2012) and Blaydes (2011)]

Hence, for the purposes of this paper - and taking into mind the limited space available we will select two of the cases that appear to be the most fruitful toward analyzing the suitability of the models presented in chapters three and four: Morocco and Tunisia. Some states fall outside of the present analysis. The Gulf Monarchies were largely able to weather the Arab Spring by leveraging their immense oil wealth (Lynch 2012). 
Bahrain was able to exploit pre-existing religious divisions within society while also being 'saved' by Saudi Arabian military intervention (ibid). In North Africa, Libya's regime permitted no real political contestation and was perhaps the closest the MENA region had to a totalitarian state, ruled by Qadhafi's strong cult of personality (ibid, Volpi 2012). Thus, it would appear that the most promising case studies - in terms of analyzing contentious politics under varying levels of political contestation and regime threat would include Egypt, Tunisia, and Morocco. In order to draw the most concrete and useful conclusions, a most similar systems design (MSSD) makes the best intuitive sense. MSSD, as outlined by Adam Przeworski and Henry Teune (1970), focuses on intersystemic "similarities and differences" among multiple cases, controlling for similarities and thereby isolating differences as explanatory variables.

As such, it would seem that Morocco and Tunisia afford the opportunity to 'isolate' more variables than with the inclusion of Egypt. Morocco and Tunisia will therefore be used as case studies in the following two chapters. Both states have been shown to be apt subjects for MSSD comparisons in numerous studies - Charrad (2003) and Anderson (1986) being the most notable (see also: Volpi 2012). These two states share numerous "cultural, linguistic" and historical backgrounds. Due to lack of space these control variables will not be examined in length.

The independent variable of concern to the present study is regime flexibility, while the outcome of interest is societal preferences (emboldened or conservative society). By showing a link between these two variables, this study hopes to synthesize institutionalism, contentious politics, and strategic frameworks in order to better 
understand how mobilization can occur under authoritarianism. Accordingly, the theoretical propositions derived from the models in chapters three and four, along with the two general hypotheses are presented below:

\subsection{Restatement of Propositions and Hypotheses}

Proposition 1 (emboldened civil society): there is some value of $r$, lets call it $r^{* *}$ (as opposed to $r^{*}$ above), where civil society is indifferent between repression and a Broadened Dictatorship, if and only if civil society's preference ordering is actually TRANSITION (1) $>$ INSURRECTION $>$ BDIC $>$ SDIC $>$ NDIC (0). In this preference ordering $x_{c}>b_{c}$ and the expression $\left(x_{c}-b_{c}\right) / x_{c}=r$ can be true.

Proposition 2 (expanded game with emboldened society): If the regime is tough - i.e. it prefers NDIC to Transition - and civil society is emboldened - i.e. it prefers Insurrection to BDIC - then there is an equilibrium in which mass mobilization will prompt regime repression and civil society will reject any concessions short of "the fall of the regime".

Proposition 3 (with conservative civil society): If civil society does not prefer Insurrection to BDIC, then it is conservative. Conservative civil society will by nature of its preference ordering be subject to the original conclusions drawn by Przeworski (1991). Specifically, that the regime's coercive power will incentivize society to choose Accept (concessions) and subsequently Enter into a Broadened Dictatorship.

Proposition 4 (threat and society): Regime strategies of co-optation and coercion affect the interrelated variables of current threat (Tc) and repressive threat $(\mathrm{Tr})-$ both over time and during episodes of contention. Flexible authoritarian regimes are those in which co-optation/concessions are deemed "cheaper" than coercion; while rigid or inflexible regimes are those in which the opposite is true. Flexible regimes will be conducive to the social construction of conservative contentious framings; while inflexible regimes will be conducive to the development of emboldened contentious framings.

And two further generalized hypotheses based upon the regime-typology above:

Hypothesis 1 (institutions, strategies, and threat): Regimes that permit high levels of contestation within parliament and exercise restraint with regards to a 
limited level of public contention are more flexible and were thereby able to survive the Arab Spring. Morocco exemplifies such a regime.

Hypothesis 2 (institutions, strategies, and threat): Regimes that significantly limited parliamentary contestation and repressed popular political contention were more likely to become destabilized by the Arab Spring movements. Tunisia exemplifies such a regime. 


\section{CHAPTER 6: Tunisia - Mounting Tensions and Shifting Preferences}

\section{1: Introduction}

A full accounting of the causes of Tunisia's Jasmine Revolution - indeed, perhaps all such revolutionary "surprises" - will most likely remain elusive to social scientists (Kuran 1991). Nevertheless, by applying the model presented in chapters 3 and 4 to the case of authoritarianism and revolution in Tunisia, we may be able to glean whether and how regime type impacts the dynamics of contention; both within Tunisia and comparatively. Toward this end, Michele Penner Angrist (2013) offers an instructive institutional assessment of the factors leading up to the 2011 revolution:

"Ben 'Ali's fall was precipitated by the refusal of civilians to stand with and for the status quo by not demonstrating, or by counterdemonstrating in support of the regime. This refusal was a product of the ways in which the domestic and external support bases of the Ben 'Ali regime had narrowed over the course of the late 1990s and 2000s, leaving the president's hold on power tenuous" (550).

Accordingly, the economic, social and political liberalization of Tunisia under Ben Ali had at least two (opposing) effects. The first was to strengthen the regime through economic and political co-optation as well as international legitimacy - in line with the authoritarian resilience paradigm. The second effect of liberalization, however, was to alienate a significant portion of society - narrowing the support base of the regime - who then "retreat[ed] to the private sphere as a realm where ordinary citizens could perform political acts of defiance towards the regime" (Cavatorta, 2012: 189; Angrist 2013). Such alienation was the unintended side effect of strategically targeted political and economic co-optation coupled with the ever-present threat and use of repression. As Cavatorta notes, the authoritarian resilience paradigm correctly assessed the strategic 
nature of such reforms - i.e. as regime-strengthening - but failed to "pay sufficient attention to how society reacted to sustained repression and dissent" (2012: 189). The nature of the Tunisian regime - a single-party dominant regime ruled by a "personalistic and patrimonial" president - meant that dissent was channeled through two primary avenues: either (a) within the single, hegemonic party apparatus - which the president dominated; or (b) through “demonstrations, strikes, and protests, which [were] often met with the use of force by the regime" (ibid). Society became emboldened when the former became increasingly narrowed and distasteful to Tunisians' sense of justice, coupled with shifts in contentious repertoires and framings that incentivized the latter (Roko 2012).

\subsection{Contentious Episodes in Tunisia}

\subsubsection{Contentious Politics and Regime Transition I: 1987-97}

In 1987 Habib Bourguiba "faced threats from outside the regime as well as from soft-liner elites who could move against the ruler" (Brownlee 2006, 50). As a result, Tunisia was primed for an elite-level political transition. The "constitutional crisis" and subsequent "constitutional coup" - or "medical coup" - by (former general and prime minster at the time) Zine Abidine Ben Ali in 1987 signaled to some a move towards democratization (ibid). However, "In retrospect, the National Pact [i.e. the package of liberal reforms promised by Ben Ali upon assuming office] seems to have been a strategic ploy that appeased the MTI [the Islamist opposition party] while Ben Ali stabilized his own position" (ibid). Hence, regime change was merely the persistence of the previous regime with "illusory" structural changes and "surface modifications" that 
“...masked fundamental continuities" (ibid). While Ben Ali introduced nominal pluralism, changed the name of the dominant party from Neo-Destour (ND) to the Democratic Constitutional Rally (RCD), and continued full steam with neo-liberal economic reforms - in order to spur direct foreign investment and garner IMF loans - the regime maintained a consistently oppressive and closed political system (Angrist 1999b, 91). These reforms set Tunisia on the path toward steady socio-economic growth throughout the authoritarian period. However, instead of steering the regime toward democracy, Ben Ali actually worked to perpetuate patterns of clientelism and statecorruption (Angrist 1999a; Anderson 1997).

Upon Ben Ali's seizure of power he "seemed bent on establishing himself as the country's most dedicated reformer", yet, "[b]y late $1988 \ldots$ the bloom had begun to fade" (Anderson 1997, 35). Despite the RCD winning nearly every parliamentary seat in 1989, Ben Ali faced threats both from the Bourguiba's old guard as well as the Islamist and Leftist political opposition. Part of this was due to key differences between Bourguiba's and Ben Ali's respective bases of support and therefore the political strategies they employed. On the one hand, Bourguiba had "consolidated control over the party and state bureaucracies by co-opting and manipulating clientele networks in ways that would concentrate power in his own hands without alienating his bases of support" (36). In this way, "rather than becoming Tunisia's sole patron, he set out to become its chief patron" (ibid). Ben Ali, on the other hand, came into office at a time of great political discord and economic crisis (37). As a result, the elite bases of support that Bourguiba had relied upon had become discredited; but were nevertheless intent on regaining their previous individual locusts of power (ibid). Consequently, Ben Ali had to rely upon a combination 
of repression and electoral control over parliament to solidify his power. Politically, to meet these challenges, Ben Ali "pursued a two-pronged approach":

"On the one hand, he introduced party-level political competition. Although this contestation did not pose a challenge to the social control of the regime, it did entrench forms of patronage through electoral channels that shored up the regime. Ben 'Ali simultaneously created nonelectoral channels of rent distribution that operated through clan ties and the security apparatus from which he hailed. This patronage served the needs of Ben 'Ali's most critical and loyal allies" (Blaydes 2011, 226).

Coercively, Ben Ali sought to cow his enemies both within the government and civil society (Angrist 1999a; 1999b).

Similar to Sadat in Egypt, the regime transition from Bourguiba to Ben Ali exemplified the relationship between liberalization and coercion (Blaydes and Lo 2012; Anderson 1997; Brownlee 2006). Both Sadat and Ben Ali came into power amidst political turmoil - sandwiched between the old guard and the traditional bases of regime opposition. However, they both also assumed power with similarly strong repressive bona fides - i.e. as being tough liberalizers (Blaydes and Lo 2012, 127-8). In the Egyptian case, "[w] hether civil society would enter into a broadened dictatorship with the regime depended to a large extent... on whether civil society viewed Sadat as the type of liberalizer that would use repression to avoid democratic transition" (127). Blaydes and Lo suggested that Sadat's 'type' was telegraphed by two factors: (1) the history of regime repression under Nasser (in which Sadat had been principally involved at times [see:

Cook 2012]; and (2) "perhaps more convincing, was the rigor with which Sadat was seen to eliminate competitors within the ruling elite" (Blaydes and Lo 2012, 127). This in many ways mirrored Ben Ali's circumstances. First, he was known to be "eminently 
qualified" at repressing any societal opposition based upon his experience supervising "Bourguiba's successive crackdowns on labor, students and Islamists" after 1984 (Anderson 1997, 37). Second, he swiftly restructured the governing personnel: "He abolished the office of party director, a position of considerable power in the 1970s...", he "reduced the autonomy of his ministers", and dismissed "Hedi Baccouche in 1989 [which] demonstrated that Ben Ali [had] no tolerance for a prime minister who show[ed] any sign of becoming a power in his own right" (ibid). Due to these factors, it could not have been clearer to those at the time as to what was at stake in opposing Ben Ali's rule. Hence, society and elites were faced with two real choices: enter into Ben Ali's new 'liberalized' regime, or fight against it and risk the consequences.

Subsequently, by 1992, Ben Ali was able to employ a strategic mix of concessions and coercion that divided society and removed any serious threat to his rule (ibid). Throughout the 1990s, on the surface, Tunisia appeared to be liberalizing - both economically and, to a lesser extent, politically. Repression was employed, but it did not bring with it widespread indignation:

"Angered by their exclusion from parliament despite strong support for their candidates who ran as independents, an-Nahdha [Tunisia's main Islamist party] activists intensified protests at the university and in working class neighborhoods. The government, in turn, stepped up its repression... Late-night raids and houseto-house searches became commonplace in some neighborhoods. Stories of torture under interrogation and military court convictions multiplied [...] the government's extensive dragnet hauled in more than 8,000 individuals between 1990 and 1992" (35).

Yet, as Anderson explains, “[m]ost Tunisians tolerated the government's repression"choosing to believe rhetoric about the 'Islamist threat' and the ramifications for 'Algerialike' political pluralism on the "vigorous" economy (ibid). The result, ten years after Ben 
Ali assumed power, was the effective elimination of any "serious political opposition" at the hands of the repressive and co-optive strategies of the regime (36). The National Pact, which "seemed to accommodate the opposition's calls for authentic multipartyism" in reality represented controlled and illusory liberalization (Brownlee 2006, 52).

Nevertheless, it served to appease a large enough slice of society to keep the opposition conservative. As Jason Brownlee concluded, "[t]he absence of a viable alliance of softliners and moderates may [have stemmed] from the lack of a formidable radical movement (maximalist opposition)" (ibid). Regardless of the actual galvanizing factor (or lack thereof), the fact was that society was not sufficiently emboldened to press the regime for any significant changes beyond the mere replacement of Bourguiba. Consequently, the majority of Tunisians, given the option between cooperating with the regime and resisting Ben Ali's efforts to consolidate his power, chose the former. Hence, the basic patrimonial, personalistic foundations of the regime persisted. Ben Ali was able to successfully enervate Bourguiba's old guard while simultaneously gaining the cooperation of the majority of society, intimidating the rest into irrelevance (Brownlee 2006).

\subsubsection{Changes in Contention: The 2008 Gafsa Mining Basin Riots}

The Gafsa Mining Revolt, which spanned from January to June of 2008, "began when a state-owned phosphate company announced a slate of new hires consisting primarily of individuals with connections to the regime, rather than locals and the children of workers who had been harmed in the line of work" (Angrist 2013, 560). The hires were supposed to have been local, given the dire socioeconomic straits the region was already mired in. When the firm reneged on its promises to the locals, in favor of 
indulging in patrimonial politics, protests and riots broke out (ibid). According to Angrist (2013), “[the firm's] action mobilized many sections of society [including] unemployed graduates, women, university students, the Tunisian diaspora, and Internet activists" (ibid). By way of summary, Gobe (2011) offers the following:

“...within Tunisia's authoritarian context, the Gafsa protest movements have shown, on the one hand, that some significant segments of Tunisian population were capable of voicing their opposition to something; and, on the other hand, it showed the limits of Tunisia's so-called 'economic miracle', which is incapable of reducing the range of regional disparities between a pauperized Tunisian South and an economically dynamic Sahel. The Gafsa Mining Basin Rebellion also reveals the fragility of 'patronage redistribution' in a region where there are few resources to be distributed, particularly employment" (20).

Put simply, the revolt was the result of decades of regime excess that created wide gaps between the 'winners' and 'losers' of neo-liberalism; and it showed that (some) Tunisians were only willing to endure so much pervasive indignity and coercive threat, despite the severity of repercussions (Gobe 2011, Cavatorta and Haugbølle 2012).

The Gafsa Revolt is significant (a) in terms of the repertoires, spaces, and frames of contention employed by protesters and civil society actors; as well as (b) for the regime's responses (Signé and Smida 2014). Firstly, "the conflict remained within the confines of the mining basin. To quote the terminology used in the sociology of social movements, there was no diffusion of the conflict from one site to another. What we witnessed was a local protest movement, which was unable to alter its scale" (Gobe 2011). Essentially, "the movement remained regionally contained and was 'essentially about advocating the rights of mine workers of the Gafsa area. It did not translate into a 
wider mobilization demanding the comprehensive rights of the Tunisian people",3 (Angrist 2013, 560). Additionally, both the regional leadership and the national leadership of Tunisia's biggest workers' union, the Tunisian General Union of Labor (Union Générale Tunisienne du Travail, or UGTT), sided with the regime (ibid). This crucial factor, combined with the "legal political formations that are relatively autonomous, the unrecognized parties, certain civil associations (legal or not) and some professional organizations, such as lawyers" being "too weakened after more than 20 years of Ben Ali's authoritarianism" to rally to the cause, meant that there was a significant lack of connective tissue linking the localized mobilization to any broader oppositional constituencies (Gobe 2011, 20). While contentious repertoires such as Internet and human rights activism were employed, "it was mainly the local militants who led campaigns of concrete support with the residents of the mining basin" (19). Roko (2011) - through interviewed conducted with Tunisian activists in 2011 - bears this out qualitatively:

"However, more than one Tunisian interviewee highlighted that the unrest in the mining town of Gafsa in 2008 turned out to be a groundbreaking event, paving the way for the 2011 mass protests (Amir, interview 2011). [...] When asked why the Gafsa riots did not set off countrywide protests, respondents pointed out that it was more difficult to relay information from the area back then. For instance, Facebook and Twitter were not commonly used at the time (Reem, Amir, interviews 2011). Furthermore, members of the trade union UGTT and lawyers from the Tunisian Bar Association stated frankly that although their members mobilized in Gafsa, there were few attempts to mobilize elsewhere in sympathy (Interviews 2011). Gafsa ultimately failed, but Amir and other activists recognize that it set an example for others, and that it helped crack the 'wall of fear' that the Tunisian regime had erected (Interviews 2011)" (74-5, emphasis added).

\footnotetext{
3 Penner Angrist quotes from Nadia Marzouki, "From People to Citizens in Tunisia," Middle East Report, No. 259 (Summer 2011), p. 17.
} 
The regime's response was notable due to the stark differential in outcomes relative to the 2010-11 Revolt. In 2008, events unfolded in just the way that authoritarian persistence theorists (e.g. Bellin 2004, Brownlee 2006) would have predicted: "[p]olice forces started a violent repression that was unsuccessful in stopping the revolt. The army intervened thereafter, killing 3 protesters and injuring 10 others. Demonstrators immediately abandoned the struggle against the regime after the army's intervention" (Signé and Smida 2014, 2). While the scale of the Gafsa riots "represent[ed] the most important protest movement seen in Tunisia since the Bread Revolt of January 1984" (Gobe 2011,1), they did not pose a significant enough threat to the regime for the military to separate itself from Ben Ali (Signé and Smida 2014, Angrist 2013). Accordingly, Signé and Smida (2014) concluded that Ben Ali's decision in 2008 was based on the (incomplete) information he had about the military's likely support as well as the strength of civil society - the best strategic decision for him at the time. Moreover, the Army's decision to stick with Ben Ali was the result of its own internal calculus concluding that Ben Ali's chances of staying in power were "too high $[\ldots]$ even if the army had refused to open fire" (19). Both Ben Ali's and the Army's decisions (and ultimate success) were in large part the result of the Gafsa contentious episode remaining a localized affair. The regime was therefore able to employ a mix of coercion and concessions to quell the mobilization free from any significant risk of enraging societyat-large. Indeed, coercion seemed to do the trick almost entirely:

"While waving the stick, the authorities were also waving the carrot: in order to calm the tension, President Ben Ali dismissed the governor of Gafsa and the Director-General of the GPC. However, this initial gesture was insufficient to 
stop the protest. In general, the concessions made by the authorities, particularly at the local level, were perceived as simple promises that would not be fulfilled" (Gobe 2011, 16).

Hence, it should be noted that, while repression succeeded in crushing the local protests, concessions were only helpful in diffusing national concerns (Gobe 2011; Angrist 2013).

This episode of contentious politics in Tunisia shows that discontent with and alienation from the regime, as of 2008, had not yet reached levels sufficient to embolden society against Ben Ali himself. Accordingly, protesters' contentious claims were policy-oriented, not regime change-oriented. As in the 1989 - 1999 transitional period, certain segments of society were opposed to the regime; but the opposition was not 'contagious' - i.e. societal actors could perceive the current threat of the regime as tenable, and were therefore not drawn out into the streets (Angrist 2013). Additionally, the role of the unions and the professional associations is instructive in this case. The former actually sided with the regime, while the latter was simply 'too exhausted' to play a significant role. Thus, it can be concluded that the strategic calculus of civil society, in 2008, still perceived cooperation with the regime - and/or the status quo - as preferable to the risk of repression and/or insurrection.

\subsubsection{Contentious Politics and Regime Transition II: 2010-11}

The self-immolation of Muhammad Bouazizi in Sidi Bouzid on December 17, 2010, has been described as "the spark that changed Tunisian sentiment toward deep socioeconomic grievances from apparent passive resignation to indignation and political activism" (Angrist 2013, 548). From there, regime brutality and social media activism 
caused protests to spread across Tunisia and, eventually, throughout the MENA and beyond (Lynch 2012). Yet, as Angrist notes, “[t]hese elements were important to the unfolding of the 2011 Tunisian Revolution, but they do not account for the entire story" (ibid). The framing of Tunisian society as governed by a 'pact of obedience' was far from the case. Indeed, "[i]n Tunisia, the middle class, and the highly educated unemployed, had experienced the Ben Ali regime as a collective humiliation, and rallied behind a fundamental, emotionally charged demand for the restoration of dignity" (Roko 2011, 116). This was a sentiment that had erupted into the streets numerous times prior to the Jasmine Revolution (e.g. in 1984, 1987, 1989, and 2008) but always succumbed to the strategic maneuvers of the regime. However, outside of these punctuated instances, contentious incidents remained few and far between (Angrist 1999b; 2013; Roko 2011). By 2010, Tunisia had devolved "into a typical, if extreme, family kleptocracy"; a fact that was laid bare via U.S. Embassy cables published by WikiLeaks detailing “the regime's deprivations" (Lynch 2012, 73). Surely though, besides the contingent events of Bouazizi's self-immolation and the WikiLeaks scandal, nothing about Tunisia's socioeconomic circumstances, nor the extent of the regime's corruption, were much different in 2008. Yet, in 2010, what first began, similar to the Gafsa riots, as a provincial uprising in Sidi Bouzid - a small, rural city of less than 35,000 - ended up precipitating events of historical scale and regional scope (ibid). This begs the question: What was different in this case?

The initial progression of events can be partially explained as a reaction to specific socioeconomic and individual dignity contentious claims against the regime. As 
Marc Lynch argues:

"Bouazizi's act of desperation was not the inarticulate expression of rage that it has been portrayed to be. It was a calculated political act designed to provoke precisely the kind of popular response it achieved. It came in the wake of a series of particularly brazen land grabs in the farmlands surrounding Sidi Bouzid, and attempts by local labor organizations to mount challenges to official abuses" $(2012,75)$.

Moreover,

"[a]s graphic as his self-immolation was, it likely would have had as little impact as previous acts of protests were it not for what would soon become a distinctive combination of factors across the region: a brutal regime response to the protests that broke out, which fueled rather than crushed dissent; the creative use of social media to spread images and reports of the brutality; and an unusually attentive international response once the protests had begun to capture the regional imagination" (ibid).

Thus, society was essentially on the path to becoming emboldened prior to Ben Ali's brutal response to the instigating contentious act (i.e. the self-immolation - itself indicative of a particularly high level of despair regardless of any pragmatic motivations). The regime's reaction, while failing to subdue the protesters, succeeded in shifting societal preferences from contentious claims on the state to claims opposed to the very existence of the regime (Pearlman 2013). 


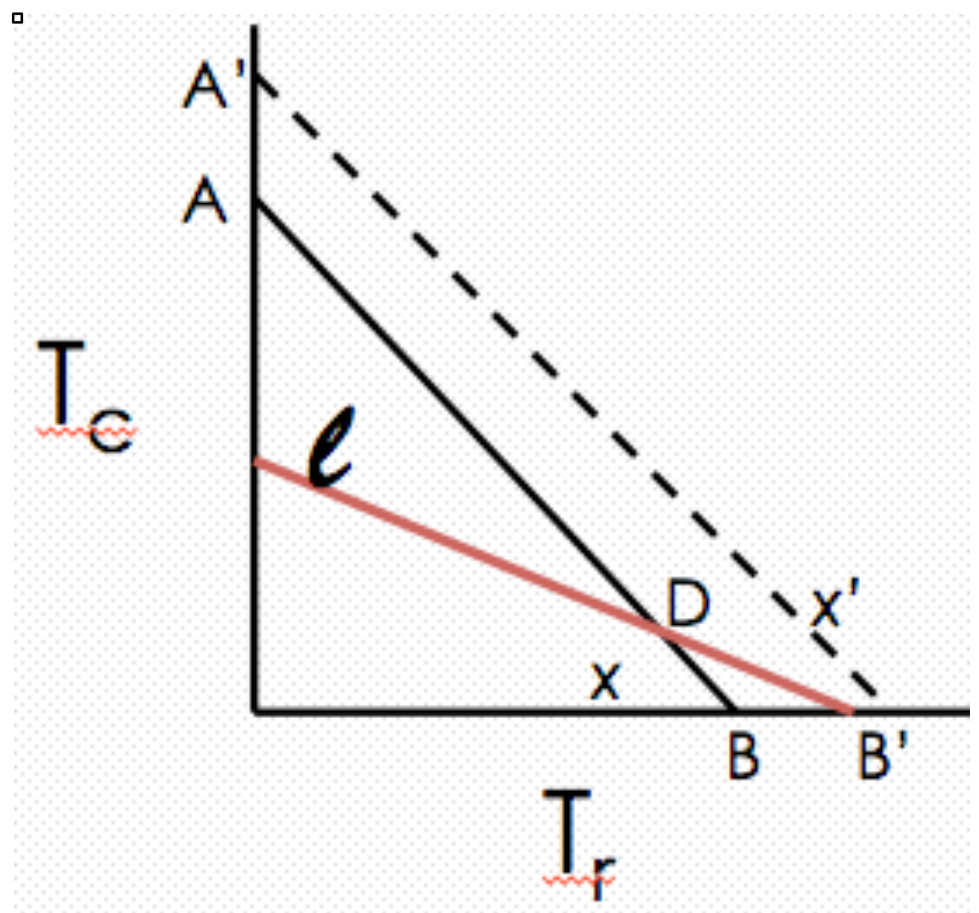

[Figure 6.1. The Arab Spring in Tunisia]

Tilly and Goldstone's framework can easily be mapped onto the events of the Jasmine Revolution. Figure 6.1 summarizes the unfolding of events in Tunisia from the start of protests until the eventual deposition of Ben Ali. Considering only the two threat variables - concessions (i.e. reductions in $T c$ ) and repression, $T r$ - it is assumed that there was some line $A B$ whereupon any combination $\{T c, T r\}$ would have defeated the protesters. However, Ben Ali's "constant cost" strategy - informed by institutional limitations that were inherent to the hegemonic party system - made $\operatorname{Tr}$ 'less expensive' than $T c$ for the regime - i.e. repression was preferred to concessions. This is represented by the constant cost line, $l$. As a consequence of the regime's cost/benefit strategy, the combination of concessions and repression necessary to defeat the protest movement is represented by the point $D$, at the intersection of $l$ and $A B$. If the regime had been able to accurately assess how society would respond to excessive violence, it may have been able 
to employ some strategy $D$ that would have stopped the Revolution in its inchoate tracks. However, this is obviously not what happened.

In hindsight it is apparent that the regime dramatically underestimated the actions required in order to bring about the end of the initial bouts of protests (Signé and Smida 2014). The brutal level of repression employed by Ben Ali is represented on the graph by $x$, a point to the left of point $D$. There were then two consequences for this regime strategy $x$ : (1) the protesters were not sufficiently deterred; and (2) the repression of the regime served to outrage and galvanize the population, effectively shifting the sufficient actions frontier to $A$ ' $B$ ' (Lynch 2012, 67-101; Tilly and Goldstone 2001, 188-9). Thus, some strategy along line $A^{\prime} B^{\prime}$ - represented by point $y$ - became the new strategy necessary to stem the tide of protest. This is where Tilly and Goldstone's framework becomes especially compelling: because repressive actions can only extend as far as repressive capacities allow for, there is no point on line $l$ that extends into $A$ ' $B$ '. How this played out on the ground was that Ben Ali regime required some repressive capacity, $y$, that could only be achieved by gaining the support of the Army. When the Army refused to fire, the regime was effectively out of options (Lynch 2012; Bellin 2012). As a direct consequence, Ben Ali was forced to flee the country to Saudi Arabia on January 14, 2011.

\subsection{4. 'Dynamics of Contention' during the Jasmine Revolution}

One set of factors that contributed to the vastly different outcome in 2010-11, relative to all previous society-regime interactions, had to do with the involvement of civil society actors - prominent among them, the UGTT (Angrist 2013). The UGTT had 
received sweeping criticism from "workers and some local regional branches" in reaction to the union having sided with the regime in 2008 (ibid). Therefore, desiring not to make the same mistake again, the UGTT firmly sided with the protesters in Sidi Bouzid. In fact, according to Angrist, "[t]he UGTT's actions, first at the local, and then at the regional and national levels, were pivotal to sparking and then geographically spreading [...] mobilization to the point that the regime was unable to contain it" (561). Beyond the unions, "[t]he National Bar Association also played a key role: on December 31, it organized a series of demonstrations in six locations across Tunisia, and on January 6, lawyers went on strike" (561). Ben Ali also lost support from within the RCD - the dominant ruling party of Tunisia. Beginning in 2005 through to 2010, the RCD's distancing posture proved to have "strategic consequences during the revolution... [when] the RCD failed to mobilize a single demonstration in support of Ben "Ali" (553).

Another set of factors that allowed for the success of the 2010-11 mass mobilization was common to both Tunisia and Egypt: "long-standing grievances, an emotional trigger, a sense of impunity, and access to new social media" (Bellin 2012, 136). Volpi (2013) mirrors this assessment by adding that in Tunisia, starting with the immolation by fire of Mohamed Bouazizi, consciously non-ordinary, non-routine political choices began to be translated into actions that undermined the dominant discourse and organization of social normality in the country" (979). As a result:

"The evolution of public behavior in response to Bouazizi's actions produced a highly unusual wave of protests that undermined the regime's (and the analysts') pre-existing understanding of the causes of stability in the country... once people realize the generalized uncertainty that has been introduced in the system by such 
non-ordinary behaviors, they are likely to reassess the way in which they ordinarily responded to the demands of the state" (979-80).

Ben Ali's strategic reaction to the protests - to dismiss them out of hand and to respond swiftly with violence - either underestimated the long-term mounting effects of "under the radar" (Anderson, 2011) social mobilization; or overestimated the Army's loyalty (Bellin 2014). The repeated interaction between the increasingly "isolated president" and society reflected a fairly predictable and consistent iterative process that served to shift society's preferences vis-à-vis the persistence of the regime over time (Angrist 2013, 561). On the one hand, Ben Ali's strategies remained fairly static; while on the other

hand, society was adapting and devising new modes and frames of contention (Rokko 2011; Angrist 2013; Volpi 2013). Essentially, “[h]ad sufficient numbers of civilians sided with the Ben 'Ali regime - either by staying home from opposition demonstrations or by staging substantial loyalist counterdemonstrations - his regime might have survived" (Angrist 2013, 561). Consequently, the Ben Ali regime's (increasing) political inflexibility served to alienate elites and organizations that had been reliable supporters in the past (such as the UGTT and the RCD), as well as to galvanize those who had historically stayed out of the fray (such as the professional syndicates and the middle class), resulting in a much different turn of events than in 1987-97 and 2008.

\subsection{Emboldening Society in Tunisia}

Angrist (2013) posits that "[i]n order for a popular movement to oust an incumbent regime, an interaction between two phenomena must unfold" (549). The first is that "masses of citizens from socioeconomic classes and political divisions must 
sustain physical protests across most of a state's territory for a significant period of time" (ibid). The second phenomenon "is that, in the face of broad and sustained mass civic protest, the architecture of the authoritarian regime must fail to counter, respond, and repress" (550). These two 'phenomena' correspond fairly neatly with the two elements of our model. Broad and sustained mass protests are indicative of a society that has become emboldened. This means that societal preferences have been altered as a consequence of shifts in contentious framing toward perceiving the current threat of the regime as untenable relative to the potential repressive threat that might await protesters. This informs the strategies of both society and the regime. Society becomes unwilling to cooperate with the regime barring significant reforms; up to and including regime change. The regime, on the other hand, is compelled to use repression and is likely to overreact, further enraging societal actors. In order to account for the shift in societal preferences leading up to the outbreak of protests in Tunisia, an analysis of the changing frames and repertoires of contention - and their relationship with the political opportunity structure (POS) - is therefore necessary (Rokko 2011).

For the average Tunisian citizen, dissatisfaction with the regime was related to disillusionment due to the lack of institutional mechanisms for dissent inherent to hegemonic party regimes. Given that the political arena was primarily a vector for clientelism and the assertion of the regime's dominance, the search for alternative modes for articulating dissent became a necessity. This fact of political life in Tunisia led to a transformation of the public sphere. As Ellen Lust explains, the dearth of effective civil society and political party outlets for citizens incentivized "more gradual but 
transformative social changes", which took place "largely under the radar", and eventually "facilitated the uprisings" (5). Specifically:

"A growing network of activists engaged in new movements - at the national, international and, to a lesser extent, regional level. In many cases, they formed cross-ideological, fluid networks with little organizational structure or central leadership, and fluid, overlapping memberships. This helped to sustain the oppositions in spite of heavy-handed repression and also shifted the focus of contestation..." $(2011,5)$.

These "under the radar" changes within society are similar to Timur Kuran's (1991) concept of "preference falsification" - the idea that "[t]he general benefits and costs associated with a public-preference choice generally depend on the choices of others" (1532). Essentially, the argument is that authoritarian regimes - in contrast to democratic states - incentivize citizens to hide their true feelings and beliefs for fear of retribution. This perspective gives lie to the popular belief that Tunisians had settled into a "pact of obedience" with the regime by acquiescing to a technocratic form of authoritarianism so long as it yielded positive economic benefits (Marzouki 2011). Further, Kuran formulates how preference falsification might bear upon "revolutionary surprises":

"Under a very broad class of situations, the threshold distribution will generate more than one self-sustaining distribution of public preferences. In other words, public opinion will feature multiple equilibria. One or more of the equilibria may harbor revolutionary implications for the prevailing social order. If such equilibria exist, however, this will not necessarily be known because thresholds are not common knowledge" $(1991,1533)$.

In this way, Tunisians - under the thumb of an oppressive regime and lacking any credible institutional recourse - retreated away from the traditional public sphere and toward at least two alternative modes of dissent: (1) a personal and societal reemphasis on Islamic and Arab ideals which facilitated a reconciliation between Islamist groups and secular actors; and (2) the 'under the radar' mobilization of society through "liberation 
technologies" and informal networks (Diamond 2009). Additionally, these

transformations within society were compounded by the increasing isolation of the Ben Ali regime - prompted by the ruling family's excess and the alienation of allies within civil society, the bourgeoisie, and the government.

\subsubsection{Institutionalized Mechanisms for Dissent in Tunisia}

Ben Ali's reliance upon huge electoral margins - in both presidential elections as well as parliamentary elections - necessarily limited the institutional mechanisms available to civil and political society and ordinary citizens for expressing dissent. Hegemonic party regimes, by nature, require the leader to limit contestation within parliament (Albrecht and Wegner 2006). As such, the Tunisian patrimonial system necessitated a litany of strategically crafted electoral rules and strategies - not limited to outright fraud. Per Lust-Okar and Jamal (2006), “...in Tunisia by the 1980s, the leader’s legitimacy [was] derived in part from his linkage to the party. Because these leaders take part in participatory politics, liberalization requires either that they compete in elections (albeit as one who holds the reigns of power) or relinquish control. The liberalization process is thus more difficult for presidents..." (355, emphasis added). This need to dominate the political scene resulted in electoral gaps between the president and the next highest opponent of over $90 \%$. Hence, the "[1] op-sided results and heavy turnout in Algeria, Tunisia, and Yemen support the image of elections as a major national affair in which opposition movements vent, voters seek patronage, and states exhibit their prowess" (Brownlee 2011, 812; emphasis added). 
The RNC - and before that the ND - was the primary vector through which political disputes were resolved and patrimonial benefits distributed (Angrist 1999a; 1999b). As a result, pluralism in the sense of multiple parties representing and articulating different sets of preferences, was functionally absent in Tunisia and Egypt (see: Brownlee 2011). Accordingly, writing in 1999 Angrist described political parties in Tunisia, as "weak and insignificant" organizations that "do not loom as credible alternatives to the ND... They are stricken with intra-leadership rivalries and conflicts... [lack] clear policy programs" and the ability to campaign effectively (Angrist, 1999a:

753). Further, "the ND uses its power monopoly to keep these parties weak" (753).

Consequently, there were very few, "alternative means of practicing and institutionalizing new forms of political governance" and little credible chance of substantive institutional reform (983, emphasis added). It follows then, that, "the possibility of a sudden and dramatic failure of a regime is best understood in terms of a lack of opportunity for an institutionalized (or partially institutionalized) process of political change" (983).

Inflexible $^{4}$ regimes more forcibly push citizens out of the political sphere, where they are made to adapt and find new modes of articulating and aggregating dissent. As Roko (2011) posits, "[a]s we have seen repeatedly, the [Tunisian] regime had, in contrast to the Monarchy in Morocco, been totally inflexible in its encounters with domestic

\footnotetext{
${ }^{4}$ It should be noted that, "[o]ne must be cautious not to equate regime flexibility [with] "reform-willingness": Most authoritarian states reform only under pressure and political liberalization is often more rhetoric than reality" (Rokko 2011,117). Flexibility should be thought of a more analogous to "adaptability" - i.e. altering rhetoric and initiating policies aimed toward diverting or sating oppositional claims while simultaneously keeping the centers of authoritarian control intact.
} 
resistance. Ben Ali relied overwhelmingly on force and saw no need to open his political system, not even to pre-empt challengers" (93). Roko then associates flexibility - i.e. "the regime's willingness to compromise with or co-opt challenging forces in order to survive" - as being "closely related to regime type" (ibid). Hegemonic party regimes, such as Tunisia, are less able to address contentious claims through policy reform - and are therefore more reliant upon repression. This is because a key source of legitimacy for such authoritarians comes from maintaining hegemonic control of parliament (Albrecht and Wegner 2006). Citizens are then more likely to cross the established oppositional norms of the regime and therefore to be vulnerable to the state coercive apparatus. Consequently, the current threat of the regime is higher in such hegemonic party states relative to more adaptive authoritarian states - e.g. lynchpin monarchies. Put simply, regimes that can offer a more credible option for policy reform are better able to convince the opposition that the regime's persistence is in everyone's interest.

\subsubsection{Coercive Alienation}

In Tunisia, the threat of regime change and popular mobilization was staved off numerous times under both Bourguiba and Ben Ali through the use of violent oppression. That the subsequent reforms initiated by Ben Ali in the 1988 National Pact were proven quickly to be hollow should be of no surprise given his demonstrated willingness to employ violent measures under Bourguiba. Yet, why did Ben Ali even bother with such an orchestrated and public display of liberalization in the first place? As Lisa Blaydes notes, soft-liners are freer (and thus more likely) to pursue the co-optative benefits of liberalization when they are confident that the (moderate) opposition will not attempt to push for further reforms for fear of a violent backlash by the regime. Accordingly, Ben 
Ali was able to fortify his position as the new president of Tunisia by garnering international and domestic legitimacy from being seen as a soft-liner, while in actuality he was merely pursuing the same strategy of patrimonial clientelism as his predecessor. Throughout his tenure, Ben Ali was consistently able to benefit from controlled liberalization by leveraging the regime's coercive apparatus to keep civil society at baythat is, right up until he wasn't.

The political liberalization 'game', punctuated and sustained by the periodic deployment of state coercion, gave lie to the regime's reformist rhetoric throughout the late 1980s and 1990s. As Angrist notes, “... as the 2000s wore on, it became increasingly evident that Ben 'Ali's intentions were only to tighten his control over the reins of power, even in the face of a diminished Islamist threat"; a threat which had previously been used to justify the regime's 'temporary' resort to repression $(2013,556)$. By 2005, following municipal elections in which the regime "invalidated all ten joint candidate lists presented by independent opposition parties that came together in the Democratic Alliance for Citizenship", it was apparent that real pluralism would never be allowed by Ben Ali or his ilk (557). In this way, the use of repression by Ben Ali served to wall the average citizen off from political activity and expression: “...the effects of harsher repression, tighter regime control over information, and higher economic growth, meant that reported incidents of riots were few until the early 2000s" (Roko, 74). This contributed to the overall inflexibility of the regime - forcing citizens to develop alternative forms of subliminal expression, preference falsification, and to network under the radar. Moreover, because there were few outlets for the expression of dissent, the regime's "highly exclusionary" tactics caused the state to "become so unresponsive to the grievances of 
Tunisian society, that it was unprepared for the crisis. Paradoxically, these regime features amounted to an advantage for protesters" (93). Therefore, by 2010, the iterative interaction between society and the regime had served to recalibrate society's preferences with regards to any promises Ben Ali might have made with regards to political liberalization. Fundamentally, the expected value of entering into a broadened dictatorship under Ben Ali was diminishing - being discounted - in the eyes of society. The combination of hollow reforms and the extremely closed and implicitly coercive nature of the regime forced citizens under the radar and alienated those who had stood by Ben Ali in the past.

\subsubsection{The Mixed Bag of Modernization in Tunisia}

In the case of Tunisia - which "scholars of democratization" lauded as an "economic miracle" - "the creation of wealth and the rise of a new globally connected middle class" conspicuously failed to become the "fulcrum for political openings" (Cavatorta and Haugbølle, 2012: 183). In fact, contrary to the democratization paradigm, socioeconomic modernization in Tunisia - exemplified by neo-liberal economic reforms and incentivized by the IMF - primarily served as a means by which the regime could bolster support among those "key social sectors that would find interests in striking an alliance with Ben Ali" (184). However, this is not to say that modernization didn't have some positive effects:

"Improvements in infrastructure allowed Tunisia to market itself as a popular tourist destination, attracting millions of visitors who brought foreign currency into the country and created employment. A relatively low unemployment rate of around 6 per cent until the mid-2000s was also considered a success story.1 Finally, the Tunisian regime was able to increase its spending on education and health, apparently confirming the validity of the model of 'social liberalism' given 
that in 2011 its Index of Human Development was still higher than its North African neighbours" (184).

Additionally, literacy rates increased from "a low 48 per cent in 1984 to 78 per cent in 2008 and women were included in this literacy drive" (183). Finally, the regime placed a heavy emphasis on education, which included "the creation of many technologically savvy youth who would go on to use social media as a tool of political dissent and finally of political mobilization" (186). Nevertheless, while during Ben Ali's tenure there was in fact "real and dynamic growth that profoundly changed Tunisian society" - with growth rates averaging 5\% (1990s), 4.7\% (2000-2007), and 3.5\% (2008-2010) - modernization in Tunisia, from a democratization as well as an authoritarian durability standpoint, was decidedly a mixed bag (Cavatorta and Haugbølle, 2012: 183; IMF, 2013)

Importantly, as Cavatorta and Haugbølle observed, "the economic miracle of Tunisia had a very dark side where under-employment, unemployment, difficult access to the labor market, income inequalities and wide regional gaps were the main features" (2012: 184). Accordingly, they offered three arguments towards dispelling the "myth" of the Tunisian economic miracle (ibid). Firstly, as one would expect in such a closed regime, much of the statistical data that was reported by the authoritarian state was "fudged". For example, "When it comes to under-employment and unemployment the reality is that reliable statistics do not exist" - estimates range from (among young people) 18 per cent to 30 per cent in 2009 , “' and soared to 45 per cent in the case of higher education graduates"” (184). Secondly, as privatization and IMF-induced restructuring entered the 2000 s, the regime "degenerated... into a predatory economic system with members of the president's family and close collaborators taking advantage 
of... networks of patronage to acquire an increasingly larger slice of the economy" (185).

On top of all of this, while the "economy continued to grow even during the difficult years of the global financial crisis (3.1 per cent in 2009 and 3.7 per cent in 2010)" the three-year period leading up to the Jasmine Revolution marked a significant drop in growth (from $6.8 \%$ in 2007 to $4.5 \%$ in 2008 ), which likely exacerbated the conditions described above (185).

Consequently, economic development was one of the more significant sources of political alienation within the public sphere. The increasingly uneven distribution of wealth coupled with the blatant corruption and cronyism of the "Ben Ali clan", served to alienate not just Tunisian laborers and the unemployed - i.e. those 'left out' of modernization - but also Tunisia's business and middle-class (185). As Volpi (2012) notes, "Crony capitalism and redistributive politics were merged [in the Maghreb states] to lock the interests of economic actors and of the ruling elite, making liberalization a factor of the deeper institutionalization of authoritarianism" (976). In this way the regime was not interested in widespread economic prosperity past its usefulness in further entrenching and solidifying the power of the regime. Perhaps if the regime had been able to spread the wealth more evenly, it would have survived. Yet, this was not a feasible possibility given the inherent limitations of hegemonic party regimes (Albrecht and Wegner 2006). Instead, the regime went overboard:

"Although the regime endorsed a neo-liberal model of development that favoured the urban middle class, its increasingly kleptocratic and repressive behaviour eroded over time the confidence of those very segments of the population that had initially acquiesced to this model of governance" (976). 
Ironically, rather than gaining crucial elite support at the 'acceptable' cost of creating a socioeconomic situation that was "often dire for the average Tunisian citizen", many business and upper-class elites were instead alienated by the "apparent greed of the ruling elite and its reluctance to allow the emergence of business politics" (976). Thus, the alignment of interests of both "ordinary working Tunisians as well as the bourgeoisie" - i.e. in opposition to the regime's policies - "made the Tunisian uprising, to an extent, a joint effort between different classes" (185). Interestingly this process reflects a sort of distorted Lispetian situation wherein modernization initially exacerbated economic disparities between classes only to have regime oppression, excesses, corruption and mismanagement nudge them both towards democracy (Lipset, 1959). By 2010, the only economic 'winners' were those closest to or most reliant upon the "Ben Ali clan", while the 'losers' were left looking for a new "mode of political activity" (Angrist, 1999a: 757).

\subsubsection{The role of Islam}

Bourguiba's post-independence policies - which followed the contours of other westward looking revolutionary leaders such as Atatürk in Turkey - pursued a "commitment to the concept of laicite, whereby Tunisia's economic underdevelopment was also interpreted as the product of cultural and religious backwardness that had to be eliminated through subscription to modernizing values and the French model of social development" (Angrist 1999b, 189). External observers have therefore tended to buy into the notion of a secular and liberal Tunisia amid a sea of Islamism. It is indeed true that the process of state formation eschewed many traditional modes of life - including tribalism (Anderson, 1987) and political Islam (Angrist 1999a) - in favor of a family code offering substantial rights for women and other liberal reforms (Charrad, 2004). 
Yet, these reforms were directed towards diminishing "the primary role and status of Islam and the grip its official interpreters had on matters related to education, the judiciary and public displays of religiosity" (Cavatorta \& Haugbølle, 2012: 190). Consequently, they must be understood in part as pragmatic strategies aimed at centralizing power and positioning the regime as the sole bulwark against theocracy - not as some cultural tendency toward western liberalism. While democratization scholarship partially missed this fact, the authoritarian resilience paradigm accurately assessed them as "tactical reforms to ally specific sectors of society to the regime, usually in an antiIslamist social coalition" (190).

However, as Cavatorta \& Haugbølle note in detail, regardless of the paradigm, these interpretations were fundamentally focused on institutions and strategies at the elite and regime-level. They therefore failed to take into account how "in the longer term the values and modes of behavior of the ruling elites and small sectors of the urban population" were increasingly "out of kilter with the ones that the majority of the population had" (190). Specifically, the combination of the regime's anti-religious stance along with "reawakening demands for the Arab-Muslim identity to be much more recognized" - brought about by increasing exposure to outside "cultural and social models" - served to expose as incongruous the values of the general population and those of the regime. Moreover, in the absence of substantial civil society institutions, personal piety became a means by which to "retreat into the private sphere" and express conscientious discontent with the regime (190-2). 
While there are many factors that led to the dominance of Ennahda in 2011, it is hard to ignore the current mood in Tunisia, reflected by a March 2013 Pew Poll where a substantial majority of Tunisians supported at least "some" religious influence in politics (Pew 2013). [24\% of respondents said that religious leaders should have "a large influence" and 30\% said they should have "some influence" in politics (Pew 2013)] Additionally, as Ellen Lust argues,

"[A] ...critical transformation was the gradual construction of bridges between Islamists and secularist oppositions, and the diminishing/dissolving fear of the "Islamist threat.' The fear that emerged among many secularists (and was promoted by the regimes) was that Islamists would hijack a political opening by using elections to push a rigid theocratic agenda."

As radical Islamism somewhat "lost its steam" in the late 1990s and 2000s, the salience of such fear mongering as a justification for the persistence of the regime diminished (Cavatorta 2013). Also, Cavatorta (2013) argues that, due to the ostensibly liberal orientation of Tunisia in the 1980s and 1990s, Ennahda was not only excluded by the regime but also by broader society. As a result, Ennahda was forced to drop its more fundamentalist platforms - thus exemplifying a phenomenon of "moderation through exclusion" (1). Consequently, these two transformations - one of societal perspective the other of organizational ideology - created a political environment where - in accordance with Seymore Martin Lipset's social cleavages hypothesis - an Islamic political alternative was no longer such an unthinkable prospect.

\subsubsection{Liberation Technologies as Repertoires of Contention}

One of the more unequivocal benefits of modernization during the authoritarian period was increased education and access to "liberation technologies" (Diamond, 2009; 
also Cavatorta and Haugbølle 2012). According to Diamond, liberation technologies e.g. "Cell phones, e-mail, and the internet" - are those tools "that empower individuals and nonstate actors... in the struggle for human freedom and political participation". This is achieved by magnifying "the speed with which individuals can organize for social change, as well as the scale on which they can do so" (340). In Tunisia, the proliferation of these tools was precipitated by the regime itself:

"Educating the workforce and acquiring technological skills for economic purposes had the unintended consequence of creating and training future dissenters who used the Internet to oppose the regime and then mobilize against it. The privatization of media was carried out with the intention of securing the airwaves for the regime, but led to unexpected outcomes in terms of what ended up being broadcast because of the commercial imperatives on the new private channels" (Cavatorta \& Haugbølle, 2012; 192).

Ellen Lust adds that "[t]echnological advances facilitated [the revolutions], but their role should not be exaggerated... possibly a more accurate position is that [these technologies] contributed to gradual, changing dynamics of states and oppositions, but they are not responsible for the change" (6). Instead, the value of liberation technology lies in interplay between the Arab social sphere, which lacked a political voice, and the increased technological savvy of citizens. Per Ellen Lust, this relationship represented a "symbiotic interchange of resources and skills between activists on the ground and bloggers, and then increasingly between the lower and middle classes, who brought their individual skills and tools together to challenge the regime" (6). Most importantly, social media offered a realm outside of the purview of the regime: "[t]he safety offered by online networks was virtual, but its emboldening impact was real. In helping people to surmount fear, it encouraged optimistic judgments about the future and willingness to embrace risk" (Pearlman, 2013: 395; emphasis added). 


\subsection{Conclusions}

By 2010, society was on the precipice of becoming emboldened. Societal preferences had shifted across nearly every social cleavage - university students/graduates, the middle class, regime elites, union leaders, the professional syndicates, as well as the lower socioeconomic strata. Some of these actors formed unlikely alliances - united by their mutual status as political pariahs - such as the secular and Islamist political organizations (Angrist 2013). Others had left Ben Ali's camp behind, such as the UGTT and slices of the RCD (ibid). Consequently, the regime's base of support had become significantly narrowed - and Ben Ali himself particularly isolated - such that it became easier for societal actors to imagine Tunisia without him - or anyone like him - at the helm. The final straw came in the form of Ben Ali's brutal response to the initial protests of 2010. From that point on, rather than any particular policy demands, Tunisians directed their emboldened contentious claims squarely at Ben Ali's feet. Once contention shifted toward the regime, mobilization accelerated beyond anything Tunisians had ever witnessed:

"Many... citizens had previously been demobilized by feelings of helplessness before an amorphous and unfixable system. [Their willingness to protest] illustrated findings that the more specifically people pinpoint blame for injustice, the greater their inclination to protest. Blame could not have been more narrowly attributed for the thousands of Tunisians who defaced the president's picture and chanted, "Ben Ali dégage!"-Ben Ali, get lost" (Pearlman 2013, 396)

Hence, once society began to frame the continuance of the regime as an unacceptable outcome - one that would result in a disappointing and humiliating return to the same iterative process (game) they had endured in the wake of the constitutional coup and the 
Gafsa riots - social actors became willing to risk violent repercussions and the destruction of the current political system for the chance at yielding credible, lasting change. Society's preferences had shifted as the result of mounting historical knowledge - based on past iterations of the Liberalization 'game' - of the increasingly alienating and narrowed hegemonic regime, and the backfiring of kleptocratic neo-liberalism and distasteful corruption. As Roko (2011) noted, "Political opportunities... changed because ordinary citizens shared a rejectionist discourse, and acquired the networks required for action mobilization. One thus understands [the POS framework] must be complemented with a social constructivist study, to fully comprehend how action frames were generated, and how people were empowered to rise up against a seemingly monolithic, hegemonic authoritarian regime" (93). This resulted in the galvanization of disparate socioeconomic and civil society actors, all pitted against the continued persistence of Ben Ali's regime. Political opportunity was generated by shifts in societal preferences and frames of contention, that fed into, and were influenced by, civil society and elite actors eventually choosing to side with the opposition. 


\section{CHAPTER 7: Morocco - Lynchpin Flexibility and Contention}

\subsection{Introduction - Monarchical flexibility}

Morocco - particularly since the ascension of King Mohammed VI in 1999 - has

pursued a mixed strategy of co-optation and coercion that has tended toward the

reduction of current threat in stark contrast to Ben Ali's Tunisia. Per Boukhars (2012):

"[m]aintaining order and equilibrium between different competing interest groups has always required the monarchy to be flexible, sensible, and practical. Coercion comes second and is utilized only when deemed absolutely necessary" (84).

Accordingly, the Moroccan authoritarian system can be generally categorized as more flexible relative to Tunisia; offering qualitatively and quantitatively more institutionalized mechanisms for expressing dissent (Vairel 2011; 2007). This should not be taken to suggest that Morocco is a democracy, or that it is on the path toward democracy (Boukhars 2010; Maghraoui 2002). Moroccans in the 1960s and 70s fell victim to severe regime policies of repression - the so-called Years of Lead - and, in subsequent decades, the monarchy has not shied away from employing coercion when deemed necessary - especially against Islamist opposition (Vairel 2011). That said, when possible, the regime "prefers' to utilize the "competitive, multiparty system" in Morocco - established in 1963 - "to create a network of rent-seeking elite [who] support the regime in exchange for the opportunity to participate in parliament" (Blaydes 2011, 222). In this way, contestatory, pluralistic elections - while often "intense" - serve primarily as an expression of patrimonialism and are therefore allowed only insofar as they continue to reify the authoritarian logic of the Moroccan regime (ibid). 
While similar in some respects to other patrimonial logics throughout the region, in practice the Moroccan system contrasts starkly with hegemonic party regimes such as Tunisia, where "state largesse [was] distributed based on proximity to the president" and through highly discriminatory access to parliament (227). Accordingly, Parliament's main purpose in Tunisia was to allocate patronage benefits to "elite and popular sectors that... benefited from Tunisia's relative economic prosperity" (ibid). Consequently, electoral competition had a far narrower constituency than in Morocco (Lust-Okar and Jamal 2002; Volpi 2012; Blaydes 2011). Morocco is able to be more inclusive in terms of granting parliamentary access, which provides an expanded arena for moderating and depoliticizing political parties and opposition movements. Moreover, the sacrosanct position of the King - as 'off limits' to opposition and contestation - combined with the monarch's comparatively distancing and 'neutral' role as 'grand arbiter' has created openings for limited, but real contentious spaces in Morocco (Vairel 2011). Consequently, contention in Morocco is a more routinized part of political and social life, and there exist credible avenues for institutional reform - though never extending to the monarchy. These factors have served to orient contentious politics within Morocco toward conservativism - meaning that society still prefers, by and large, to work within the system. Hence, it is the contention of this chapter that authoritarianism in Morocco managed - through its flexibility and adaptability - to 'weather the storm' of the Arab Spring by moderating, but not stifling, patterns of contention. 


\subsection{Contentious Episodes in Morocco: Protesting in restrained 'spaces'}

\subsubsection{Contentious Politics and Regime Transition III: 1999-2002}

While not as tumultuous as the regime transition in Tunisia from Bourguiba to Ben Ali, the 1999 Moroccan royal succession mirrored the former in two main ways. First, both transitions occurred in the wake of leaders who had lost their luster. In Morocco, by the end of the $20^{\text {th }}$ Century, King Hassan II's 38-year rule "was tarnished by human rights violations, corruption and a discredited political system", and Morocco was "beset with enormous economic and societal difficulties" (Maghraoui 2001, 12; Boukhars 2010, 77). By contrast, upon his father's death, King Mohammed VI, “instantly became a symbol of hope for a democratic Morocco" (Maghraoui 2001, 12). Thus, both King Mohammed VI and Ben Ali came to power bolstered by their lofty liberalizing rhetoric.

Once he was in office the young monarch expounded his liberalizing intentions:

"...in his first addresses to the nation he expressed his extreme attachment to a constitutional monarchy, economic liberalism, politics of regionalization and decentralization, economic liberalism, edification of the rule of law, safeguarding of human rights and individual and collective liberties, and maintaining security and stability for all" (Boukhars 2010, 77).

Indeed, Mohammed VI did proceed to make good on some aspects of his liberalization platform - e.g. he tempered "the most authoritarian aspects of the regime" and "encouraged more openness and more participation in the political process" (Cavatorta 2009, 144). Additionally, he made significant progress with regards to human rights policy by allowing political exiles back into the country and establishing "an independent commission to compensate victims of human rights violations” (Maghraoui 2001, 14). 
Secondly, however, in both cases liberalization rhetoric and its corresponding policies ultimately served to mask fundamental continuities. For Morocco, the chief continuity was the preservation of the single sacrosanct fact of Moroccan political life: that "all societal forces" must accept the "uncontested role of the Monarch as the linchpin of the system" (Boukhars 2010, 76). Accordingly, per Boukhars, Mohammed VI's ascension to the throne reflected a mere "upgrad[ing]" of "strategies of adaptation" - not a dramatic shift toward democratization. Correspondingly, two years subsequent to the transition, "[e]nthusiasm for Mohammed VI's rule [had] waned [with] [a]verage Moroccans wonder[ing] if rampant injustice and corruption [could] be eliminated as long as the 'steel masks' - the old guard of advisors, dignitaries and generals who became so powerful under Hassan II -" remained at the King's side (Maghraoui 2001, 12). Essentially, the makhzen - the "administrative structure, legal framework and military manpower" that serves to ensure the monarch's control over politics - remained firmly in place, stamping out any domestic and international hopes for democratization (ibid). What the king's strategy of 'liberalization without democratization' illustrates is that rhetoric, concessions, and co-optation are generally sufficient toward gaining the acquiescence of much of society. However, this does not mean that this period was without contention or authoritarian repression.

The King's efforts to distance himself from the hardline past of Hassan II's rule included the proposal of "a large-scale, state-financed plan to improve the conditions of women in five areas": including education, reproductive care, parliamentary quotas for women and more gender equitable practices within the economic sphere (Maghraoui $2001,16)$. While generally met with enthusiasm, the fifth such area became very 
controversial with the country's Islamists (ibid). The divisiveness along Islamic-secular lines led to "dual protests" in March of 2000. In the capital, Rabat, "between 200,000 and 300,000 people representing women's groups, human rights movements and political parties marched in support of the plan" (AP). In Casablanca, though, "Moroccan Islamists staged one of the largest demonstrations since independence" (Maghraoui 2001, 17). By "gathering some 200,000 marchers [the] show of force intimidated the king and the government" and the plan was withdrawn (ibid). Later that same year, the Islamist group Al Adl Wal Ihsane (Justice and Charity) and human rights activists were the victims of widespread arrests and police beatings in response to protests "demanding the legalization of their Muslim fundamentalist group and an end to a ban on their newspapers, which [had] been in place for more than a decade" (Reuters 2000). Yet, concurrent to the targeted curtailments of some political rights - especially with regards to Islamists - and the use of the coercive apparatus, Mohammed VI appeared on television to advertise "a $\$ 12$ million fund to compensate some victims of human rights abuses" along with an order to create "a human rights body to examine some 5,000 complaints" (ibid).

The regime's divide and rule tactics vis-à-vis political contention are well illustrated in transitional events describe above. Contention was directed toward policy issues that served to pit secular political groups and actors against Islamists. This allowed the regime to navigate the complicated political position the Monarch has relative to political Islam in Morocco. According to Maghraoui (2001), the "king's hands are tied" to a certain degree when it comes to dealing with Islamists (17). Essentially, the king - as "Commander of the Faithful" as well as a modern head of state - has to 
carefully navigate "between the monarchy's role of protector of private religious rights and the role of the state as the guarantor of civil rights", while "creating a semblance of reform [and] respecting Morocco's cultural specificity" (ibid). This explains the duality of Moroccan politics, where Islamists who are willing to cooperate with the regime (the PJD) are welcomed into parliament, while those who oppose "a modern democratic project that confines religion to the private sphere and enforces the rule of law in the public realm" (Justice and Charity) are made illegal (ibid). Additionally, it explains why the regime would roll back certain liberal reforms (such as in the women's rights example above) in the face of significant Islamist blowback; while also explaining why such a policy would be proposed in the first place.

Regime transition in Morocco in 1999 began with lofty liberalizing pronouncements - some of which were made manifest while others were 'delayed' or rolled back. What certainly did not change was the fundamental core of authoritarian monarchical power. Mohammed VI was able to offer secular political groups and actors sufficient policy concessions in order to successfully broaden his base of power. While activists were dueling against each other in the streets, the regime was able to employ restrained repression combined with policy concessions in order to bring contestation to a halt. Mohammed VI's machinations paid off, as he was able to appoint "an apolitical, technocratic elite to key positions in the administration and the economy" (Maghraoui 2002, 34-5). This strategy culminated in the 2002 legislative elections, which served to cement the King's hold on power:

"[Representing a] sign of ongoing depoliticization [was] the campaign for the September 2002 legislative elections. Almost across the board, the political 
parties downplay[ed] their political programs and tout[ed] their technocratic and managerial credentials instead. At the same time, private economic actors... threaten[ed] to enter the political fray with the intention of applying their mise ' $a$ niveau policies in the political sphere" (ibid).

Mohammed was thus able to take control of the reins of power, change little about the basic authoritarian functionings of the state, steer civil society in a more technocratic, depoliticized direction, and shape contentious politics in Morocco such that it posed little serious threat to the reassertion of the monarchy. Consequently, "the so-called transition prompted by the monarchical succession, far from opening opportunities for protesters, gave way to reinvented discipline on the on the activist scene" (Vairel 2011, 41). Finally, all of this was possible while simultaneously employing very little violence relative to the Bourguiba-Ben Ali transition - thus mitigating the alienation of social actors.

\subsubsection{Patterns of Contention in Morocco: $2002-2008$}

\subsubsection{Overview}

In contrast to Tunisia, Morocco did not witness any major contentious episodes after the consolidation of its newest ruler that were on par with the Tunisian Gafsa mining uprising in 2008. The Gafsa riots were seminal because they exemplified the kind of punctuated and isolated instance of contention in a sea of cowed silence that characterized the state of social mobilization in the country during the tenure of Ben Ali. Protests would break out periodically and be dispersed with such viciousness (combined with token reforms) that society would recede until tensions sufficiently mounted down the line. Political contention in Morocco, on the other hand, was characterized by the consistency and (relative) low-intensity of mobilization and protests throughout Mohammed VI's reign. According to Vairel (2011), “[i]n Morocco the number and 
strength of mobilizations go beyond what one would expect from politics under an absolute monarchy" (41). Roko (2012) confirms this assessment: "in Morocco, riots occurred intermittently throughout the country in the 1990s and early 2000s, and people were accustomed to them as a local, contingent way of expressing grievances" (74). Consequently, this section details not any particular contentious episode but rather it analyzes the patters of contention that arose in reaction to the monarchy's partialliberalizing strategy of 'divide and rule'. It shows that, while the stability of the regime was largely kept in tact, it began to show some seams as normative-rhetorical and utilitarian promises were shown to lack credibility (Maghraoui 2011).

\subsubsection{Limiting contention}

In line with Przeworski (1991) and Blaydes and Lo (2012), the more severe repression of the 1960-70s in Morocco under Hassan II served to telegraph the 'tough' liberalizer credentials of the regime; and therefore to allow the strategic opening of the regime toward a broadened dictatorship (Vairel 2011; Maghraoui 2001). Indeed, Morocco was arguably able to sustain a much 'broader' authoritarian state than Tunisia. This was because, contrary to Tunisia, the capacity for repression in Morocco did not translate into the death of civil and political society; rather, repressive capacity and institutional strategies allowed political contention to exist in a tacitly-sanctioned, but limited form. Hence, by 2005, political dissent was funneled through either of two main avenues: within parliament and a co-opted civil society, or within and between secular and Islamic mobilizations. With regards to the former, Vairel (2011) argues that,

"The success of the repertoire of civil society reflect[ed] the profound transformations in the activist Arab milieus. Activists' political and physical 
defeat by regimes and security apparatuses... led to a new understanding of their commitments: the game in town [was] no longer revolution but reform, be it democratic or Islamic" (36; emphasis added).

Within society, on the other hand, "actors formally involved in far left organizations chose to internationalize their struggles, but by doing so they paid a heavy price in transforming their practices and programs from mobilization and street activism to participation in public policies and cooperation with the authorities" (37). The use of violence by the regime also served to engender a "political learning that power in numbers comes from 'holding the ranks' rather than 'controlling the street'" (ibid). To this end, "the generalized use of sit-ins - attested by media and fieldwork - testif[ed] to the self-limitation of Egyptian and Moroccan protesters" (ibid). Yet, while the regime benefited from its more restrained and strategic use of concessions and co-optation over coercion - a sort of 'speak lightly but carry a big stick' strategy - it meant that the regime had to periodically address the gap between its liberal rhetoric, past injustices, and current policies (Maghraoui 2001; Vairel 2008; 2011).

\subsubsection{The first seam: the give and take of human rights politics}

The campaign for truth and reconciliation in Morocco (2004-8), modeled explicitly on South Africa and other historical examples, was devised as a way to confront the atrocities committed by the regime in the past as well as to hold accountable those who were responsible (Vairel 2008). While the monarchy was bound by its professed commitment to human rights to acquiesce to such a process, the fact that activists by and large chose to work within the confines of the limited contentious space offered by the regime all but guaranteed that real accountability was never really on the table (ibid). The Equity and Reconciliation Commission (ECR), created by King 
Mohammed VI in 2004, was meant primarily to address the torture and atrocities committed during the Years of Lead (roughly 1960s-1980). Around the ECR's hearings, victims, victims' families, and activists gathered in great numbers, employing a diversity of contentious repertoires in order to coax the state toward justice. In this vein, "Moroccan activists initiated a series of sit-ins that gathered human rights activists and victims carrying candles and roses, brandishing portraits of missing people or wearing them around their necks" (38). These gatherings served multiple purposes: as spaces for the expression of contentious claims, as "commemorative, since they [were] a means to establish the truth and prevent the memory of state crimes from adding away"; and "as emotional," with actors returning to "the place of their sufferings" (38).

According to Vairel:

"These contentious gatherings are symbolical markings of space; they are ways of mapping the Moroccan dishonor of past state violence. The Moroccan Forum for Truth and Justice (FVJ) mobilizations and those of its allies and rivals, the Moroccan Association for Human Rights (AMDH) and the Moroccan Organization for Human Rights (OMDH), opened numerous and virulent debates through which the idea of a truth and reconciliation commission was imposed. In other words, their actions imposed the necessity of a settlement that would be not only a technical and financial one but one which also derives legitimacy from the way it conforms to international standards" (38).

While remarkable from a case-study of contention standpoint, the employment of (mostly) peaceful, multifaceted and diverse repertoires of contention ended up aiding the regime in shifting the focus of the contestation from "the involvement of political actors and the economic beneficiaries of the coercive policies, for example in cases of expropriation of victims or theft of properties" toward a less impactful - to the regime emphasis on publicly "unveiling the truth" and reconciling with a traumatic past (Vairel 
2008, 239). This was a consequence of crippling restrictions on exactly what could be presented as truth - neither Hassan II's culpability nor the culpability of "former torturers in the current regime" could be mentioned (ibid; HRW 2005). As a result, the case of the Year of Lead victims in Morocco, "clearly demonstrate[s] the importance of threats in protesters' calculations regarding the start of mobilizations", in that the regime was able to leverage its coercive threat to partially dictate the direction of contention (Vairel 2011, 42). In sum, the level of peaceful contentious interaction with the state was significant when compared with a closed authoritarian regime such as Tunisia, but nevertheless significantly constrained.

\subsubsection{Another Seam - socioeconomic stress and depoliticized elections}

Mohammed VI's partial-liberalization strategy necessitated a restrained use of coercion in order to avoid tarnishing his sacred, traditionally-derived status as Morocco's protector, as well as to conform to his perception as being above the political fray.

Therefore, his technocratic regime relied in part upon what S.M. Lipset called "performance legitimacy" - the legitimacy a government derives from providing the material goods citizens expect and/or desire (1959). Hence, the eruption in 2007 of "violent protests in the town of Sefrou over a 30 percent hike in the cost of bread" served as "a reminder of how volatile social peace and public order" could be when any of the key sources of legitimacy began to be questioned (Boukhars 2010, 53). Tellingly, "the government's decision to quickly roll back this hike [was] a clear testament to its understanding of the mood of the country and the fear of a repeat of the 1981 [riots in Casablanca], which claimed the lives of hundreds of people" (ibid). Susan Slyomovics (2009) describes the progression of events: 
"Initially, demonstrations were spearheaded by women's organizations from nearby Bhalil to protest the rising costs of foodstuffs; events turned violent once the forces of the provincial governor (not the municipality) entered the scene. What happened appears to have been visually documented almost as it transpired, through videos and photographs, some made with cell phones in Sefrou and posted on weblogs and YouTube. These were images that served to contest official representations even at the level of terminology: was this the chaotic urban crowd rioting over bread or a people's revolt, termed an intifada (uprising) in postings?" (322)

The economically-motivated riots in Sefrou mirrored those in 2008 in Tunisia in three primary ways: (1) they both provoked swift responses from the national government due to fears of a recurrence of the bread riots of the 1980s (1981 in Morocco; 1984 in Tunisia); (2) they employed many of the new(er) repertoires of contention that would be integral in 2010-11 - e.g. blogs, cell phones, etc.; and (3) they failed to spread beyond the immediate city/region and were successfully demobilized by regime actions. The difference, however, was that Ben Ali employed severe repression and token, rhetorical reforms, while Mohammed VI strongly favored economic concessions over repression his complete roll-back of the price hike illustrates a key divergence in regime strategies between Morocco and Tunisia.

\subsubsection{Contentious Politics and Regime Continuity: \#Feb 20 (2011)}

In a deft display of political maneuvering reminiscent of the 1999 transition, King Mohammed VI managed to weather the 2011 Arab Uprising in Morocco by relying upon the same authoritarian logic that had sustained the monarchy since his father's time and which he had honed throughout his own reign. The Moroccan regime employed a combination of liberalizing and economic concessions that served to steer contention away from the Royal Palace and toward acquiescing to the less traumatic outcome of conservative partial-liberalizing reforms (Maghraoui 2011; Lynch 2012). Indeed, similar 
to 1999 , any claims that the regime's reforms might have been "an indication of the monarchy's willingness to bow to democratic demand, and, as such [serve as] an example for the Arab world to emulate" were dashed once it became apparent that "the monarchy in fact ceded none of its essential prerogatives, thus preserving its control of the Moroccan political scene intact" (Maghraoui 2011, 679). Indeed, rather than a shining example of democratic reform in the region, the response of Mohammed VI to the Arab Spring served instead as a how-to guide on authoritarian persistence for similarly situated regimes (such as Jordan) (Lynch 2012, 142-43).

In order to determine what factors contributed to Morocco surviving the Arab Spring, we can again turn to Angrist's (2013) two interactive "phenomena" that "must unfold $[\ldots]$ for a popular movement to oust an incumbent regime": (a) pervasive and widespread protests; and (b) a failure on the part of the regime to appropriately "counter, respond, and repress" the mobilization (550). With regards to the former, according to Roko's (2012) field interviews of activists:

"[One interviewee] estimated the... number of protesters each weekend to hover around 300,000, but he believed that the numbers had to reach the millions for the regime to yield further concessions (Interview 2011). The largest single rally in the spring had probably never exceeded 80,000 people (Nizar, interview 2011). Obviously, the scale of this protest movement never equaled that of the mass demonstrations in Tunisia" (106).

Furthermore, with regards to the second phenomenon, while there were initial bouts of police abuse and state-sanctioned violence, the monarchy was swift to propose "a preemptive reform initiative" that served to dis-embolden society - effectively demobilizing the Arab Spring in Morocco (Lynch 2012, 142). The state's predisposition 
for choosing concessions over coercion was immediately apparent in their response to the protests:

"Until the mass protests started to stir up the popular districts in the late spring of 2011, the Moroccan state did not respond with much repression. The Makhzen was careful to strike only when the media was absent, and repression was harsher in more remote locations. Nevertheless, the Moroccan regime was surely worried about protests from the start, and turned to its preferred methods of co-optation and pre-emption to take the steam out of this emerging political force" (Roko 2012, 109).

Significantly, the contentious framing that characterized the February $20^{\text {th }}$ movement differed substantially from that of Tunisia's Jasmine Revolution in that the protesters never explicitly turned against the head of the regime:

"Moroccans... [launched] a series of protests modeled explicitly on the Tunisian and Egyptian examples. They had to proceed cautiously in a system where the monarchy personified the state and enjoyed considerable popular support despite the usual catalogue of political and economic grievances afflicting the country. They carefully balanced protestations of loyalty to the king with their complaints about corruption, the cost of living, and the absence of opportunity" (Lynch 2012, 114; emphasis added).

Thus, while the protests turned out "a surprisingly large number of people across the country", who "sustained weekly protests that grew in size and representation as a wide range of political trends joined in", the largely non-violent protests "focused tightly on calls for democracy, accountability, and the rule of law, and carefully avoided direct challenges to the king" (ibid). Nevertheless, there was a moment when "Morocco might well have tipped in the direction of massive mobilization", following the aftermath of a 
terrorist attack on April $28^{\text {th }}$ that "killed over a dozen people" in Marrakesh (141). As a result of the attacks, "security forces began to take a much harder line toward protesters, with increasing reports of police abuse", that "began to radicalize some of the activists' demands" (142). It was at this point that the king "called for a snap referendum on a sweeping set of constitutional reforms, which maintained the core powers of the monarchy but did offer some real concessions to more representative and participatory government" (ibid).

Goldstone and Tilly (2001) provide that "[b]oth concessions to alleviate current threats, and repressive threats to respond to (and deter) protest actions are costly, but the costs will differ greatly depending on the size of the group, the nature of the current threats, and the costs of repression" (186). Hence, we can deduce- due to the need to preserve the prestige of the monarchy as well as the fact that the example of Ben Ali's ouster loomed large over the MENA - that the Moroccan regime believed repression to be too costly to rely upon entirely (Lynch 2012). Furthermore, as we have seen, the 'Liberalization Game' in Morocco - as it had been reiterated over time - had instilled in all parties concerned a contentious framing that lent (some) credibility to the prospects of political reform (Vairel 2011). Thus, the regime's immediate reactions to the protests were governed by a "constant cost line" that favored "Concessions" $(T c)$ over "Repression" $(\operatorname{Tr})$. Based on the analysis above, we can assume that line $A B$ - i.e. the level at which some combination $(T c, T r)$ would be sufficient to discourage protests - did indeed shift to the right in response to harsh coercion (to some degree), but, due to the 
overall more measured approach of the Moroccan regime, $A^{\prime} B^{\prime}-$ the new $A B$ frontier was not placed so far as to go beyond the constant cost line of the regime.

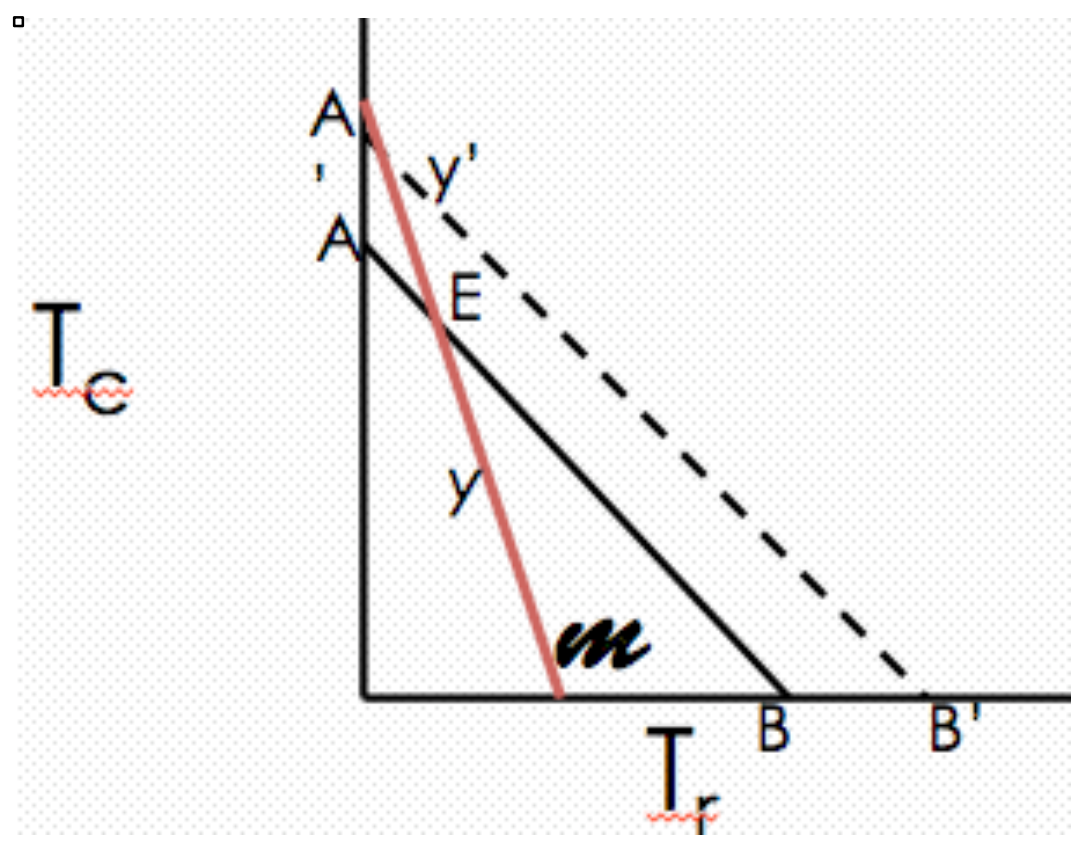

[Figure 7.1. The Arab Spring in Morocco]

Hence, a higher level of policy and economic concessions than usual in Morocco was necessary to cause demobilization, but it was still within Mohammad VI's means to successfully do so without threatening his place. The reason for this, from a regimeinstitutional standpoint, was that the monarchy was never targeted by the regime and therefore was able to serve up constitutional and parliamentary 'sacrificial lambs', the sacrifice of which would not seriously threaten the monarchy's real foundations of power. Society acquiesced to the regime's tactics because it had not yet become emboldened. This meant that society still believed that - from a strategic point of view, based upon its interactive, historical experience with regime liberalization - entering into a broadened dictatorship was preferable to risking insurrection, repression, or regime 
change. Accordingly, society as a whole was never sufficiently galvanized and united against the regime, as it was in Tunisia and Egypt; and therefore the regime was able to bring protesters back from the brink [see: figure 7.1].

\subsection{Institutional Determinates of Regime Flexibility in Morocco}

\subsubsection{Overview}

Morocco is indisputably an authoritarian state (Schedler 2002; Diamond 2002). However, since Mohamed VI came to power in 1999, Morocco has "emerged as the most liberal Arab state, where basic freedoms are protected and nurtured, though not unconditionally" (Boukhars 2010, 41). This orientation mirrors the regime's preference for concessions and co-optation over repression - i.e. the mitigation of current threat through coercive restraint - affecting the level of repressive threat - and a history of credible partial-liberalization. This is because, for the Moroccan monarch policy concessions - e.g. economic and political liberalization - and co-optation are "cheaper" relative to coercion than they are for hegemonic party regimes (Albrecht and Wegner 2006). This has to do with the sources of monarchical legitimacy and the king's relationship with Parliament. With regards to the former the monarchy is premised upon the "doctrine of dual authority [...] whereby the monarch claims an inherent hereditary right to the spiritual and temporal" as both head of state and the head of Islam in Morocco (Boukhars 2010, 66). As explained by Abdeslam Maghraoui (2001), “This dual political system allows the Moroccan king to claim constitutional legitimacy, while preserving his traditional authority based on a unique combination of the Sunni notion of bay'a [allegiance] and the Shi'i notion of the imam" (13). All of this creates a dilemma 
for protesters: "the ambiguous governance structures of the Monarchy, the superficially modern institutions of Parliament and courts, and the Makhzen that permeates the entire structure, make for a difficult protest target” (Roko 2012, 118). The monarchy's 'strategic mix' - hinged on the ability of the king to simultaneously permit contestatory politics while distancing himself from it - served to orient society toward conservativism when the Arab Spring bled into Morocco. At least four factors influenced the turn of events in Morocco in 2011: (1) the past experience of tangible political change (albeit never toward democracy); (2) the presence of sanctioned contentious spaces for the expression of dissent; (3) the depoliticization and/or moderation of political opposition; and (4) the lack of pervasive, brutal repression (after 1999). Combined these factors meant that society never became emboldened, directly challenging the king's right to rule.

\subsection{2. 'Lynchpin' Contention and Contestation}

The king is therefore able to leverage his constitutional, traditional, and religious sources of power "to nourish an image of [being] an arbiter above politics - supposedly neutral vis-à-vis any group of society", the consequence of which is that "[t]he monarchy as the ultimate Moroccan power centre cannot be contested by parliamentary government; in turn, for those actors who accept the rules of the game, there is a sphere for articulation and political contest, namely parliament and elections" (Albrecht and Wegner 2006, 129). What this means in practice is that, according to Boukhars,

"In Morocco, the parliament [is] not set up as an independent institution to make laws and ensure government accountability. Its main function has always been to play an auxiliary role in supporting the monarch, legitimizing his decisions, and protecting him against criticism and backlash resulting from unpopular social and economic policies" $(2010,71)$. 
Accordingly, the monarch is freer both to allow elements of the opposition into parliament (e.g. Islamists), and to permit a "tamed style of protest articulation" by employing a strategy of 'divide rule' (Albrecht and Wegner 2006, 129; 130-35; LustOkar and Jamal 2002). The divide and rule tactic can be described as the institutional rules and policies of the monarch which promote a highly pluralistic political arena wherein political parties vie for access to the state patrimonial apparatus (Lust-Okar and Jamal 2002; Boukhars 2010). As summarized by Cavatorta (2009), this tactic works as follows:

"[By playing] one sector of the opposition against the other, depending on the issue, [the monarch] is thereby able to remain the sole and unaccountable arbiter of the political system by carefully managing repression and co-optation. For the international community, this is quite a positive outcome as stability is guaranteed; for the secular, liberal opposition, a degree of influence is also guaranteed as long as it ultimately rallies to the regime; and for Islamists, the current situation is akin to the continuation of colonial rule by an indigenous elite, although some sectors of institutionalized Islamism benefit from co-optation" (151).

By permitting some pluralism and mobilized contention, the divide and rule tactic essentially makes the 'Liberalization Game' credible process for effecting change. Essentially, ceteris paribus, actors can be assumed to possess strategic preferences in line with Przeworski's (1991) formulation - i.e. broadened dictatorship becomes the expected equilibrium. Through the existence of contestatory institutions in Morocco the "possibility of a gradual reform of the regime is perceived to exist, domestically and internationally... and alternative means of practicing and institutionalizing new forms of political governance are already being considered and routinized to some degree, processes of regime change are articulated in more structured and predictable patterns that is, reform of institutions" (Volpi, 2012: 983; emphasis added). Accordingly, co- 
optation in such regimes is less alienating than in patrimonial regimes where there are fewer channels for state-sanctioned political dissent outside of the leader's party. The absence of the kinds of (severe) alienating institutions and regime strategies that pushed Tunisians out of the political sphere - eventually isolating the regime - has served to keep Moroccan society relatively conservative in its orientation. The historical example of tangible political reform, the lack of a single political institution, person, or party to fully blame for social ailments, and coercive restraint have simultaneously kept equilibrium-threatening social mobilizations at bay while preserving the centers of authoritarian power in Morocco.

\subsubsection{Opposition Politics and Depoliticization in Morocco}

In Morocco the political opposition "serves a channeling and moderating function" - dissent is channeled through state-controlled institutions, while managed pluralism is used "as a means of turning radical resistance into controlled opposition" (Boukhars 2010, 21). The fact that Morocco's elections are generally acknowledged to be "free and fair" does not mean that they are not 'controlled' (McFaul and Wittes 2008). For instance, electoral rules are explicitly crafted so as to engender pluralistic and contestatory representation in parliament - thus ensuring that the king remains invaluable in his role as grand arbiter (Lust-Okar and Jamal 2004). Once in office, the monarchy "gives political parties limited legislative or executive powers that bear no relation to their representation of the popular will as revealed in elections" (Jandari 2012, 14-15). Consequently, while there are over thirty political parties in Morocco, most "are not more than 'political shops' opening for business during election season, shutting their doors until next time (19). 
Contrary to the intermediary role of political parties in liberal democratic systems - e.g. aggregating popular interests, organizing political society, and informing the public on relevant policy issues - parties in Morocco are expected to play "an auxiliary role in supporting the monarch, legitimizing his decisions, and protecting him against criticism and backlash resulting from unpopular social and economic policies" (Jandari 2012, 5; Boukhars 2010,71). Parties are legally restricted - under the 2005 law on political parties - from "constructing and mobilizing a distinctive political identity rooted in religion, region, language, or race" (Boukhars 2010, 79). The Constitution "plainly locates" sovereignty with the king, relegating the government and parliament to "managing social and economic affairs" (Maghraoui 2002,30). Moreover, given what little room the law leaves for policy-oriented differentiation, upon entering into parliament, political parties effectively "shelve their programs and platforms" in favor of acting as "the mere executor of the policies and broad orientations set by the monarch" (Boukhars 2010, 79). Parties that fail to fall into line are "rotated" out of favor, which effectively prevents "the emergence of any one personality or collective of actors as independent centers of competing power" (82). Contrary to Tunisia - and to a somewhat lesser extend Egypt and Algeria - access to parliament in Morocco is more flexible and less narrowly constrained (Volpi 2012). Access comes through nominal political pluralism, rather than being funneled through a hegemonic party; those who fall out of favor can more easily regain it (ibid; Blaydes 2011).

Political parties have thus largely come to accept this state of affairs and have "virtually disengaged from the political sphere" (Maghraoui 2002, 30). The political "division of labor" leaves economic policy in the hands of a king-appointed technocratic 
elite - amounting to a "shadow government that operates alongside and often against the official cabinet" - while parliamentarians are left to scrounge over patrimonial allocations (30). Society is not ignorant of the democratic façade that parliament represents; yet they have not tended to express dissatisfaction by turning to Islamist parties. The liberal orientation of Moroccan society keeps many seculars in line - for fear of a Algeria-like Islamist electoral coup (Volpi 2012). In the 2007 election, for instance, "Moroccans did not sweep Islamists into power", rather, "[m]ost of those dissatisfied with the status quo chose other options - including not voting or spoiling their ballots - to express their displeasure" (McFaul and Wittes, 20). This is significant as a contentious repertoire, given the difficulty of registering to vote in Morocco, and therefore the fact that "[a] sizable chunk of the populace would take the time and trouble to register, go to the polls, and then deliberately spoil their ballots represents a major act of protest" (29). According to Mcfaul and Wittes, the widespread vote spoilage in the 2007 elections represented not just a referendum on the failure of political opposition in Morocco, but also a deep-seated resentment toward the political system the palace had engendered (29).

Nevertheless, while voter turnout in 2007 was considered low, and vote spoilage was endemic - citizens did vote genuinely. In a testament to the depoliticized nature of politics in Morocco, citizens who voted tended to do so on purely utilitarian grounds:

"...majorities flocked to the polls in places where they believed their vote might matter. Moroccans have a utilitarian conception of politics. This is the reason why the Moroccan voter is often referred to in the kingdom as khobzite, a word derived from khboz (bread). A khobzite is somebody who has no political conviction and who follows his/her pure self-interest... When Moroccans see a potential benefit in voting, they do so in great numbers, as was amply 
demonstrated in Rehammna. In this small rural and very poor district in southern Morocco, Fouad El-Himma, a close associate of the King, won a clean sweep. Seventy-two percent of the electorate voted for him and his two handpicked allies" (Boukhars 2010, 39).

In the particular district cited by Boukhars, voters chose El-Himma because "they believed he would be able to deliver on his promises and improve their miserable lives" (ibid). As an exercise in competitive clientelism, elections in such districts can be understood as serving the authoritarian logic of the monarchy - hence, in rural areas and throughout the Sahara region, voting tends to follow "tribal lines", "feudal lines", or both (ibid). Because socioeconomic life in Morocco so often revolves around connections, social networks, and quid pro quo relationships, the electoral system provides many disadvantaged citizens who are otherwise bereft a sliver of leverage with which to bargain: i.e. their vote (ibid). By participating in elections they can thereby gain access to the otherwise elite-dominated socioeconomic realm - breaking them into the "networking game that is essential to get a job and circumvent the many rigid bureaucratic hurdles and delays" (41). Thus, the depoliticization of political parties as well as elections - i.e. the separation of socioeconomic policy from other policy realms - created a system where wide spread corruption within the government could plausibly be treated as an issue of "public management" rather than "political accountability" (Maghraoui 2002, 30). Thus, on one hand, liberalization and electoral pluralism served as sources of political legitimacy for the king, while on the other hand, they served to establish the rules by which utilitarian performance legitimacy would be judged (e.g. Lipset 1959). 


\subsubsection{Moderation and Exclusion of Islamic Contention in Comparative Perspective}

According to Vairel (2011),

"If one takes into account actors' claims and self-definitions (PJD defines its stance as 'a critical through constructive opposition' while Justice and Spirituality claims to be "the sole and true opposition in Morocco"), the distinction between radicals and moderates vis-à-vis Islamism appears to be less an analytical tool than a by product of contests around boundaries, classifying operations, and labeling inside movements and during confrontations with regimes" (34-5).

Essentially, the dichotomy lies within non-violent repertoires of contention - the PJD opts to enter into electoral politics and therefore to self-moderate, while Justice and Spirituality "pursues a popular though self-limiting strategy of mobilization" (34-5). The opportunity here for institutional comparison is instructive. Contrary to Morocco, the hegemonic party regimes in Tunisia and Egypt ostracized and repressed Islamists (with very little prejudice) from fully-legitimate participation in the 'electoral/legal politics frame' (Angrist 1999a; 2013; Albrecht and Wegner 2006; Vairel 2011). The effects of doing so were not necessarily radicalizing, however. As Angrist (2013) and Cavatora and Merone (2013) point out, in Tunisia repression served to moderate, not radicalize, Ennahda; and in Egypt, the MB candidates were periodically allowed to participate as independents in 2008, while the MB off-shoot Hizb al-Wasat (Center Party) selfmoderated and was still "refused official registration by the Parliament Political Parties Committee four times" (Vairel 2011, 35). Moreover, al-Wasat's cofounder Abu al-“Ala' Madi became "one of the most prominent Islamist members" within the Egyptian Kifaya protest movement (Vairel 2011,35).

What this shows is that exclusion from electoral politics does not necessarily dictate whether or not a party radicalizes - insofar as 'radicalizes' refers to resorting to 
violence. However, there is still support for the claim that inclusion serves as a moderating force vis-à-vis opposition to the regime. The causal mechanism in this case is quite clear: electoral inclusion necessarily implies becoming more moderate and less oppositional, otherwise the strategic cons would outweigh the pros for the regime, and incumbent elites would opt for a more exclusionary policy. In illustrative cases, such as Egypt in 2008 and Algeria in 1990-1, where Islamist groups were allowed to participate in elections within a hegemonic party state, incumbents quickly reversed their decision once it became clear, through large electoral yields, that Islamists posed too much of a threat to the status quo - i.e. dominant party hegemony within parliament (Volpi 2012). Morocco (and Jordan), on the other hand, could afford to allow Islamists to participate in electoral politics due both to an electoral system that ensured no party could gain too large a seat-share, as well as the monarchy's ability to moderate parliamentary politics through arbitration and 'setting the rules of inclusion' (Albrecht and Wegner 2006, Vairel 2011, Jamal and Lust-Okar 2006). Consequently, the inclusion of the PJD in Moroccan elections served to simultaneously moderate that party's oppositional fervor while also tainting its Islamic and anti-corruption credibility (Maghraoui 2002). The excluded Justice and Spirituality, on the other hand, was,

"weakened by the king's strategic backing of social programs... [and] politically isolated; apart from having been able to mobilize support in opposition to the 1991 war in Iraq, or on behalf of the Palestinians, or against women's rights, it has shown no real political potential" (Maghraoui 2002, 31).

The handling of Islamist politics in Morocco illustrates the regime's ability to simultaneously pursue a more flexible, inclusive strategy relative to those of Tunisia or Egypt, while nevertheless remaining authoritarian in character. The Islamist opposition 
is given an institutional avenue for expressing dissent that ultimately serves to broaden, but never jeopardize, the dictatorship.

\subsubsection{Coercive Flexibility}

The pattern of revolution throughout the Arab world in 2010-11 began with protests that were then brutally repressed, thereby sparking widespread outrage and precipitous social mobilization (Lynch 2012; Angrist 2013). Such it was that protests overwhelmed the usual police-enforced repressive apparatus and warranted the involvement of the military - leading to regime transition (e.g. Tunisia, Egypt) and insurrection (e.g. Libya and Syria). Yet, the Arab Spring experience in Morocco did not reflect this revolutionary pattern - not in the scope of protests nor in the regime's response. This had to do in part with the historical role of repression in Morocco:

“The fact that the Makhzen's coercive apparatus appears less intrusive in people's lives than Ben Ali's security forces were to Tunisians, and that overt repression is rarely seen in Morocco, also prevented Moroccans from acquiring the same urgent need to change political conditions in the country. In spite of towering economic and social problems, the sense of injustice has been less heightened and people have felt less desperate to act" (Roko 2012, 108).

Moreover, "[d]ue to the less repressive circumstances in Morocco, oppositional

discourses could be nurtured more openly" (ibid). As noted above, coercion and oppression was certainly an omnipresent fact of Moroccan political life:

“...high levels of repression made clear that any violent attempt to overcome power would lead to a harsh response and a bloody failure. The violence of the incumbent regimes has been the way to make implausible a forceful overthrow, whether by Socialists or Islamists, of the Moroccan monarchy or the Egyptian regimes of Sadat and Mubarak. In that sense the coercive apparatuses of both countries have been efficient, leading to trajectories of moderation of the regime's opponents" (Vairel 2011,36). 
However, during the reign of Muhammad VI, coercion was doled out much more strategically and sparingly - the mere capacity and threat of it became enough to temper any potential opposition (ibid). The monarchy was able to leverage coercive capacity to push for controlled liberalization. While Egypt and Tunisia also introduced a measure of pluralism and liberalizing reforms, the regimes lacked the capability of the lynch pin monarchies to divert contentious claims away from the regime, thus requiring a heavier hand (Volpi 2012; Bellin 2004; 2012).

The reason the Moroccan regime was able to manage such a flexible and less overtly dominating strategy had to do with all of the previous factors outlined above. The partial-liberalizing track record of the regime, the presence of limited spaces for mobilization, and the depoliticized and moderate orientation of politics and civil society all served to incentivize society to 'play within the rules' (Vairel 2010, Volpi 2012, Angrist 2013). The fact that all of these elements of the Moroccan authoritarian system were held in place by the monarch - himself ostensibly beyond political accountability meant that even when society did mobilize, the object of dissent became a subject of confusion and dissonance. If the king ever actually employed coercion on the level of Tunisia or Egypt - at least within the confines of the newly-liberalized space engendered by Muhammad VI - his carefully balanced sources of legitimacy would be placed in serious danger. As such, coercive restraint was not only a 'perk' of the lynch pin regime type, but a requisite. Thus, the monarchy's (relatively) restrained deployment of coercion, mixed with fairly prompt policy concessions, were enough to take the wind out of the inchoate February $20^{\text {th }}$ movement's sails. 


\subsection{Conclusion: Institutions and contentious framing in Morocco}

In the game theoretic terms outlined in chapter three, Moroccan society never veered significantly from the preference ordering hypothesized by Przeworksi (1991). By remaining what I have termed conservative, society continued to have sufficient faith in liberalization, while also being sufficiently cowed by the state's coercive capacity without becoming outraged by it. This resulted in society's belief in 2011 that the expected outcome of a broadened dictatorship was preferable to risking insurrection and regime repression. This faith on the part of society was based on the historical experiences of past iterations of the 'Liberalization Game' in Morocco during the reign of Mohammed VI (e.g. 1999, 2004-2008). The dynamics of contention and reform over time led to a contentious framing within society deeming current threat-even after an initial increase in repressive threat by the regime in 2011 - as insufficient to risk the high levels of mobilization experienced in Tunisia and elsewhere. Accordingly, the orientation of society - both prior to and during the February $20^{\text {th }}$ movement - cannot be explained without reference to the institutions that affected contentious framing. Framing dictated the specific nature of the contentious claims made by the movement's participants - i.e. consciously excluding the king as an object of protest. Also historically engendered and informed, the regime's quickness to resort to concessions over repression quickly deescalated the situation. In this way, the depoliticizing, moderating, and patrimonial institutions of the regime - premised upon the unique place of the monarchy within the political system and society - permitted for a relatively higher degree of flexibility than regimes where mobilization quickly escalated out of control. 
CHAPTER 8: Model Summary, Limitations, and Conclusions

\subsection{Modeling Institutional Determinants of Contentious Framing}

\begin{tabular}{|c|c|c|c|c|c|}
\hline $\begin{array}{l}\text { Parties in } \\
\text { parliament }\end{array}$ & $\begin{array}{l}\text { Sources of } \\
\text { legitimacy }\end{array}$ & $\begin{array}{l}\text { Opposition } \\
\text { management }\end{array}$ & $\begin{array}{l}\text { Regime } \\
\text { strategy }\end{array}$ & $\begin{array}{l}\text { Dynamics of } \\
\text { contention } \\
\text { (over time) }\end{array}$ & $\begin{array}{l}\text { Dynamics of } \\
\text { contention } \\
\text { (acute } \\
\text { episodes) }\end{array}$ \\
\hline $\begin{array}{l}\text { Pluralistic/ } \\
\text { high } \\
\text { contestation }\end{array}$ & $\begin{array}{l}\text { Outside } \\
\text { parliament } \\
\text { and } \\
\text { "power } \\
\text { broker" } \\
\text { status }\end{array}$ & $\begin{array}{l}\text { 'Divide and rule'; } \\
\text { parliamentary } \\
\text { 'cycling' }\end{array}$ & $\begin{array}{l}\text { Concessions } \\
>\text { coercion } \\
\text { (flexible) }\end{array}$ & $\begin{array}{l}\text { Allowed-but- } \\
\text { constrained } \\
\text { dissent; } \\
\text { depoliticization }\end{array}$ & $\begin{array}{l}\text { Society is } \\
\text { conservative; } \\
\text { regime } \\
\text { restraint; } \\
\text { trends } \\
\text { toward } \\
\text { stabilization }\end{array}$ \\
\hline $\begin{array}{l}\text { Hegemonic/ } \\
\text { low } \\
\text { contestation }\end{array}$ & $\begin{array}{l}\text { Dominance } \\
\text { of } \\
\text { parliament }\end{array}$ & $\begin{array}{l}\text { 'Winners and } \\
\text { losers'(exclusivity); } \\
\text { competition w/in } \\
\text { hegemonic party }\end{array}$ & $\begin{array}{l}\text { Coercion }> \\
\text { concessions } \\
\text { (inflexible) }\end{array}$ & $\begin{array}{l}\text { Alienation; } \\
\text { 'under the } \\
\text { radar' } \\
\text { mobilization }\end{array}$ & $\begin{array}{l}\text { Society } \\
\text { emboldened; } \\
\text { regime } \\
\text { overreaction } \\
\text {; possible } \\
\text { destabilizati } \\
\text { on }\end{array}$ \\
\hline
\end{tabular}

[Table 8.1. Patterns of Contention in Tunisia and Morocco]

Now is a good time to revisit our question from chapter one: why do institutions matter?

If Kuran (1995) was right, authoritarian regimes inherently stifle just the kinds of public expressions of dissent that analysts require in order to be able to recognize and predict looming instability. Focusing on institutions, then, simply reinforces the basic unit-ofanalysis - 'forest for the trees' - misapprehensions that led to previous revolutionary surprises. However, this presents researchers with quite the dilemma. Kuran's methodological suggestions - interpretation and 'thick' description - necessarily require the researcher to know that they are investigating a state where preferences are likely to be falsified. Thus, one still has to have some basis upon which to be able to recognize which institutions are more or less conducive to forcing dissent 'under the radar'. 
Therefore institutions matter because some states appear to be better than others at allowing some publicized contention without ceding control of the political sphere. Dominating, inflexible regimes - such as hegemonic party regimes (e.g. Tunisia) - are those in which dissent is stifled and elite and non-elite actors are more likely to be too alienated and fearful to express themselves. These regimes may appear to be stable, but that stability can often be an illusion. The particular institutional arrangements of the state may telegraph that this is the case.

Table 8.1 illustrates the general model derived from the theoretical and case-study chapters. In hegemonic party regimes, the president's 'legitimacy crisis' necessitates a dominating, exclusionary control over parliament. This leads to the bifurcation of 'winners' and 'losers' who either benefit or are left out of very tightly controlled policies of economic and political liberalization. This is reflected by the 'Liberalization Game', wherein 'robust' coercive capacity incentivizes the regime to broaden its support through narrow political opening because the opposition will be cowed into entering into the 'broadened dictatorship' for fear of repression. What analyses such as Przeworski (1991) and Blaydes and Lo (2012) leave out is that this game is repeated - as such elite and nonelite actors know, based on past iterations, what to expect out of future iterations. Flexible regimes provide enough examples of genuine liberalization and political openings to keep most participants invested in the political system. As such, current threat (over the long run) and repressive threat (during acute contentious episodes) are kept low enough that society remains conservative. Hence, when protests do break out, as they inevitably will from time to time in (partially) closed regimes, demobilization in return for state concessions is preferred to insurrection. 
Thus, the game theoretic model of the repeated Liberalization Game begins with a move by the regime - either repression /concessions in response to mobilization or stay/open in response to regime crises or transitions. Society or civil society enters the game with a particular preference ordering - either conservative or emboldened. For this narrative, assume that society is conservative. The game will play out with the regime choosing to offer concessions, demobilization will occur and the regime will open up. However, if repeated plays of the game result in repression being used excessively, or political opening/ concessions lacking credibility over time, current threat will increase and society will be less willing to demobilize. When repressive threat and current threat are employed in response to mobilization, society can shift from playing the conservative game to entering the emboldened game. Going back to the Threat (opportunity) model, this is the result of the inflexible strategic 'mix' of the regime that favors repression over concessions.

$\square$

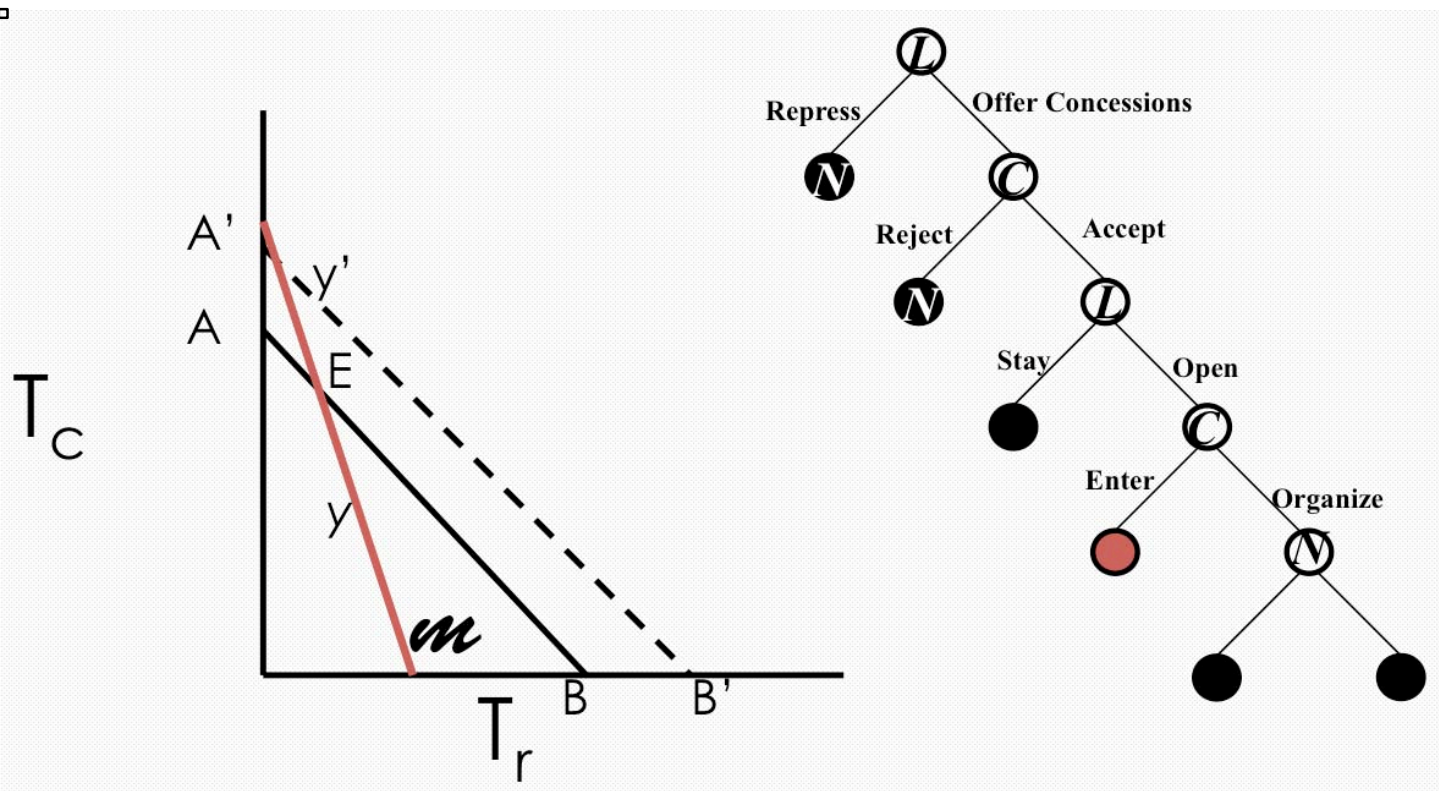

[Figure 8.1: Concessions are favored over repression; society is conservative] 


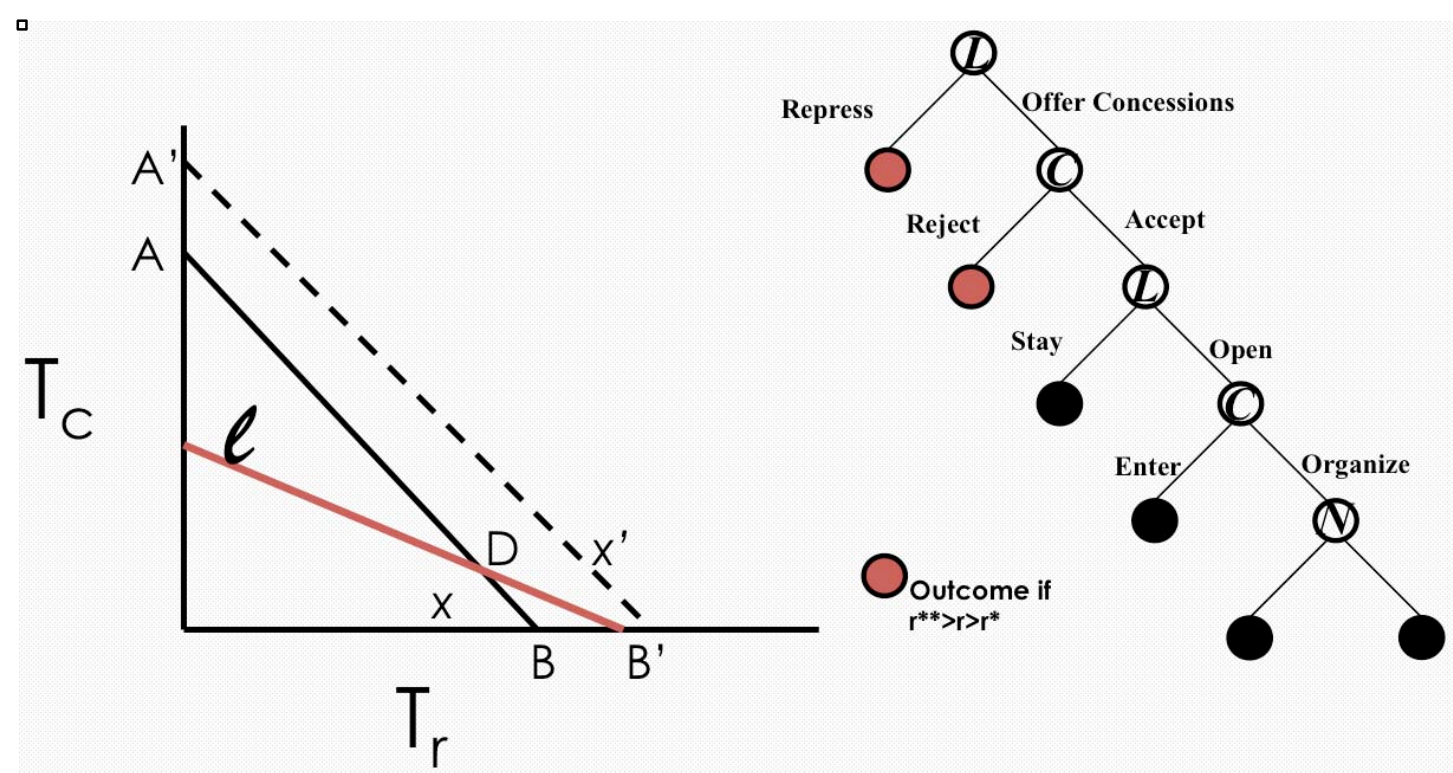

[Figure 8.2: Repression is favored; society becomes emboldened (red node is expected outcome)]

Figure 8.1 shows the typical scenario - exemplified by Morocco - where the (acutely employed) strategic mix $\mathrm{Tc}>\mathrm{Tr}$ keeps society conservative and therefore the Liberalization Game plays out much as Przeworski theorized. Figure 8.2, however, shows the strategic outcome of protests were the strategic mix $\operatorname{Tr}>\mathrm{Tc}$ has emboldened society, insurrection or a narrowed dictatorship is likely to result. These figures show the play of events as they might play out in a particular acute contentious episode. The novel point here is that society remembers past plays of the conservative Liberalization Game, and may come into a new iteration either already emboldened - due to mounting current threat - or predisposed to becoming emboldened. In Tunisia, protests began larger than normal, but isolated. They became widespread due to regime brutality and and unwillingness to view Ben Ali's eventual offer of concessions as credible. Consequently, the events of the Jasmine Revolution reflected a confluence of historical and acute state- 
society interactions. The state's response largely conformed to its tried and true predisposition for violent political sphere dominance, the difference from 1989 and 2008 was that society's preferences shifted vis-à-vis the persistence of the regime based in part upon historical iterations of the Liberalization Game.

\subsection{Omissions and Limitations}

Due to space limitations, this study will focus primarily on domestic institutional, structural, and societal variables. These variables are not discounted, but simply bracketed-off for future incorporation and analysis. Tunisia's international experience is reflective of Morocco's and other MENA states'. The role of globalization and the international community has been largely deleterious to democratization prospects in Tunisia. The effects of IMF-induced neo-liberal restructuring are discussed in detail by Hess (2013), Lynch (2012), and others. Some of these negative effects included incentivizing crony capitalism and justifying the regime domestically and internationally along lines of performance legitimacy and co-operation with counter-terrorism operations. On the other hand, external factors - e.g. WikiLeaks - served to expose excesses of the regime - especially those of Ben Ali's wife's luxurious lifestyle. Also, the penetration of international media into the lives of ordinary Tunisians served to inform citizens about alternative modes of expression and ideology - e.g. religion. Brownlee (2007) focused on the international legitimation incentives behind Ben Ali's nominal liberalizing and democratizing reforms.

In External-Internal Linkages in Democratization: Developing an Open Model of Democratic Change (2002), Hakan Yilmaz argues, that "the decision of the authoritarian rulers to launch democratic reforms [is] determined by a comparison of their evaluations 
of the external costs of suppression and the internal costs of toleration" (79).

Accordingly, with respect to MENA authoritarianism, Brownlee (2009) posits that "[i]n Syria, Tunisia, Iraq, and Libya independence from foreign pressures for restraint left the regimes free to suppress domestic insurgencies" (Brownlee, 58). Brownlee explains that the relative immunity with which Bourguiba and Ben Ali were able to employ violent coercion was the result of Tunisia lacking any single, irreplaceable source of international financial support. Tunisia, during the Bourguiba period, largely relied upon a mixture of aid from the USSR, Europe - especially France - and the broader Arab world. This meant that aid was spread out and therefore no one state had any significant leverage on the regime's political actions. Further, in the 1990s and 2000s, when Ben Ali embarked on widespread suppression of Islamists, his interests happened to be compatible with American and western foreign policy concerns - namely the threat of radical Islamist terrorism. Thus, internal/external linkages primarily served to reify the mechanisms and strategies that had historically bolstered the regime, while at the same time creating a more awakened and technologically connected social sphere.

\subsection{Flexibility and the Arab Spring}

We can revisit the 'continuum of contestation' from Chapter Five to assess how the above analysis relates to other MENA regimes. Jordan conforms largely to Morocco's experience - in fact Jordan may have based its response to mobilization in part upon Morocco's success in using concessions to prompt demobilization (Lynch 2012). Egypt, while more flexible in terms of allowing for more contestation in parliament and with a long history of frequent mobilization and contentious episodes - i.e. more frequent and expressive than Tunisia - nevertheless employed much more brutal 
repression than Morocco (Blaydes 2011; Lynch 2012; Vairel 2011; Volpi 2012). Egypt was also more similar to Tunisia than to Morocco in its repression of Islamists (Albrecht and Wegner 2006). Consequently, the contingent shock of Ben Ali's sudden departure served to embolden protesters in Egypt who had spent the previous decade networking and mobilizing in response to external (the 2002 Palestinian Intifada, 2003 Iraq War) and internal (Mubarak's succession, police brutality). When Mubarak responded with violence similar to that which enraged Tunisians in late 2010, Egyptians were no longer willing to acquiesce to Mubarak's offers of concessions - amounting to reengaging in the Egyptian version of the iterative Liberalization Game stretching back to Sadat in 1979 and further (Cook 2012; Lynch 2002; Blaydes and Lo 2012). Syria represented a similar progression of events, possessing elements of the revolutionary building blocks found in Tunisia, Libya, Iraq, and Egypt (Lynch 2012; The Economist 2014).

Algeria presents an interesting case of a regime where protesters reflected similar contentious framings as those is Morocco, despite it being a hegemonic party regime (Volpi 2012). Abdelaziz Bouteflika remained quite popular at the outbreak of the Arab Spring; and therefore protesters never came to call for the end of the regime as they had in Tunisia, Egypt and elsewhere (ibid). According to Volpi:

“...the opposition was constrained by the realization during the civil conflict [of the early 1990s] that there was a cohesive officer corps supporting the regime that was willing and able to use all necessary force to quell dissent. In the Winter of 2010 , both repression by the security forces and the inability of the opposition forces to present a united front contributed to the lackluster outcomes of the string of protests that stirred the country - that is, a lifting of the state of emergency and some small constitutional amendments" (20120, 977-8). 
Furthermore, similar to the Moroccan system, the Algerian ruling elites, "could open channels of communication with existing opposition forces in order to offer reforms that met some of the demands of the protesters, as mediated by these established political actors" (984). Thus the credible "reformist model" that Bouteflika had presented, combined with a significant coercive history that split society between anti-establishment Islamist remnants and moderated opposition actors (which includes some Islamists), resulted in a more violent and less concessionary, but still successful effort on the part of the regime to demobilize protesters who remained conservative overall (ibid). What this shows is that the findings of this Thesis are not limited to a particular linchpin monarchy/hegemonic party regime dichotomy. Avenues for future research should bear out that regime flexibility is determined by regime strategies with regards to political contestation and social contention, not any particular institutional arrangements, per se.

\subsection{Conclusions and Further Research Opportunities}

Looking back at our two main hypotheses:

Hypothesis 1 (institutions, strategies, and threat): Regimes that permit high levels of contestation within parliament and exercise restraint with regards to a limited level of public contention were more flexible and were thereby able to survive the Arab Spring. Case 2, Morocco exemplifies such a regime.

Hypothesis 2 (institutions, strategies, and threat): Regimes that significantly limited parliamentary contestation and repressed popular political contention - i.e. that were inflexible - were more likely to become destabilized by the Arab Spring social movements. Case 1, Tunisia exemplifies such a regime.

We can at least conclude that regime flexibility in Morocco allowed that regime to weather the storm of the February $20^{\text {th }}$ Movement; while Ben Ali's oppressive inflexibility set Tunisian society on the path to becoming emboldened by successive and unjust repetitions of the Liberalization Game. Thus, the regime was unable to surmount 
the Jasmine Revolution's contentious claims calling for the end of the regime. As the above analysis shows, this framework can be applied more broadly to the other Arab Spring states. Thus, there indeed is an argument to be made that institutionalism has a place in constructivist accounts of political contention in general and social revolution in particular. Nevertheless, this model requires additional refinement and empirical testing.

Two further opportunities for application of the model are immediately apparent:

(a) Field work that takes on Timur Kuran's (1995) challenge to locate and decipher subliminal preferences where they differ significantly from the oppressive veneer of ostensibly stable regimes. This would necessarily entail qualitative work, such as Roko's (2012) investigation of Tunisian and Moroccan activists' motivations. This paper suggests some institutional markers of such regimes (and their counterfactuals). The study would then compare social preferences derived through 'thick' description in regimes that have such institutional markers with those that vary in terms of the markers of inflexibility.

(b) A quantitative statistical analysis may also be possible. Cross-regional comparisons over time and space with flexibility as an indexed independent variable and successful revolutionary contention as the dependent variable, may serve as a test to the theoretical framework. Whether or not enough such cases exist is the inherent problem of revolutionary studies (Skocpol 1979). In which case it may be prudent to broaden the scope of the dependent variable to include variations of contentious politics' 'success' - though Skocpol criticizes this approach (ibid). 


\section{References}

Albrecht, Holger (2013). "Authoritarian Transformation or Transition from Authoritarianism." In The Arab Spring in Egypt: Revolution and Beyond. Edited by Baghat Korany and Rabab El-Mahdi, 252-270. Cairo: University of Cairo Press. 2013. . Raging against the Machine : Political Opposition under Authoritarianism in Egypt. First ed. 2013. 2005. "How can opposition support authoritarianism? Lessons from Egypt". Democratization. 12 (3): 378-397. and Oliver Schlumberger. 2004. "Waiting for Godot': Regime Change Without Democratization in the Middle East". International Political Science Review. 25 (4): 371-392.

Alexander, Christopher. 1997. "Back from the Democratic Brink: Authoritarianism and Civil Society in Tunisia". Middle East Report. (205): 34-38.

Alimi E.Y., and Meyer D.S. 2011. "Seasons of change: Arab spring and political opportunities". Swiss Political Science Review. 17 (4): 475-479.

Allani A. 2009. "The Islamists in Tunisia between confrontation and participation: 19802008". Journal of North African Studies. 14 (2): 257-272.

Anderson, Lisa. 1987. "The State in the Middle East and North Africa". Comparative Politics. 20 (1): 1-18.

Associated Press. "Moroccans and Women: Two Rallies." The New York Times. March 13, 2000. Print.

Bates, Robert H. "From Case Studies to Social Science: A Strategy for Political Research." Oxford Handbooks Online. 21 Jul. 2014. http://www.oxfordhandbooks.com/view/10.1093/oxfordhb/9780199566020.001.0 001/oxfordhb-9780199566020-e-7.

Benstead, Lindsay, Ellen, Lust M, Malouche, Dhafer, Sotlan, Gamal, and Wichmann, Jakob. "Islamists Aren't the Obstacle." Foreign Affairs (February 14, 2013). Accessed: March 8, 2013.

Beinin, Joel. Social Movements, Mobilization, and Contestation in the Middle East and North Africa. Palo Alto: Stanford University Press, 2011.

Beinin, Joel, and Frédéric Vairel. "Introduction: The Middle East and North Africa Beyond Classical Social Movement Theory." In Social Movements, Mobilization, and Contestation in the Middle East and North Africa. Stanford, California: Stanford University Press, 2011.

Bellin, Eva. 2004. "The Robustness of Authoritarianism in the Middle East: Exceptionalism in Comparative Perspective". Comparative Politics. 36 (2): 139157.

Bellin, Eva. 2012 "Reconsidering the Robustness of Authoritarianism in the Middle East." Comparative Politics. (January): 127-149.

Blaydes, Lisa,. Elections and Distributive Politics in Mubarak's Egypt. New York: Cambridge University Press, 2011. 
Blaydes, Lisa, and James Lo. 2012. "One man, one vote, one time? A model of democratization in the Middle East". Journal of Theoretical Politics. 24 (1): 110146.

Boix, Carles, and Susan C. Stokes. 2003. "Endogenous Democratization". World Politics. 55 (4): 517-549.

Boix, Carles, and Susan Carol Stokes. 2009. The Oxford handbook of comparative politics. Oxford: Oxford University Press. http://www.oxfordhandbooks.com/oso/p

Boukhars, Anouar. 2010. Politics in Morocco Executive Monarchy and Enlightened Authoritarianism. Hoboken: Taylor \& Francis. http://www.SLQ.eblib.com.au/patron/FullRecord.aspx?p=557268.

Büth, Tim. "Taking Temporality Seriously: Modeling History and the Use of Narratives as Evidence." American Political Science Review, no. 3 (2002): 481-93.

Burns, John F. "Morocco's King Loosens Grip, and Holds On." New York Times. June 28, 1999. Print.

Campante, Filipe R, and Davin Chor. 2012. "Why was the Arab World Poised for Revolution? Schooling, Economic Opportunities, and the Arab Spring". Journal of Economic Perspectives. 26 (2): 167-188.

Carothers, T. (2002). The End of the Transition Paradigm. Journal of Democracy, (1), 521.

Cavatorta F., and Haugbolle R.H. 2012. "The End of Authoritarian Rule and the Mythology of Tunisia under Ben Ali". Mediterranean Politics. 17 (2): 179-195.

Charrad, M. States and Women's Rights The Making of Postcolonial Tunisia, Algeria, and Morocco. Berkeley: University of California Press, 2001.

Diamond, Larry J. "Thinking About Hybrid Regimes." Journal of Democracy 13, no. 2 (April 2002): 21-35.

Diamond, Larry Jay. The Spirit of Democracy: The Struggle to Build Free Societies throughout the World. 1st ed. New York: Times Books/Henry Holt and, 2009.

Gandhi Jennifer, and Adam Przeworski. 2006. "Cooperation, Cooptation, and Rebellion Under Dictatorships". Economics \& Politics. 18 (1): 1-26.

Gandhi, Jennifer, and Ellen Lust-Okar. 2009. "Elections Under Authoritarianism". Annual Review of Political Science. 12 (1).

Geddes, Barbara. "What Causes Democratization?." Oxford Handbooks Online. 21 Jul. 2014.

http://www.oxfordhandbooks.com/view/10.1093/oxfordhb/9780199566020.001.0 001/oxfordhb-9780199566020-e-14.

Goldstone, Jack A. 2001. "Toward a Fourth Generation of Revolutionary Theory.". Annual Review of Political Science. 4 (1).

Goldstone, Jack A., and Charles Tilly. 'Threat (and Opportunity): Popular Action and State Response in the Dynamics of Contentious Action'. In Silence and Voice in the Study of Contentious Politics, ed. Ronald R. Aminzade, J.A. Goldstone, D. McAdam, E.J. Perry, W.H. Sewell, S. Tarrow, and C. Tilly, 179-94. Cambridge: Cambridge University Press, 2001.

Gobe, Eric. "The Gafsa Mining Basin between Riots and a Social Movement: meaning and significance of a protest movement in Ben Ali's Tunisia." (2010). 
Herb, Michael. 1999. All in the family: absolutism, revolution, and democracy in the Middle Eastern monarchies. Albany: State University of New York Press.

Hess S. 2013. "From the Arab Spring to the Chinese Winter: The institutional sources of authoritarian vulnerability and resilience in Egypt, Tunisia, and China". International Political Science Review. 34 (3): 254-272.

Hostrup Haugbølle, Rikke, and Francesco Cavatorta. 2011. "Will the Real Tunisian Opposition Please Stand Up? Opposition Coordination Failures under Authoritarian Constraints". British Journal of Middle Eastern Studies. 38 (3): 323-341.

Huntington, Samuel P. The Third Wave : Democratization in the Late Twentieth Century. Norman ; London: University of Oklahoma Press, 1993.

Ialnazov, Dimiter. "A Game Theory Interpretation of the Post-Communist Evolution." Journal of Economic Issues (M.E. Sharpe Inc.), no. 1 (2011): 41-57.

Korany, Bahgat and El-Mahdi Rabab (2013). "Introduction." In The Arab Spring in Egypt: Revolution and Beyond. Edited by Baghat Korany and Rabab El-Mahdi, 252-270. Cairo: University of Cairo Press. 2013.

Klandermans, Bert. 1984. "Mobilization and Participation: Social-Psychological Explanations of Resource Mobilization Theory". American Sociological Review. 49 (5): 583-600.

Kraetzschmar, Hendrik. 2011. "Mapping Opposition Cooperation in the Arab World: From Single-Issue Coalitions to Transnational Networks". British Journal of Middle Eastern Studies. 38 (3): 287-302.

Kuran, Timur. 1995. "The Inevitability of Future Revolutionary Surprises". American Journal of Sociology. 100 (6).

2004. "Why the Middle East is Economically Underdeveloped: Historical Mechanisms of Institutional Stagnation". Journal of Economic Perspectives. 18 (3): 71-90.

Langohr, Vickie. "Too Much Civil Society, Too Little Politics: The Case of Egypt and the Arab Liberalizers," in Authoritarianism in the Middle East: Regimes and Resistance, eds. Michele Penner Angrist and Marsha Pripstein Posusney, (Boulder: Lynne Rienner Press), 2005.

Lipset, Seymour Martin. "Some social requisites of democracy: Economic development and political legitimacy." American political science review 53, no. 01 (1959): 69105.

Lust, E. (2011) Why now? Micro transitions and the Arab uprisings, APSA Comparative Democratization Newsletter, 9(3), pp. 1, 3-8.

Lust-Okar, Ellen, Jamal, Amaney A. "Rulers and Rules Reassessing the Influence of Regime Type and Electoral Law Formation." Comparative Political Studies. 35. No. 3 (April 2002): 337-366.

Lucas, Russell E. 2004. "MONARCHICAL AUTHORITARIANISM: SURVIVAL AND POLITICAL LIBERALIZATION IN A MIDDLE EASTERN REGIME TYPE". International Journal of Middle East Studies. 36 (1): 103-119.

Lynch, Marc. "A Barometer for Arab Democracy." http://lynch.foreignpolicy.com/posts/2012/10/16/arabs_still_want_democracy. Accessed March 8, 2013. 
(2012). The Arab Uprising. New York: Public Affairs

Maghraoui, Abdeslam. "Monarchy and Political Reform in Morocco." Journal of Democracy, no. 1 (2001): 73-86.

. "Political authority in crisis: Mohammed VI's Morocco." Middle East Report (2001): 12-17.

. "Depoliticization in Morocco." Journal of Democracy, no. 4 (2002): 24-

32.

Maghraoui, Driss. 2011. "Constitutional reforms in Morocco: Between consensus and subaltern politics". Journal of North African Studies. 16 (4): 679-699.

Malesky E., and Schuler P. 2011. "The single-party dictator's dilemma: Information in elections without opposition". Legislative Studies Quarterly. 36 (4): 491-530.

McFaul, Michael, and Tamara Cofman Wittes. "The limits of limited reforms." Journal of Democracy 19, no. 1 (2008): 19-33.

Mauck, Trevor, and Jeannie Sowers. "Monarchical Suppression of the Legislature: Morocco 1996-2007." (2008).

Meyer, David S., and Debra C. Minkoff. 2004. "Conceptualizing Political Opportunity".Social Forces. 82 (4): 1457-1492.

"Moroccan police violently breaks up graduates' rally." BBC Worldwide Monitoring: AlJazeera TV, Doha. June 13, 2007. Online. Accessed July 21, 2014

Munck, Gerardo L. "Democratic Theory after Transitions from Authoritarian Rule". Perspectives on Politics. 9 no. 2 (2011):333-343.

O'Donnell, Guillermo A., Philippe C. Schmitter, and Laurence Whitehead. 1986.Transitions from authoritarian rule. Baltimore: Johns Hopkins University Press.

Ottaway, Marina, and Amr Hamzawy. Protest movements and political change in the Arab world. Vol. 5. CARNEGIE endowment for International Peace, 2011.

Penner Angrist, Michele. 1999a. "The Expression of Political Dissent in the Middle East: Turkish Democratization and Authoritarian Continuity in Tunisia". Comparative Studies in Society and History. 41 (4): 730-757.

1999b. "Parties, parliament and political dissent in Tunisia". The Journal of North African Studies. 4 (4): 89-104.

2013. "Understanding the Success of Mass Civic Protest in Tunisia". The Middle East Journal. 67 (4 Autumn): 547-564

Piattoni, Simona. 2001. Clientelism, interests, and democratic representation: the European experience in historical and comparative perspective. Cambridge: Cambridge University Press.

Posusney, Marsha Pripstein. Authoritarianism in the Middle East : Regimes and Resistance. Boulder, Colo.: Lynne Rienner Publishers, 2005.

Przeworski, Adam. Democracy and the Market : Political and Economic Reforms in Eastern Europe and Latin America. Cambridge ; New York: Cambridge University Press, 1991.

(1999). "Minimalist Conception of Democracy: A Defense." In The Democracy Sourcebook, edited by Robert A. Dahl, Ian Shapiro, and Jose A. Cheibub, 12-17. Cambridge: The MIT Press, 2003. 
(2010). Democracy and the Limits of Self Government. Cambridge University Press.

, Alvarez, Cheibub, and Limongi. 1996 "What Makes Democracy Endure." Journal of Democracy 7.1: 39-55.

Roko, Johan Rognlie. 2012. Contentious Politics in the Maghreb A Comparative Study of Mobilization in Tunisia and Morocco. Saarbrücken: LAP LAMBERT Academic Publishing. http://nbn-resolving.de/urn:nbn:de:101:1-201206068586.

Rustow, Dankwart A. 1970. "Transitions to Democracy: Toward a Dynamic Model". Comparative Politics. 2 (3): 337-363.

Schedler, Andreas. 2002. "The Menu of Manipulation." Journal of Democracy 13, no. 2 (April): 36-49.

Skocpol, Theda. States and Social Revolutions a Comparative Analysis of France, Russia, and China. Cambridge ; New York: Cambridge University Press, 1979.

Signé, Landry, and M. P. A. Remy Smida. "The Army's Decision to Repress: A Turning Point in Tunisia's Regime Change." (2014). http://iisdb.stanford.edu/pubs/24616/Landry_Final.pdf

Slyomovics, Susan (2009) 'Introduction to Clifford Geertz in Morocco: 'Why Sefrou? Why anthropology? Why me?”, The Journal of North African Studies, 14:3, 317 325 .

Tessler M., Jamal A., and Robbins M. 2012. "New findings on Arabs and democracy". Journal of Democracy. 23 (4): 89-103.

Tilly, Charles. 1997. "Contentious politics and social change". African Studies. 56 (1): 51-65.

Vairel, Frédéric . "Protesting in Authoritarian Situations: Egypt and Morocco in Comparative Perspective." In Social Movements, Mobilization, and Contestation in the Middle East and North Africa. Stanford, California: Stanford University Press, 2011. .

2008. "Morocco: From Mobilizations to Reconciliation?" Mediterranean Politics, 13:2, 229-241

Volpi, F. A. A. 2013. Explaining (and re-explaining) political change in the Middle East during the Arab Spring: trajectories of democratization and of authoritarianism in the Maghreb. Democratization, 20, 6, 969-990.

. "Framing Political Revolutions in the Aftermath of the Arab Uprisings". Mediterranean Politics. 19 (1): 153-156. 